\title{
CERAMIC TO METAL SEALS FOR HIGH-TEMPERATURE THERMIONIC CONVERTERS
}

TECHNICAL DOCUMENTARY REPORT NO. RTD-TDR-63-4109

\section{October 1963}

\author{
Air Force Aero Propulsion Laboratory \\ Research and Technology Division \\ Air Force Systems Comm and \\ Wright-Patterson Air Force Base, Ohio
}

Prolect No. 8173, Task No. 817305-21

(Prepared under Contract No. AF 33(657)-10038 by

The Bendix Corporation, Red Bank Division, Eatontown,

New Jersey; M. L. Dring, Principal Author.) 


\section{DISCLAIMER}

This report was prepared as an account of work sponsored by an agency of the United States Government. Neither the United States Government nor any agency Thereof, nor any of their employees, makes any warranty, express or implied, or assumes any legal liability or responsibility for the accuracy, completeness, or usefulness of any information, apparatus, product, or process disclosed, or represents that its use would not infringe privately owned rights. Reference herein to any specific commercial product, process, or service by trade name, trademark, manufacturer, or otherwise does not necessarily constitute or imply its endorsement, recommendation, or favoring by the United States Government or any agency thereof. The views and opinions of authors expressed herein do not necessarily state or reflect those of the United States Government or any agency thereof. 


\section{DISCLAIMER}

Portions of this document may be illegible in electronic image products. Images are produced from the best available original document. 


\section{NOTICES}

When Government drawings, specifications, or other data are used for any purpose other than in connection with a definitely related Government procurement operation, the United States Government thereby incurs no responsibility nor any obligation whatsoever; and the fact that the Government may have formulated, furnished, or in any way supplied the said drawings, specifications, or other data, is not to be regarded by implication or otherwise as in any manner licensing the holder or any other person or corporation, or conveying any rights or permission to manufacture, use, or sell any patented invention that may in any way be related thereto.

Qualified requesters may obtain copies of this report from the Defense Documentation Center (DDC), (formerly ASTIA), Cameron Station, Bldg. 5, 5010 Duke Street, Alexandria 4, Virginia

This report has been released to the Office of Technical Services, U.S. Department of Commerce, Washington 25, D.C., for sale to the general public.

Copies of this report should not be returned to the Research and Technology Division unless return is required by security considerations, contractual obligations, or notice on a specific document. 


\section{FOREWORD}

The work described in this report was initiated by the Air Force Aero Propulsion Laboratory of the Research and Technology Division, Wright-Patterson Air Force Base, Ohio, under Contract AF 33(657)10038, Project 8173, Task No.817305-21。 The applied research and engineering development activities which are the subject of this report have been carried on primarily at three divisions of The Bendix Corporation. These are the Red Bank Division, Eatontown, N. J.; Bendix Products - Aerospace Division, South Bend, Ind。; and Research Laboratories Division, Southfield, Michigan. It is impossible to acknowledge individually the significant contributions to this effort made by the many members of the technical staffs of these divisions. The following persons played active parts in the major areas of investigation throughout most of the project period:

$\begin{array}{ll}\text { W. L. Schalliol } & \text { Bendix Products Aerospace Division } \\ \text { R. E. Hess } & \text { Bendix Products Aerospace Division } \\ \text { R. Kiwak } & \text { Research Laboratories Division } \\ \text { D. Scruggs } & \text { Research Laboratories Division } \\ \text { J. Ritz } & \text { Red Bank Division } \\ \text { R. Kuhnapfel } & \text { Red Bank Division }\end{array}$

Certain processing activities requiring special equipment were carried out by the Hamilton-Standard Division of United Aircraft Corporation, and by the Sonobond Corporation, under subcontract. Assistance in the studies of materials compatibility at extremely high temperatures was provided by the Ceramic Engineering Department of The University of Illinois, Champaign, Illinois, under a consulting contract with The Bendix Corporation.

This report covers all work performed under the contract referenced above during the period from l October 1962 through 30 September 1963. 
The project was monitored by Captain E. F. Redden and Mr.A.E. Wallis for the Air Force Aero Propulsion Laboratory of the Research and Technology Division, AFSC. Mr. M. L. Dring was Project Manager for The Bendix Corporation.

This report is identified by The Bendix Corporation as Red Bank Division Engineering Report RBESO 3404-4. 


\begin{abstract}
A rather broad investigation was carried on in the materials and methods which are considered possibly useful in forming ceramic to metal seals and composite structures for use in the environment of cesium-plasma thermionic converters.

Initially, studies of five specific means of joining refractory metals to alumina were undertaken, as well as studies of metallizing methods, of forming graded tungsten-alumina composites, and of the possible metals and ceramics which could be utilized best in structures operated at $2000^{\circ} \mathrm{C}$. The broad character of the investigation at the start of this project was necessary to ensure that all joining means which showed some possibility of successful application to this problem were evaluated. The five joining methods studied are:

- Formation of a continuous electroplated layer of refractory metal across the adjacent surfaces of metal and ceramic.

- Welding of a metal member to the ceramic by ultrasonic welding techniques; i.e., without heat.

- Use of high temperature brazing alloys.

- Formation of a bond between metal and ceramic by the diffusion of compatible intermediate materials into both structural members.

- Welding of single oxide ceramics directly to refractory metals using electron-beam welding equipment.
\end{abstract}

The study of metallizing methods was started because the first three of the joining methods listed require the use of a metallized surface of the alumina.

About six months from the start of work, it was determined that three of the five methods for joining refractory metals to alumina which were under study were not practically feasible. The methods considered impractical are: formation of a continuous electroplated joint, welding by ultrasonic energy, and welding with electron beam 
techniques. The studies on these methods were ended. Significant achievements have been made in the other studies. A metallizing process has been developed by which a strongly adherent sintered tungsten film can be applied to commercially-available, high-purity, silica-free alumina. No fluxing materials or active metals which are susceptible to attack by cesium are used in this process. Bonding of alumina to molybdenum has been successful by several methods developed from the diffusion seal study. Some of these have been tested at $1500^{\circ} \mathrm{C}$ successfully; i.e., with neither structural failure nor loss of hermeticity resulting from the test. Methods of fabricating graded-composition, tungsten-alumina emitter and envelope structures have been developed.

Techniques for making brazed joints between refractory metals and high-purity alumina metallized with tungsten, using high temperature brazing alloys, are considered to be well enough developed for use of these structures near $1500^{\circ} \mathrm{C}$. Diffusion joing methods for molybdenum or niobium and alumina are also considered to be processes which are immediately applicable to joining molybdenum or niobium and commercially available high-purity alumina for use at this temperature.

Tungsten, rhenium, hafnia, thoria, and yttria have been identified as the most promising materials for $2000^{\circ} \mathrm{C}$ service. The techniques developed for fabrication of tungsten-alumina composite bodies are considered to be directly applicable to formation of composite structures utilizing combinations of the materials for $2000^{\circ} \mathrm{C}$ service. Diffusion bonding of tungsten or rhenium to hafnia, thoria, or yttria demonstrates a high potential capability as a means of joining these materials for use at $2000^{\circ} \mathrm{C}$.

\section{PUBLICATION REVIEW}

The publication of this technical documentary report does not constitute Air Force approval of the report's findings or conclusions. It is published only for the exchange and stimulation of ideas. 


\section{TABLE OF CONTENTS}

1.0 INTRODUCTION
2.0 GENERAL CONSIDERATIONS
$2.1 \quad$ Preliminary Materials Evaluation
$2.2 \quad$ Test Bodies
$2.3 \quad$ Predicted Temperature Environment
$2.4 \quad$ Thermal Cycling Tests

3.0 CERAMIC-METAL JOINT SYSTEMS UTILIZING ALUMINA 13

3.1 Problems of Ceramic Composition 13

3.2 Metallizing Process Studies 13

3.3 High Temperature Brazing Studies 16

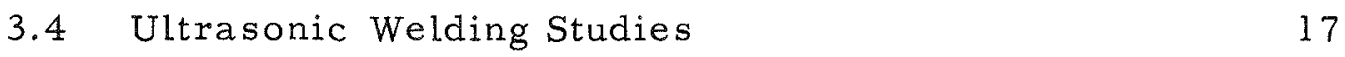

3.5 Electroformed Seal Studies 20

3.6 Electron Beam Welding Studies 26

$\begin{array}{lll}3.7 & \text { Diffusion Seal Studies } & 27\end{array}$

4.0 ALUMINA - TUNGSTEN COMPOSITE STRUCTURES

5.0 MATERIALS AND STRUCTURES FOR USE AT

5.1 Materials Selection 50

5.2 Investigations of High Temperature Stability 52

5.3 Investigations of Expansion Characteristics 55

5.4 Joint Systems and Composites 56

6.0 CONCLUSIONS AND RECOMMENDATIONS 60

$\begin{array}{ll}6.1 \text { Conclusions } & 60\end{array}$

6.2 Recommendations 62

Appendix A: Bibliography on Cesium Corrosion 63

Appendix B: Thermal Analysis of Idealized Solar-Powered

Thermionic Generator in Earth Orbit 65

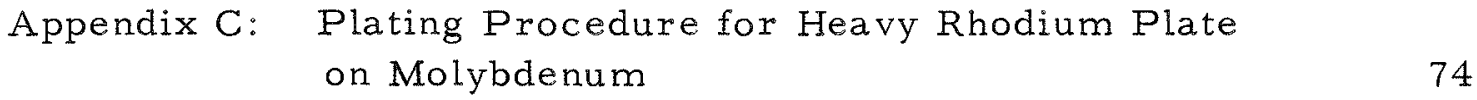


page blank

vi 


\section{LIST OF ILLUSTRATIONS}

\begin{tabular}{|c|c|c|}
\hline Figure No. & Title & Page \\
\hline 1 & Cross-Bending Test Piece & 6 \\
\hline 2 & $\begin{array}{l}\text { Three Fundamental Modes of Cylinder-To- } \\
\text { Diode }\end{array}$ & 7 \\
\hline 3 & Parts for Seal Evaluation Sample & 8 \\
\hline 4 & Revised End-Cup Shape & 8 \\
\hline 5 & $\begin{array}{l}\text { Possible Temperature Conditions of Uncooled } \\
\text { Ceramic-Metal Seals in Thermionic }\end{array}$ & \\
\hline & Converters & 9 \\
\hline 6 & $\begin{array}{l}\text { Basic Equipment Arrangement for Thermal } \\
\text { Cycling Tests }\end{array}$ & 11 \\
\hline 7 & Resistance Heated Furnace & 11 \\
\hline 8 & Phase Diagram: Niobium-Palladium System & 18 \\
\hline 9 & Development Steps in Ultrasonic Welding Study & 19 \\
\hline 10 & $\begin{array}{l}\text { Sections of Ultrasonic Weld Showing Interaction } \\
\text { Conditions }\end{array}$ & 21 \\
\hline 11 & Tantalum Interleaf Used in Ring Welding Trials & 21 \\
\hline 12 & Development Steps in Electro-Formed Seal Study & 22 \\
\hline 13 & $\begin{array}{l}\text { Electroplated Rhodium on Molybdenum - } 980^{\circ} \mathrm{C} \\
\text { Stress-Relief Anneal }\end{array}$ & 24 \\
\hline 14 & $\begin{array}{l}\text { Electroplated Rhodium over a Lapped Joint } \\
\text { between Two Sheets of Molybdenum }\end{array}$ & 25 \\
\hline 15 & $\begin{array}{l}\text { Niobium-Alumina Diffusion Seal Using Nickel } \\
\text { Intermediate Material }\end{array}$ & 33 \\
\hline 16 & $\begin{array}{l}\text { Alumina Cyclinder and Niobium Cup Showing } \\
\text { the Niobium-Nickel Bond Area }\end{array}$ & 34 \\
\hline 17 & Principle of Composite-Cup Structure & 38 \\
\hline 18 & $\begin{array}{l}\text { Sintered Composite Cup Made from Twelve } \\
\text { Incremental Layers }\end{array}$ & 38 \\
\hline 19 & $\begin{array}{l}\text { Powder Loading Equipment for Continuously } \\
\text { Graded Composite }\end{array}$ & 44 \\
\hline 20 & Fabrication Stages of Composite Envelope & 46 \\
\hline 21 & Cross Section of Graded Composite Envelope & 48 \\
\hline 22 & $\begin{array}{l}\text { Lattice Parameters for Cubic Solid Solutions } \\
\text { of Two Rare Earth Oxides in Thoria }\end{array}$ & 52 \\
\hline 23 & $\begin{array}{l}4000 X \text { Electronmicrograph of } 80 \text { Rhenium - } \\
20 \text { Yttria Mixture Subjected to } 2045^{\circ} \mathrm{C}\end{array}$ & 54 \\
\hline
\end{tabular}


Figure No.

Title

Page

$24000 X$ Electronmicrograph of 80 Rhenium-

20 Yttria Mixture Subjected to $2365^{\circ} \mathrm{C}$

54

$24000 X$ Electronmicrograph of 75 Tungsten -

25 Yttria Mixture Subjected to $2300^{\circ} \mathrm{C}$

55

Rhenium-Yttria Sample Bonded with Yttrium

58

Composite Cup Formed of Rhenium and

Stabilized Hafnia

59

Heat - Balance Schematic

66

$B-1$

Thermionic Electrode Temperature Profiles -

Case I: $T_{1}(0)=2000^{\circ} \mathrm{C}$

70

$B-3$

Thermionic Electrode Temperature Profiles -

Case II: $T_{1}(0)=1500^{\circ} \mathrm{C}$ 


\section{LIST OF TABLES}

\begin{tabular}{|c|c|c|}
\hline ble No. & Title & Pag \\
\hline 1 & $\begin{array}{l}\text { Properties of Potential Materials for Use in } \\
\text { Thermionic Converters }\end{array}$ & 4 \\
\hline 2 & Results of Cross-Bending Tests & 15 \\
\hline 3 & $\begin{array}{c}\text { Average Tensile Strengths of Various Metal- } \\
\text { lizing Slurries on High Alumina Ceramics }\end{array}$ & 15 \\
\hline 4 & $\begin{array}{l}\text { Average Tensile Strengths of Yttria-Bearing } \\
\text { Metallizing Slurries }\end{array}$ & 16 \\
\hline 5 & $\begin{array}{l}\text { Interlayer Materials Used on Alumina and } \\
\text { Molybdenum Flat Sheets }\end{array}$ & 30 \\
\hline 6 & $\begin{array}{l}\text { Coatings Applied to Alumina Cylinders and } \\
\text { Molybdenum Cups Showing the Resulting } \\
\text { Vacuum Capabilities }\end{array}$ & 31 \\
\hline 7 & Properties of Alumina Powders & 39 \\
\hline 8 & Properties of Tungsten Powders & 41 \\
\hline 9 & Sintering Aids and Bond Promoting Materials & 41 \\
\hline 10 & $\begin{array}{l}\text { Effect of Tungsten Addition on Density and } \\
\text { Shrinkage of } \mathrm{Al}_{2} \mathrm{O}_{3}\end{array}$ & 42 \\
\hline 11 & $\begin{array}{l}\text { Effect of Nickel on Density and Shrinkage of } \\
\text { Tungsten Sintered at } 3400^{\circ} \mathrm{F}\end{array}$ & 42 \\
\hline 12 & Composition of Gradations in Seven Layer Cup & 46 \\
\hline 13 & $\begin{array}{l}\text { Gradations of Materials Used in Twelve Layer } \\
\text { Cup }\end{array}$ & 47 \\
\hline 14 & Shrinkage and Density Measurements & 47 \\
\hline 15 & Materials for Thermionic Converter Structures & 51 \\
\hline 16 & $\begin{array}{l}\text { Typical Values of Vacuum and Temperature - } \\
\text { Metal-Ceramic Compatibility Tests }\end{array}$ & 53 \\
\hline 17 & Tentative Material Selection for Use at $2000^{\circ} \mathrm{C}$ & 57 \\
\hline
\end{tabular}




\subsection{INTRODUCTION}

The activities of this development effort have been directed toward raising or eliminating the present operating temperature limits for seal areas of converter envelope structures by the development of new ceramic to metal sealing techniques. The present limitation on operating temperatures of state-of-the-art ceramic to metal seals is a significant factor in the design of high temperature thermionic converters.. Because of the need to limit temperatures of the ceramic to metal seals to a maximum somewhat less than $1000^{\circ} \mathrm{C}$, and temperature gradients in the ceramic body to low values, long thermal paths and structural shapes which are effective heat chokes must be used. Rapid dissipation of heat transmitted to the seal area and the ceramic body must also be provided to maintain these areas at suitable temperatures. These design requirements, imposed by the present limitations on ceramic to metal seals, complicate the structural design of converter envelopes, reduce the structural integrity, and contribute to the thermal losses which reduce over-all converter efficiency.

The investigations carried on include studies of refractory metals and ceramics for use above $1500^{\circ} \mathrm{C}$, development of techniques for forming ceramic-metal composites, and methods of achieving seals between metallized alumina and refractory metal members, and between unmetallized alumina and refractory metal members.

The temperature goal for materials and seals being developed under this project is $2000^{\circ} \mathrm{C}$. Because of the nature of the problems which had to be investigated before there could be any expectation of achieving this goal, the project was divided into four parts:

$$
\begin{aligned}
& \text { Part I The development of seals between high } \\
& \text { purity alumina and molybdenum, with life } \\
& \text { capabilities at temperatures above present } \\
& \text { state-of-the-art but limited, because of base } \\
& \text { material characteristics, to a maximum } \\
& \text { temperature in the order of } 1500^{\circ} \mathrm{C} \text {. The } \\
& \text { following tasks were established under } \\
& \text { Part I: }
\end{aligned}
$$

Manuscript released by the author October 1963 for publication as an RTD Technical Documentary Report. 
Task 1 - Metallizing Process Studies

Task 2 - Brazing Bond Studies

Task 3 - Ultrasonic Welding Studies

Task 4 - Electroformed Seal Studies

Task 5 - Electron Beam Welding

Studies

Task 6 - Diffusion Seal Studies

Part II The development of ceramic-metal composite materials from which converter envelopes can be fabricated with controlled gradation of composition throughout the envelope body.

Part III The study of refractory materials, the analysis of materials systems occurring in seal areas as a result of various alloying, diffusion, or reaction bonding mechanisms, and the optimization of particular characteristics of material systems utilized.

Part IV The study of material systems to determine those with characteristics at temperatures near $2000^{\circ} \mathrm{C}$ which indicate their probable usefulness for converter structures operated above $1500^{\circ} \mathrm{C}$.

The tasks of Part I were undertaken simultaneously. This was done so that continual comparative evaluation could be maintained of the development status of the various joint systems under study. In this way, when progress in the development of any system was found to be more rapid than that of the others, the situation would be quickly apparent. Effort could then be concentrated on the development of that system which offered che expectation of the earliest successful conclusion. 


\subsection{GENERAL CONSIDERATIONS}

\subsection{Preliminary Materials Evaluation}

The literature was searched for data which would enable the most promising candidates to be identified for the ceramic and metal members of thermionic converter structures. Some of the properties that were considered in selecting structural materials for use in a cesium thermionic converter are:

1. Melting point.

2. Sublimation rates and vapor pressures.

3. Resistance to cesium vapor and compatibility with other materials in the system.

4. Thermal expansion characteristics.

5. Thermal shock resistance.

6. Thermal conductivity.

7. Electrical resistivity.

8. Mechanical properties (strengths, elastic modulus).

The severity of the physical requirements soon eliminated all candidates except the following:

$\begin{array}{ll}\text { Molybdenum } & \text { Alumina } \\ \text { Niobium } & \text { Beryllia } \\ \text { Rhenium } & \text { Hafnia } \\ \text { Tungsten } & \text { Magriesia } \\ \text { Tantalum } & \text { Thoria } \\ & \text { Yttria } \\ & \text { Zirconia }\end{array}$

Some of the pertinent characteristics of the se are shown in Table 1.

Susceptibility to attack by cesium was an important consideration in material selection. Although no experimental work was planned or performed to evaluate susceptibility of materials to attack by cesium, a thorough search was made of the literature reporting such experimental work. A bibliography of report material on cesium reaction investigations is included in Appendix $A$. 
Table 1 - Properties of Potentral Materials for Use is Thermionic Converters

\begin{tabular}{|c|c|c|c|c|c|c|c|c|c|c|c|}
\hline \multirow{2}{*}{ MATERIAL } & \multirow{2}{*}{$\begin{array}{l}\text { MELTING } \\
\text { POINT } \\
{ }^{\circ} \mathrm{C}\end{array}$} & \multicolumn{2}{|c|}{$\begin{array}{l}\text { THERMAL CONDUCTIVITY } \\
\mathrm{CAL} / \mathrm{CM} / \mathrm{M}^{2} / \mathrm{CM} / \mathrm{SEC} /{ }^{\circ} \mathrm{C}\end{array}$} & \multicolumn{2}{|c|}{$\begin{array}{l}\text { THERMAL EXPANSION } \\
\mathrm{CM} / \mathrm{CM} /{ }^{\circ} \mathrm{C} \times 10^{6}\end{array}$} & \multicolumn{2}{|c|}{$\begin{array}{l}\text { ELECTRICAL RESISTIVITY } \\
\text { OHM.CM }\end{array}$} & \multirow{2}{*}{$\begin{array}{l}\text { THERMAL } \\
\text { SHOCKK } \\
\text { RESISTANCE }\end{array}$} & \multicolumn{2}{|c|}{$\begin{array}{l}\text { SUBLIMATION RATE IN HIGH VACUUM } \\
\text { (APPROX. CM PER YEAR) }\end{array}$} & \multirow{2}{*}{$\begin{array}{l}\text { COMPATIBILITY WITH } \\
\text { CESIUM }\end{array}$} \\
\hline & & $20^{\circ} \mathrm{C}$ & $2000^{\circ} \mathrm{C}$ & $20^{\circ} \mathrm{C}$ & $2000^{\circ} \mathrm{C}$ & $20^{\circ} \mathrm{C}$ & $2000^{\circ} \mathrm{C}$ & & AT $1500^{\circ} \mathrm{C}$ & AT $2000^{\circ} \mathrm{C}$ & \\
\hline $\mathrm{Al}_{2} \mathrm{O}_{3}$ & 2015 & 007 & 002 & 60 & 120 & $1 \times 10^{16}$ & $1 \times 10^{3}-1 \times 10^{7}$ & GOOD & $14 \times 10^{2}$ & $30 \times 10^{2}$ & GOOD AT $1475^{\circ} \mathrm{C}$ \\
\hline $\mathrm{BeO}$ & 2550 & 050 & 004 & 80 & 110 & $1 \times 10^{10} 1 \times 10^{20}$ & $1 \times 10^{3} 1 \times 10^{9}$ & EXCELLENT & $10^{3}$ & 64 & $\begin{array}{l}\text { IMPURE BeO (WITH } 10 \% \\
\text { GLASSY BINDERS) REPORT } \\
\text { ED ATTACKED AT } 800^{\circ} \mathrm{C}\end{array}$ \\
\hline $\mathrm{H}_{2}$ & 2777 & 0004 & & 58 & 70 & $1 \times 10^{12}$ & $1 \times 10^{2}$ & FAIR & & & GOOD AT $1580^{\circ} \mathrm{C}$ \\
\hline NgO & 2800 & 008 & 002 & 110 & 200 & $1 \times 10^{13}-1 \times 10^{19}$ & $1 \times 10^{2} 1 \times 10^{8}$ & FAIR & $10^{2}$ & $10^{5}$ & GOOD AT $1200^{\circ} \mathrm{C}$ \\
\hline $\mathrm{rhO}_{2}$ & 3300 & 002 & 0005 & 80 & 110 & $4 \times 10^{13}$ & $1 \times 10^{2} 1 \times 10^{8}$ & FAIR TO POOR & $10^{-4}$ & 1 & GOOD AT $1235^{\circ} \mathrm{C}$ \\
\hline $\mathrm{ZrO}_{2}$ & 2677 & 0004 & 0005 & 72 & 93 & $1 \times 10^{8}$ & $1 \times 10^{0}$ & FAIR & $10^{1}$ & $10^{4}$ & GOOD AT $1265^{\circ} \mathrm{C}$ \\
\hline \multirow{2}{*}{$\begin{array}{l}\mathrm{MgO} \\
\mathrm{Al}_{2} \mathrm{O}_{3}\end{array}$} & 2135 & 004 & 001 & 90 & & $>3 \times 10^{7}$ & $<2 \times 10^{5}$ & FAIR TO POOR & & & \\
\hline & & 001 & 0007 & 55 & 97 & $>1 \times 10^{14}$ & $1 \times 10^{3}$ & GOOD & & & \\
\hline $\mathrm{Nb}$ & 2415 & 013 & 023 & 73 & 74 & $141 \times 10^{6}$ & $>42 \times 10^{-6}$ & GOOD & $10^{5}$ & $10^{-2}$ & \\
\hline Mo & 2610 & 035 & 025 & 49 & 80 & $57 \times 10^{-6}$ & $62 \times 10^{-6}$ & GOOD & $10^{-4}$ & $25 \times 10^{-1}$ & G00D AT $1000^{\circ} \mathrm{C}$ \\
\hline To & 2996 & 013 & 019 & 65 & 78 & $135 \times 10^{-6}$ & $789 \times 10^{-6}$ & GOOD & $25 \times 10^{.7}$ & $2 \times 10^{-4}$ & \\
\hline w & 3410 & 040 & 025 & 46 & 73 & $55 \times 10^{-6}$ & $59 \times 10^{-6}$ & 6000 & $2 \times 10^{8}$ & $75 \times 10^{-5}$ & G000 AT $1000^{\circ} \mathrm{C}$ \\
\hline
\end{tabular}

NDTE DATA PRESENTED ABOVE ARE REPRESENTATIVE VALUES FROM SEVERAL SOURCES MUCH OF THE $2000^{\circ} \mathrm{C}$ DATA HAD TO BE EXTRAPOLATED DUE TO LACK OF HIGH TEMPERATURE INFORMATION 
Molybdenum was selected for the initial experimental part of the project on the basis of melting point, sublimation rate, fabricability, and availability. It is readily available in high purity sheet form of the desired thicknesses, and a considerable volume of knowledge is on hand concerning its usage for electrode materials in cesium-filled thermionic converters.

There are several ceramic materials that have attractive properties for use up to $1500^{\circ} \mathrm{C}$. The se include alumina, beryllia, hafnia, thoria, and the magnesium aluminate spinel. Only high purity forms of these materials were considered in order to avoid the possibility of introducing materials which would poison the converter with unwanted impurities, and to provide a basic material that could be modified if known additives are found to be desirable. Of the se materials, alumina was the obvious choice for several reasons:

1. The state-of-the-art of using alumina for vacuum tight applications is highly developed in the electronic tube industry, thus impervious material of high purity is readily available in many shapes.

2. Considerable information and experience is available on ceramic-to-metal seals using alumina at lower temperatures.

\section{$2.2 \quad$ Test Bodies}

It was not considered necessary to standardize the shape of test pieces used for preliminary evaluation of bonding techniques. Small ceramic wafers and metal strip pieces were used. These were of arbitrary shape and size, usually determined by availability considerations. The exception to this was the preliminary evaluation of metallizing materials and processes. In this work on metallizing. test pieces of the form shown in Figure 1 were used in a "crossbending" test to provide a basis for comparison. The test made with this type of test sample was a go-no-go type, used to eliminate the more obviously unsatisfactory metallizing compositions. A material was considered to have failed this test if the failure of the test piece occurred from stripping of the metallizing rather than fracture in the ceramic.

Metallizing materials which survived the cross-bending test were subjected to tensile tests in accordance with ASTM specification 


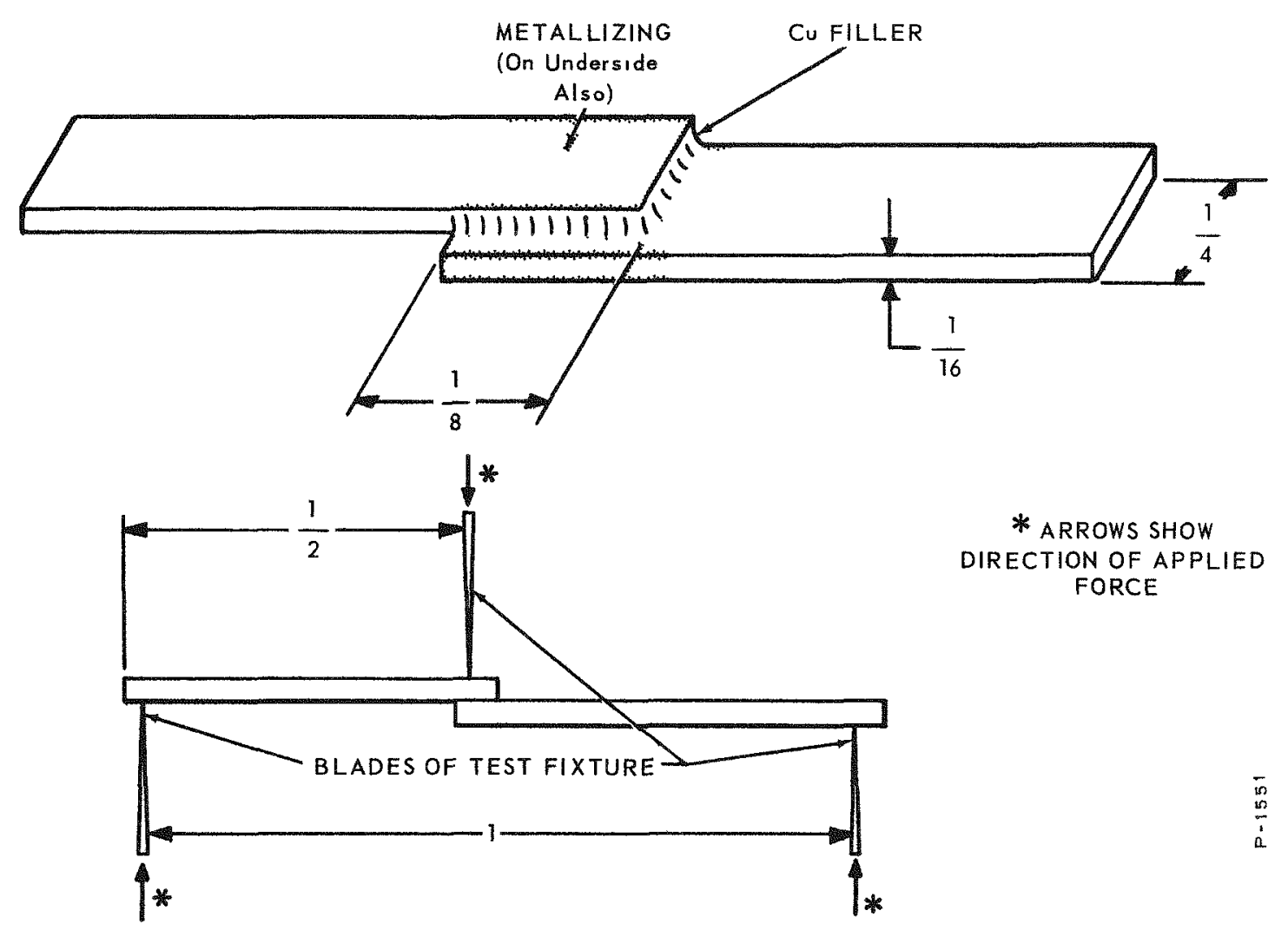

Figure 1 - Cross-Bending Test Plece

F-19-61T. The body for this test is standard as defined in the specification and is available from ceramic manufactureres in many formulations.

Ceramic and metal envelope structures used in the fabrication of present versions of thermionic converters consist of a ceramic cylinder which is sealed directly to refractory metal disks or cylinders. As the assembly heats up to the required operating temperature or cools down to an ambient or lower temperature, thermal stresses are induced in the bonded components by the differences in their rates of thermal expansion or contraction. Thermal stresses are minimized in present converter structure designs by the need for maintaining the ceramic, and seals, at low temperatures. However, the thermal stresses which will occur when ceramics and seals can be exposed to high temperatures become significant design considerations. These stresses must be controlled within certain limits in order to prevent bond failure, physical distortion, and fracture of the ceramic or metal. The magnitudes 
of the stresses which will develop depend on the choice of ceramic, metal, and joining process as well as the applied heat treatment. If it is as sumed that the se parameters are held fixed, the magnitude of the thermal stresses will still vary widely as a function of the structural configuration. It is, therefore, important that the induced stresses be known so that it will be possible to obtain the best ratio of structural dimension of the selected configuration and to ensure the structural integrity of the components which form the unit.

Three generalized arrangements of the ceramic and metal parts of converter emitter and envelope structures are shown in Figure 2. Prior to establishing a test body shape for this program, consideration was given to the stress effects which could be expected from each of these configurations. There are no published techniques adequate for analysis of these structures under the temperature environments being studied. Those analysis techniques which have been identified as possibly useful are not carried far enough to enable their use in this problem.

The development of analytic relationships and methods for solution of these stress problems was undertaken as a separate study, contributing to this program but not a direct part of it supported by the present contract. It was intended that this study would provide the basis on which test sample shape and dimensions could be selected. However, this study has not yet been completed to the point where it can serve as the selection basis. Preliminary relationships have been derived under the limitation of a number of assumptions.

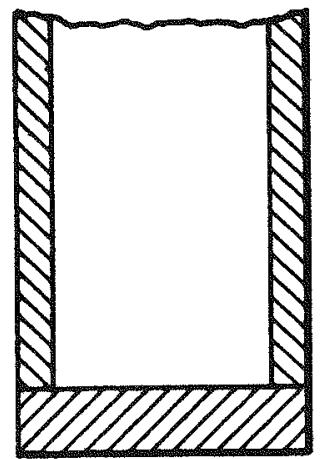

(1) THE FLAT JUNCTION

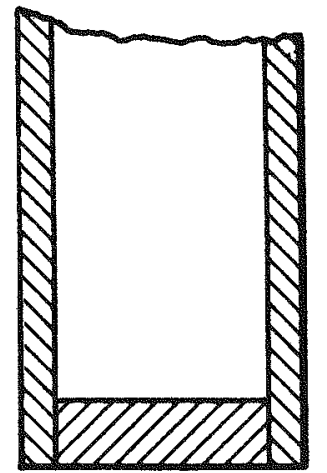

(2) THE INTERNAL JUNCTION

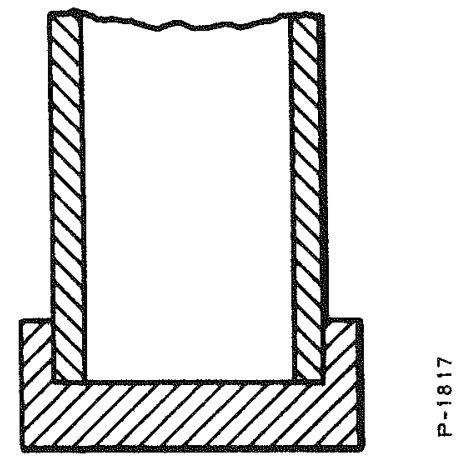

(3) THE EXTERNAL JUNCTION

Figure 2 - Three Fundamental Modes of Cylinder-To-Diode 


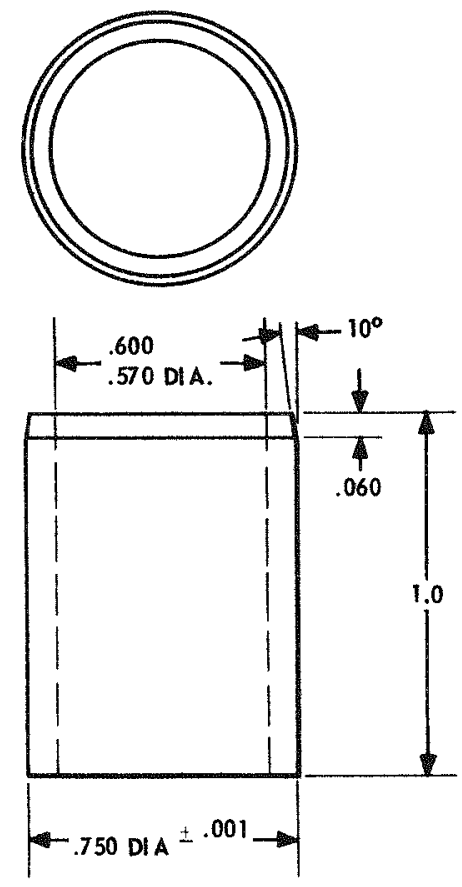

CYLINDER - ALUMINA

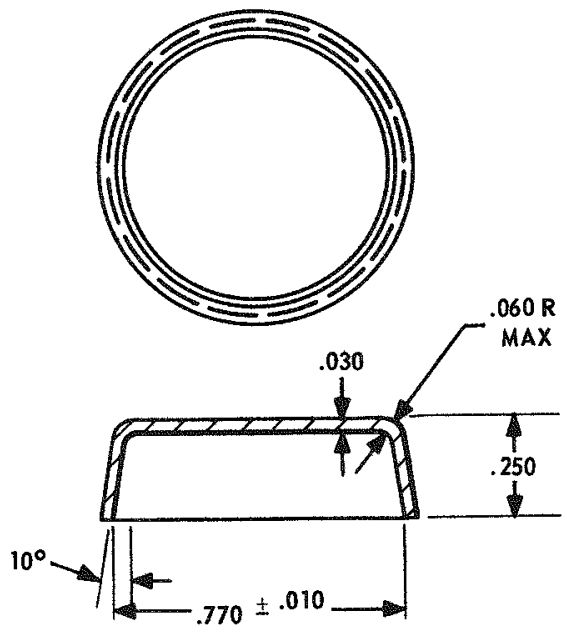

END - CUP - MOLY BDENUM

Figure 3 - Parts for Seal Evaluation Sample

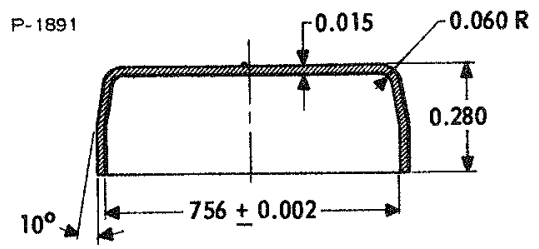

Figure 4 - Revised End-Cup Shape

The test body shape for final seal evaluation was as shown in Figure 3. This configuration was chosen to approximate envelope sizes of present converters having an emitter area of two square centimeters. While the shape approximates that of present converter envelopes, many characteristics of it were arbitrarily chosen, some on the basis of easing piece procurement. Toward the end of the program, end-cups of the revised shape shown in Figure 4 were procured in niobium for use in the studies of high temperature brazes and of diffusion seals. 


\subsection{Predicted Temperature Environment}

In order to define the severity of the temperature environment to which the structures being studied would be exposed, the probable conditions of a number of missions were compared qualitatively. An orbital mission with a ninety minute orbital period was selected as the one which would probably impose as severe thermal cycling conditions as any. A thermal analysis was performed to establish the timetemperature relationships for converters of an idealized generator in the ninety minute orbital mission. A report of the analysis is included in Appendix B. Figure 5 shows the envelope of the temperatures which would occur in the structure of a converter operative with the emitter at $2000^{\circ} \mathrm{C}$ and the collector at $900^{\circ} \mathrm{C}$. It was as sumed that, in a converter utilizing ceramic-metal structures which could resist $1500^{\circ} \mathrm{C}$ or higher, the radiator temperature would be very nearly the same as the collector temperature. The temperature of a ceramic-metal seal in the converter of the analysis would fall within the shaded region, for example, as shown by the broken-line curve of Figure 5.

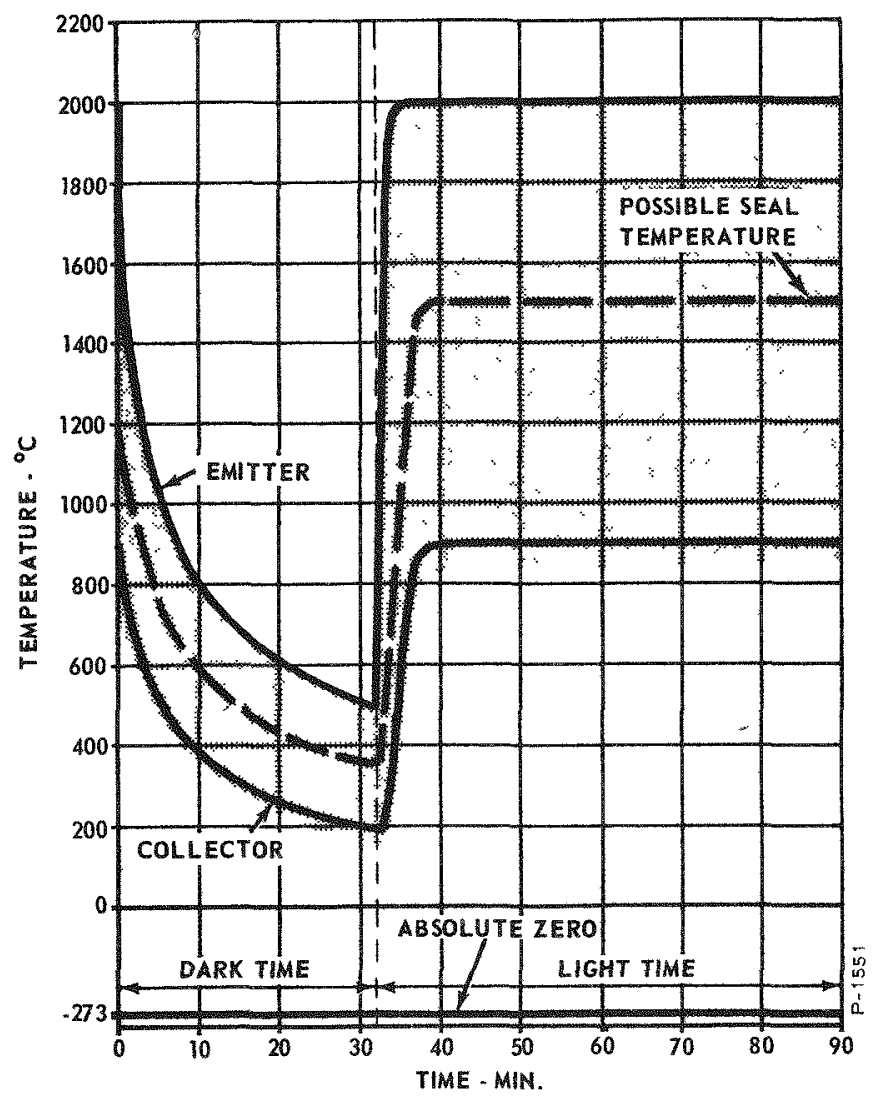

Figure 5 - Possible Temperature Conditions of Uncooled Ceramic - Metal Seals in Thermionic Converters 


\subsection{Thermal Cycling Tests}

The extremes of the time-temperature relationship shown in Figure 5 were intended to define the extremes of the probable use environment and to be the basis for design of thermal cycling equipment and procedures. The requirement for high rate of change of temperature at the thirty-minute point of the orbit posed a problem. Approximating the cooling curve did also.

Induction heating was selected as a promising method of providing these temperature excursions. A relatively simple test setup was established and is shown in Figure 6. However, test runs on dummy specimens showed that it was impossible to provide a satisfactory time-temperature profile with the existing controls.

Therefore, a resistance - heated furnance was built. This furnace is shown in Figure 7 , and consists of:

1. A water cooled base plate with feedthroughs for power, the rmocouples, and inert gas.

2. Water cooled terminals for attachment of the heater.

3. A ceramic stool for the specimen.

4. A W $-5 \mathrm{Re} / \mathrm{W}-25 \mathrm{Re}$ thermocouple to monitor the temperature of the emitter. (This was variously placed under and on top, according to the specimen). Temperatures are recorded on an L\& $\mathrm{N}$ type $\mathrm{H}$ circular chart recorder.

5. A spiral heater of tungsten wire. This is a standard shelf item used in vacuum evaporations.

6. A series of molybdenum heat shields.

7. A water cooled outer shell.

Power control is provided by a manually operated Powerstat and a $115 \mathrm{~V}$ to $20 \mathrm{~V}, 2.5 \mathrm{VA}$ stepdown transformer. Quite exact duplication of the specified heating and cooling curves was possible with this equipment, using manual programming.

Some question was raised about midway through the program concerning the effects of residual oxygen in the furnace atmosphere, which consisted of argon drawn directly from the storage tank, on the seal integrity. The presence of small amounts of oxygen was indicated 

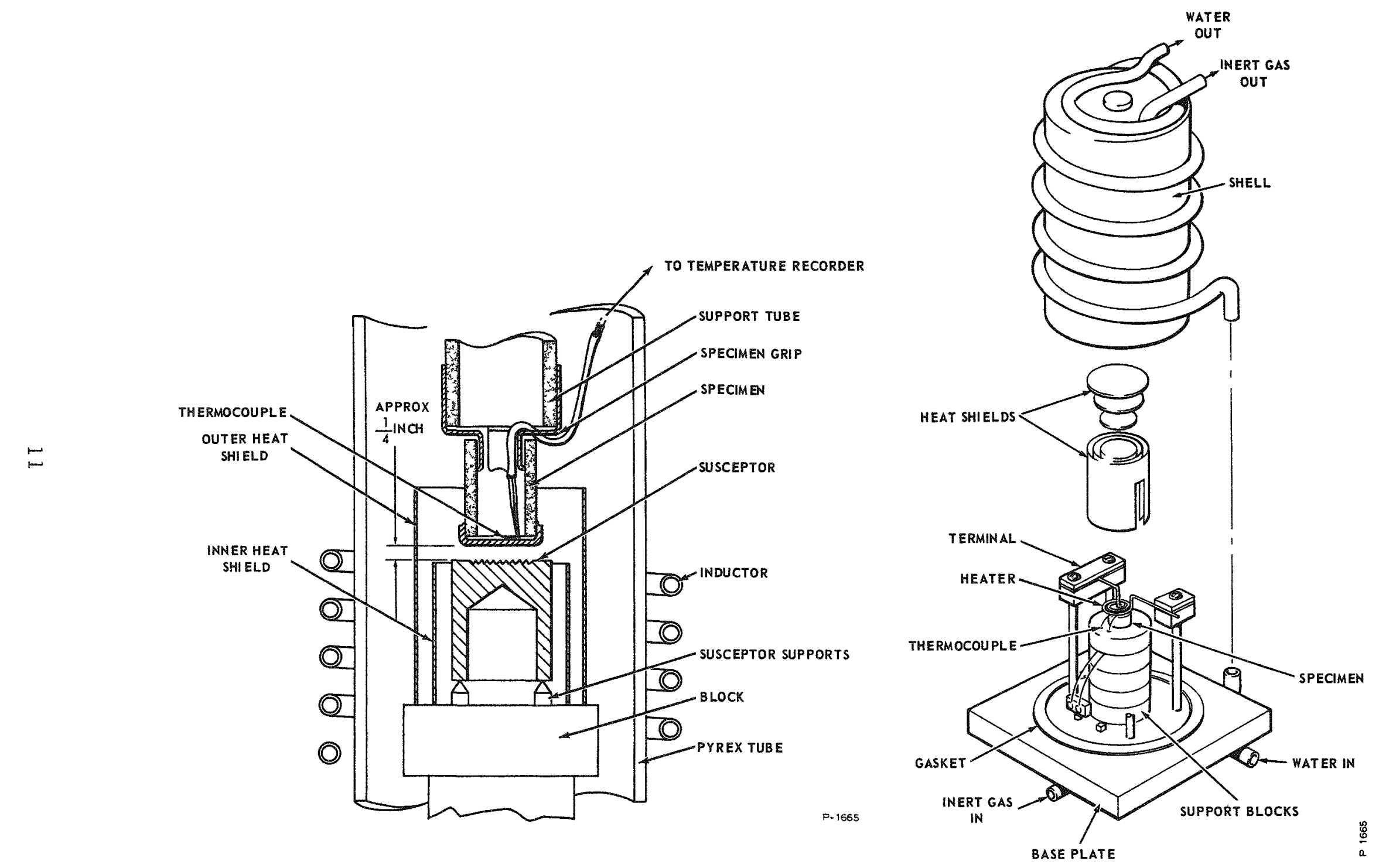

Figure 6 - Basic Equipment Arrangement for Thermal Cycling Tests

Figure 7 - Resistance Heated Furnace 
by discoloration of the metallic parts of the specimen and of the heat shields. Accordingly, a getter furnace was added to the system to purify the argon prior to entry to the furnace. The getter was titanium sponge held at $750-800^{\circ} \mathrm{C}$, and its effectiveness was demonstrated by lack of discoloration in subsequent testing. However, the cleaner atmosphere had no apparent effect on the test results.

Samples subjected to thermal cycling were first tested for hermeticity. They were then slowly heated to the maximum specified test temperature, soaked for a sufficient period to stabilize the conditions and then subjected to cyclical temperature variation, approximately as shown in the curve of Figure 5. If, after thermal cycling was completed, visual examination of the pieces disclosed no apparent structural failure, the samples were tested for hermeticity. 


\subsection{CERAMIC-METAL JOINT SYSTEMS UTILIZING ALUMINA}

\subsection{Ceramic Composition}

The composition of ceramic bodies which could be used in cesiumplasma thermionic converter sturctures is limited to those which do not contain silica. This restriction is necessary because silica is heavily attacked by cesium, particularly at the extremely high temperatures which these structures must resist. Although there are some silica-free aluminas available, they are not numerous. Also, because of the difficulties which have been encountered in metallizing these aluminas, they are not used extensively and are not, in general, readily available.

It was considered important that the aluminas for this investigation be commercially available formulations. Importance was placed on this condition so that sealing methods developed would be immediately applicable to existing materials available to all agencies active in thermionic development.

A survey of commercially available silica-free alumina ceramics disclosed that at least four high aluminas (95 to $99.5 \%)$, an aluminamagnesia spinel, single crystal sapphire, and polycrystalline $99.7 \%$ alumina could be used in the program. As a basis for comparison of strength of seal and ease of metallizing, a commercial $96 \%$ alumina which contained $3 \%$ silica was chosen as a "control" body.

Single crystal sapphire was not considered for study because of the high cost of necessary sizes and shapes and because of the differences in thermal expansion rates along the different axes.

\subsection{Metallizing Process Studies}

The metallizing process studies were undertaken to ensure that characteristics of metallizing systems would be adequate for the requirements of thermionic converter structures. Activities in the beginning were directed at determining the bond strength characteristics of conventional metallizing systems applied to a number of commercially available silica-free alumina bodies. A number of body and metallizing slurry combinations were screened to determine those combinations which showed the best bond strength characteristics. The cross-bending tests, described in Section 2.2, were used for this screening process. 
Some results of these cross-bending tests are shown in Table 2. Seals which consistently parted in the metallized layer were considered too weak for consideration. Seals which failed by fracture of the ceramic member were considered acceptable. From this study two formulations were found to have sufficient strength to warrant further study. These are:

$$
\begin{aligned}
& 85 \mathrm{Mo}=10 \mathrm{Mn}=5 \mathrm{TiH}_{2} \\
& 97 \mathrm{Mo}=3 \mathrm{Ti}
\end{aligned}
$$

After the first "weeding-out" phase, the different ceramic bodies were tested for adherent strength of the metallizing by subjecting them to the standard ASTM tensile tests (ASTM F-19-61T). A basis for comparison was established by metallizing a commercially available $96 \%$ alumina, $3 \%$ silica body with a standard moly-manganese mixture and with the two titanium additive mixtures. Table 3 compares the strengths of the various metallizing mixes on four different bodies.

While the tests indicated that reliable strengths are obtainable with the titanium-additive metallizing mixes on silica-free high alumina ceramics, some question remained whether manganese and titanium would resist cesium vapor attack.

A search for a metallizing mix that would equal the strengths of the previously investigated slurries, and which would also be compatible with cesium vapor, was initiated. A tungsten-yttria combination was developed which, when applied to high purity aluminas as a metallizing slurry and subjected to cross-bending tests, showed bond strength in excess of the ceramic. ASTM tensile tests confirmed the cross abending tests and, in fact, showed that the new metallizing mixture gave bond strengths well in excess of those obtained with the best titanium additive formulations. Tests of a molybdenum-yttria mix which was formulated and applied similarly to the tungsten-yttria mix showed low bond strengths. It is theorized that grain growth in the molybdenum-yttria system at sintering temperatures prevents the larger molybdenum particles from being transported into the ceramic grain boundaries to form an anchor for the metallizing layer.

The most promising metallizing composition is $98 \%$ tungsten $2 \%$ yttria (by weight). This slurry was applied to the $99.5 \%$ purity alumina by brush and the pieces were sintered in wet hydrogen (dewpoint, $+35^{\circ} \mathrm{C}$ ) at $1650^{\circ} \mathrm{C}$ for forty five minutes. Brazes for test purposes 
Table 2 - Results of Cross-Bending Tests

\begin{tabular}{|c|c|c|c|}
\hline Body & Metallizing & No. of Samples & Results* \\
\hline 995 & Mo-Mn-TiH 2 & 6 & Good \\
995 & Mo-Ti & 6 & No Good \\
995 & Mo-Ce & 5 & No Good \\
995 & Mo-Li-Mn & 5 & No Good \\
995 & Mo-Mn & 7 & Good \\
$50-50$ & Mo-Mn-TiH & 4 & Good \\
$50-50$ & Mo-Mn & 6 & Good \\
$50-50$ & Mo-Ti & 5 & Good \\
$98-2$ & Mo-Mn-TiH2 & 5 & Good \\
$98-2$ & Mo-Mn & 5 & Good \\
$98-2$ & Mo-Ti & 6 & Nood, Good \\
$96-3$ & Mo-Mn & 6 & Good \\
$96-3$ & Mo-Mn-TiH & 12 & 5 \\
\hline
\end{tabular}

" "Good" indicates failure in the ceramic. "No Good" indicates failure in the seal.

Table 3 - Average Tensile Strengths of Various Metalizing Slurries on High Alumina Ceramics

\begin{tabular}{|l|c|c|c|}
\hline \multirow{2}{*}{ Body* } & \multicolumn{3}{|c|}{ Metallizing Slurries**; } \\
\cline { 2 - 4 } & $80-20$ & $85-10-5$ & $97-3$ \\
\hline $96-3$ & 9,680 & 14,500 & 13,900 \\
995 & $(a)$ & 4,900 & 10,000 \\
$98-2$ & 2,570 & 4,630 & 6,900 \\
$50-50$ & 6,630 & 6,970 & 7,210 \\
\hline
\end{tabular}

(a) No usable strengths.

* Body code: 96-3 - 96 Alumina, 3 Silica

995 - 99.5 Alumina, 0.25 Chromia, 0.25

Magnesia

98-2 - 98 Alumina, 2 Magnesia

50-50 - Alumina-Magnesia Spine1

*** Metallizing code:

80-20 - 80 Molybdenum, 20 Manganese

85-10-5 - 85 Molybdenum, 10 Manganese, $5 \mathrm{TiH}_{2}$

97-3 - 97 Molybdenum, 3 Titanium 
were made to the unplated metallizing in dry hydrogen (dew-point, $-60^{\circ} \mathrm{C}$ ) at $1100^{\circ} \mathrm{C}$ using copper as the filler metals.

Table 4 compares tensile strengths of three metallizing mixes on the commercial $96 \%$ alumina, $3 \%$ silica body and on a $99.5 \%$ alumina, (silica-free) body. The bond strength superiority of the tungsten metallizing used on either ceramic body is readily apparent.

\subsection{High Temperature Brazing Studies}

The constituent of present conventionally formed ceramic-metal seals which imposes the temperature limitation (disregarding for the moment the acceleration of cesium attack with increase in temperature) is the filler metal used to effect the braze. "High temperature" stateof-the-art seals employ high purity copper as the braze material and the upper limit of use for these is considered to be in the range of $900^{\circ}$ to $950^{\circ} \mathrm{C}$.

A survey of metals and alloys with melting points above that of copper $\left(1083^{\circ} \mathrm{C}\right)$ but below safe usage point of the ceramic $\left(1750^{\circ} \mathrm{C}\right)$ was initiated to determine if this temperature limit could be raised. The metal to be used for higher temperature brazed joints would also be required to withstand cesium vapor attack.

Test seals were attempted between a 99.5 alumina ceramic cylinder and a molybdenum plate using a molybdenum-titanium metallizing at the

Table 4 - Average Tensile Strengths of Yttria-Bearing Metallizing Slurries

\begin{tabular}{|c|c|c|c|}
\hline Body & $97-3$ & $98 \mathrm{~W}-2$ & $98 \mathrm{M}-2$ \\
\hline $96-3$ & 13,900 & 19,860 & 8,510 \\
995 & 10,000 & 19,950 & 1,290 \\
\hline Body Code: $96-3-$ & 96 Alumina, 3 Silica \\
& $995-99.5$ Alumina, 0.25 Chromia, \\
\hline & \begin{tabular}{l} 
0.25 Magnesia \\
\hline
\end{tabular}
\end{tabular}

Metallizing Code:

97-3 - 97 Molybdenum, 3 Titanium

98W-2 - 98 Tungsten, 2 Yttria

98M-2 - 98 Molybdenum, 2 Yttria 
interface and employing various braze materials. Nickel and nickeliron alloys gave no bond. The nickel alloyed with molybdenum at $1350^{\circ} \mathrm{C}$ and the resulting alloy was non-wetting to the ceramic. Cobalt and iron gave excellent adherences to the ceramic-metal assemblies but the high coefficient of thermal expansion of these filler metals accentuated the expansion mismatch between the molybdenum metal member and the ceramic tube, causing gross fractures in the ceramic at the seal area.

To improve the expansion match between the ceramic and the metal members, molybdenum was replaced by niobium. Brazes were attempted between a $99.5 \%$ alumina ceramic metallized with the tungstenyttria composition and a niobium plate, using palladium as the filler metal. Successful vacuum-tight seals were made but the control of temperature was critical. Any slight overshoot of temperature or of time at the brazing temperature resulted in severe erosion of the niobium plate, and, in many cases, a series of small holes formed at the seal area resulting in lack of hermeticity. The cause of this effect was investigated. It can be seen from the phase diagram of the system niobium (columbium) and palladium shown in Figure 8 that the melting point of palladium coincides within a few degrees with the melting point of a palladium-niobium eutectic. It is apparent from this diagram that in attempting a braze to niobium with palladium, solution between the two metals would take place.

The corrosive effect of palladium on niobium during the brazing operation can be avoided by substituting a niobium-palladium eutectic alloy for the pure palladium.

\subsection{Ultrasonic Welding Studies}

Studies of the application of ultrasonic welding techniques to this joining problem were undertaken as a part of this program because of the apparent simplicity of joining thin gage refractory metals to metallized ceramic components. It was the intent of this task to develop the specific techniques needed to weld $0.001^{\prime \prime}, 0.005^{\prime \prime}$, and $0.025^{\prime \prime}$ thick molybdenum sheet to a Mo-Mn metallized alumina.

Ultrasonic welding is basically a process for joining metals by introducing high-frequency vibratory energy into overlapping workpieces. A brief transmission of this energy into a work-piece consisting of two like metallic members under moderately low static force will produce a sound metallurgical bond. 


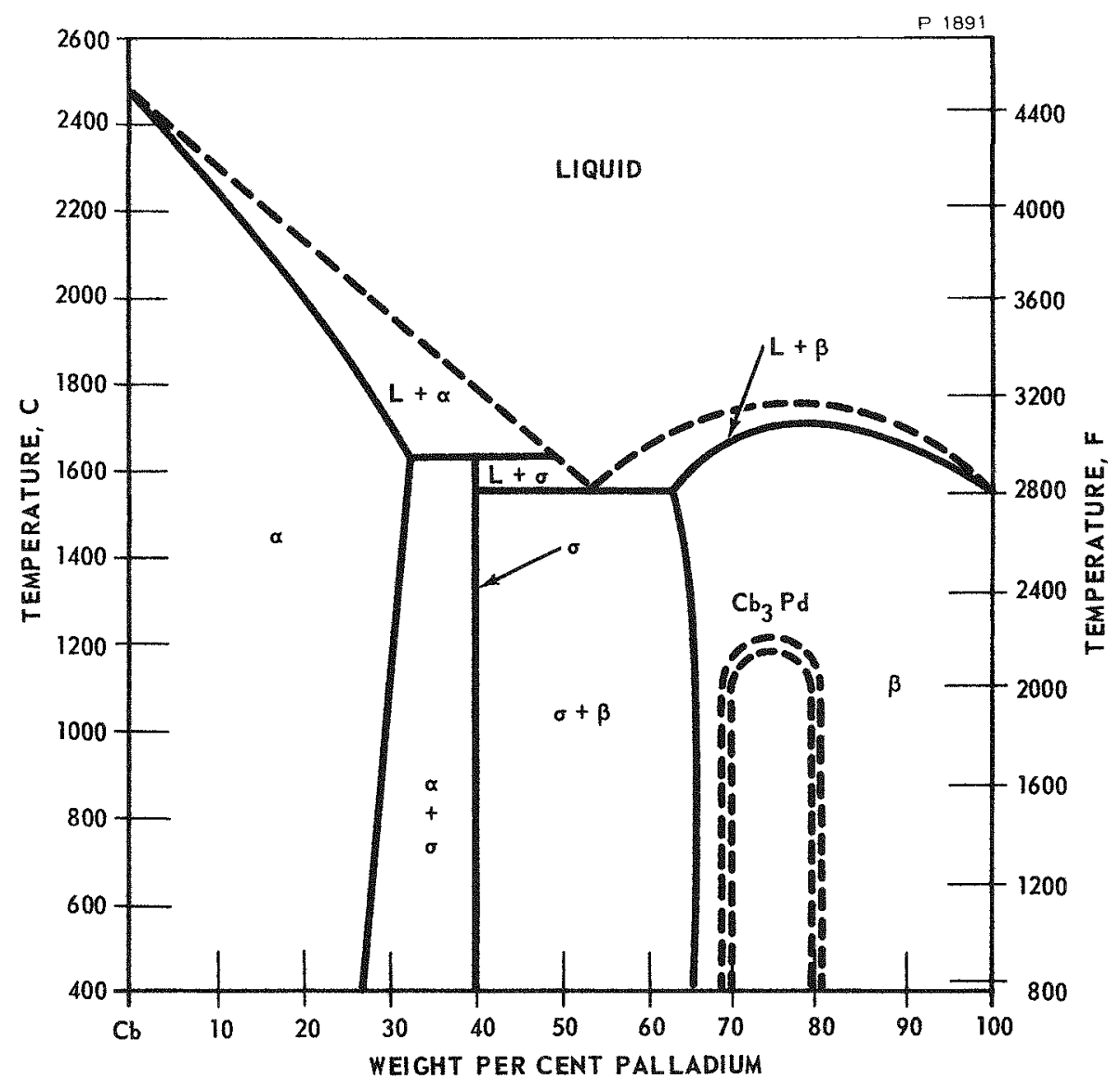

Figure 8 - Phase Diagram: Niobium-Palladium System

The ultrasonic process has several advantages over other methods of joining. These advantages include the following:

1. Close dimensional tolerances in assembly can be obtained because thermal distortion does not occur.

2. A wide variety of dissimilar material combinations can be joined.

3. Variation in size of components does not affect the quality of the weld.

This joint is effected without fluxes or filler metals, without arc, electrical transmission, or melting of the weld metal. There is, therefore, no cast structure and only negligible thickness deformation. This deformation affects the surfaces of the welded parts only by 1 or 2 percent of the total weldment thickness. 
The logical approach to the development of techniques for this application was first to make singular spot welds between metallized ceramic and metal, then to attempt overlapping singular welds, and finally to develop techniques by which a ring weld could be made using a circular sonotrode (welding tip). Schematic illustrations of these steps are shown in Figure 9.

The principal variables in this process are:

1. Metallic surface condition.

2. Power available for welding.

3. Clamping force requirements.

4. Time of welding.

5. Radii of welding tips.

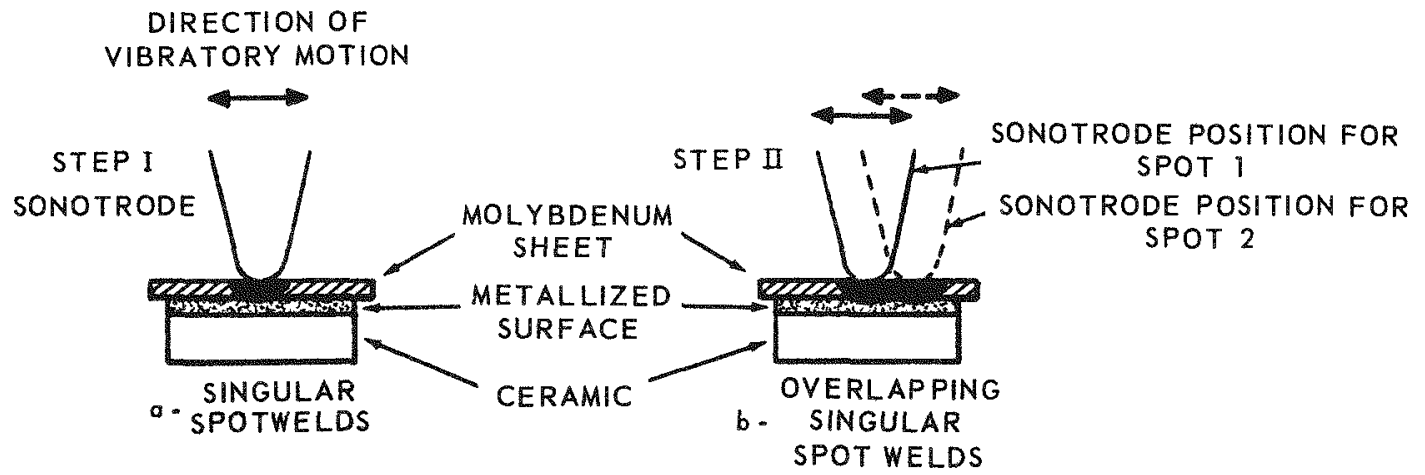

VIBRATORY MOTION

IN CIRCULAR DIRECTION

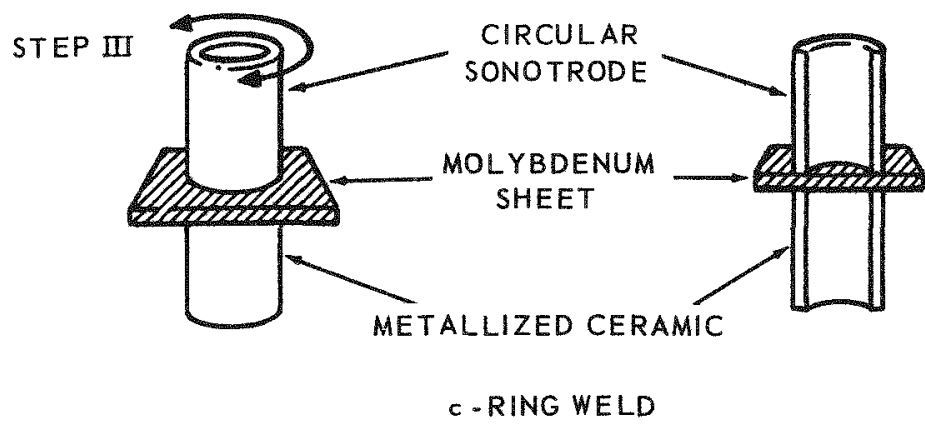

Figure 9 - Development Steps in Ultrasonıc Welding Study 
Some 125 singular spot welds were attempted under controlled variation of the critical variables.

The results of preliminary singular spot weld attempts indicated that the most critical problems are associated with the radius of the sonotrode and conditions at the interface of the molybdenum sheet and the metallized coating. Changes in the radius and material of the sonotrode had little effect on the inability to produce satisfactory welds. The interface problem was somewhat improved by the use of $0.0005^{\prime \prime}$ thick tantalum foil between the surfaces of the molybdenum and the coated ceramic. Although some spot welds were obtained which showed good strength, the repeatability of the process was poor.

The weld shown in Figure 10, in which 0.005 -inch molybdenum was welded to the metallized alumina using a tantalum interleaf, resulted in a good bond. The section of the bond shows interaction between the molybdenum and the tantalum, an extreme amount of gathering of tantalum metal, and a bond line between the tantalum and the metallized alumina that does not appear sound. The weld, however, was relatively strong.

In an attempt to produce a weld of the form shown in Figure 9 using a circular sonotrode, it was found that even with the maximum clamping force a weld could not be made and the force which was applied resulted in fracture of the ceramic.

Figure 11 shows the tantalum interleaf sheet following this attempt at ring welding. The view in this figure is toward the side of the tantalum sheet which was in contact with the metallized surface. The un marked section of the ring pattern could readily be due to ceramic breakage or to non-parallel faces. In ring welding the direction of tip motion is circumferential instead of linear. The direction of tip motion can be seen in this illustration by the stress pattern in the tantalum foil.

Because of the lack of progress towards development of a successful technique, this activity was halted.

\subsection{Electroformed Seal Studies}

This study was undertaken to investigate the problems of and the techniques required for electroplating a junction layer of refractory metal over a metal surface in intimate association with the metallized surface of a ceramic. It was believed that a seal formed in this way could be operated up to the temperature limitations of the metallized ceramic system. 


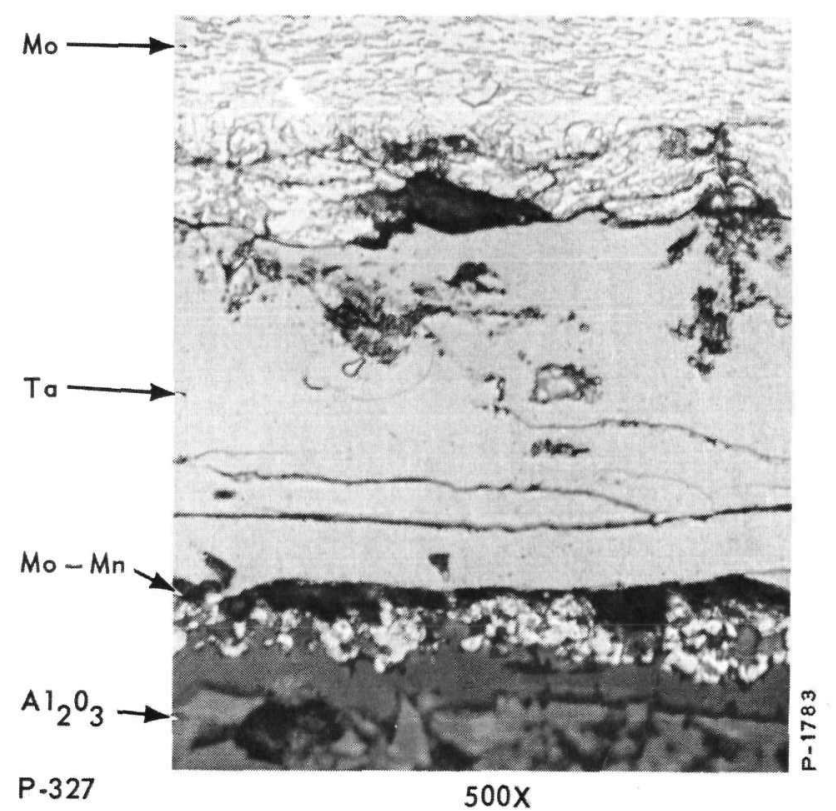

Figure 10 - Sections of Ultrasonic Weld Showing Inte raction Conditions

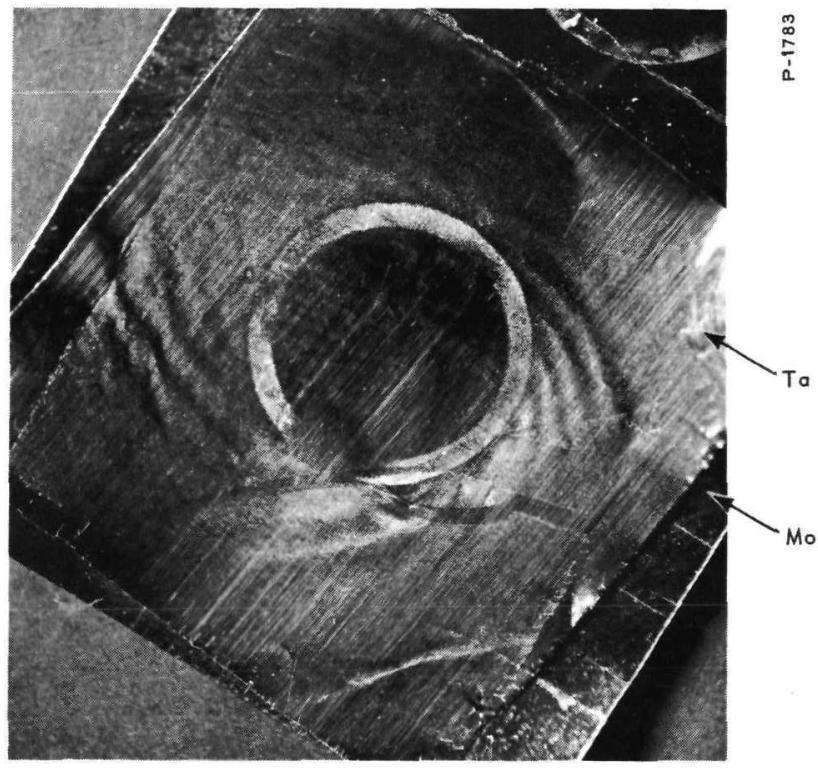

Figure 11 - Tantalum Interleaf Used in Ring Welding Trials

Rhodium was selected for the plating material after eliminating other candidate materials by a consideration of the following characteristics:

1. Melting point near $2000^{\circ} \mathrm{C}$.

2. Low vapor pressure.

3. Chemical compatibility with molybdenum.

4. Low relative cost.

5. Ability to be plated.

This investigation was divided into the following successive parts to isolate each of several problems for individual study:

1. Develop techniques for "heavy" rhodium plate on brass base.

2. Modify techniques from item 1 as required to optimize "heavy" rhodium plating on molybdenum base. 
3. Develop techniques to plate over the joint area of lapped sheets of molybdenum.

4. Plate rhodium on the metallized surface of alumina.

5. Plate over the joint area of molybdenum sheet lapped over a metallized alumina surface.

These steps are shown schematically in Figure 12.

The first two steps in this plan of investigation were successfully accomplished. Plating parameters were optimized such that a total thickness of $0.005^{\prime \prime}$ of rhodium was successfully achieved on a brass substrate. It should be noted that, until very recently, a plating thickness of 0.0005 " was considered "heavy" rhodium plating. Electroplating of rhodium on molybdenum has been found to be more difficult than on brass because of cracking due to the development of high stresses in the plated rhodium. Although the stress conditions also exist in the rhodium plated on a brass substrate, the effect is not as serious. A better bond is formed between the brass and the rhodium.

The use of an intermediate layer of electroplated chromium or nickel was considered as a possible means of improving the bond when plating rhodium on molybdenum. Plating trials using these intermediate

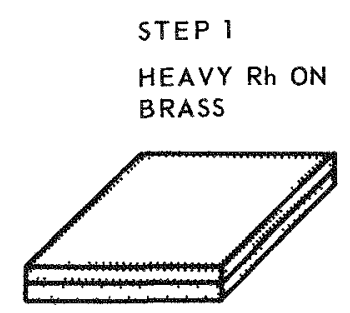

STEP 2

HEAVY Rh ON MOLY SHEET

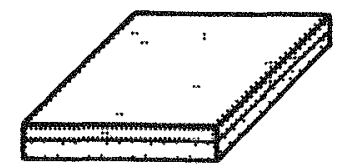

STEP 3 Rh OVER LAPPED MOLY SHEETS

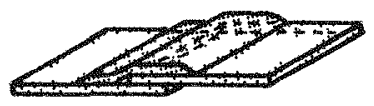

STEP 4

Rh ON METALLIZED $\mathrm{Al}_{2} \mathrm{O}_{3}$

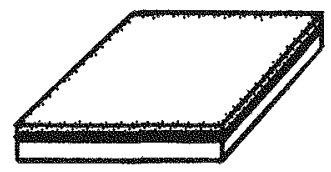

STEP 5

Rh ON LAPPED MOLY SHEET AND METALLIZED Al $2 \mathrm{O}_{3}$

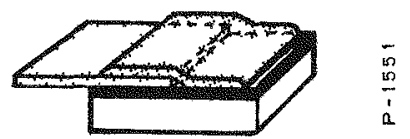

Figure 12 - Development Steps in Electro-Formed Seal Study 
materials were unsuccessful. Neither nickel nor chromium gave evidence of improving the bond of rhodium plated on a molybdenum substrate.

Stress - relieving thermal treatments were also considered as a processing step which might be used to reduce the cracking effects due to the highly stressed plated coatings. Plated specimens were annealed in vacuum for periods up to one hour at $540^{\circ} \mathrm{C}$ and $980^{\circ} \mathrm{C}$. Annealing at $980^{\circ} \mathrm{C}$ eliminated essentially all coatings discontinuities. A section of a plated sample annealed in this manner is shown in Figure 13a. An additional $0.001^{\prime \prime}$ of rhodium was then plated on the sample. After a final annealing at $980^{\circ} \mathrm{C}$, this specimen was again sectioned. The section is shown in Figure $3 \mathrm{~b}$. The plated material shows excellent adhesion and good coating integrity.

Plating of rhodium over a lap-joint between two sheets of molybdenum was considered the next step toward accomplishment of an electroformed ceramic-metal seal. This presented the following additional problems:

1. How to join the materials together prior to plating.

2. How to eliminate seepage of plating solution into resulting crevice between sheets.

3. How to form joint so that a continuous plated surface would result spanning the lap joint.

For initial studies, molybdenum sheets were joined together by spot welding using an organic lacquer to fill the space between them. The upper sheet was beveled at approximately a $30^{\circ}$ angle to minimize the step at the junction of the two sheets. Several specimens of this configuration were plated with approximately $0.0015^{\prime \prime}$ of rhodium. Figure 14 is a photomicrograph of a cross-section of one of these lap joints. It can be seen that plating over this type of joint is possible, however, many processing difficulties must still be overcome before a reliable hermetic closure is obtainable repeatably.

Study of this method of obtaining high-temperature ceramic-metal seals was discontinued because of the greater immediate promise of success shown by other processes also under study. However, the electroplated rhodium concept is still considered to be a feasible approach to obtaining a high temperature seal. The experience gained in plating rhodium should be applicable in plating rhenium for use as an emitter surface on a different refractory metal substrate. A description of the steps in the plating process for applying rhodium to molybdenum is contained in Appendix $C$. 


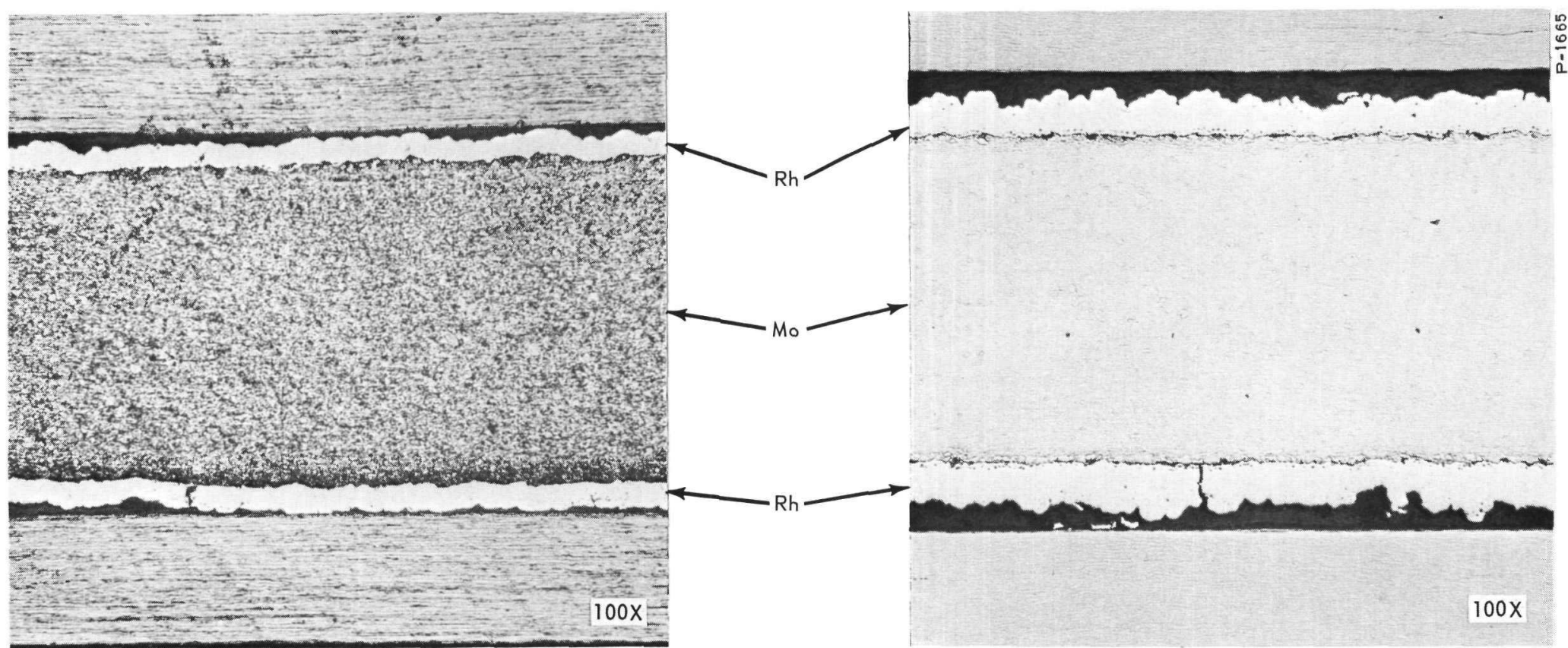

(a) - 1 Plating Cycle

(b) - 2 Plating Cycles

Figure 13 - Electroplated Rhodium on Molybdenum - $980^{\circ} \mathrm{C}$ Stress-Relief Anneal 
Mo (UPPER SECTION OF LAP JOINT)

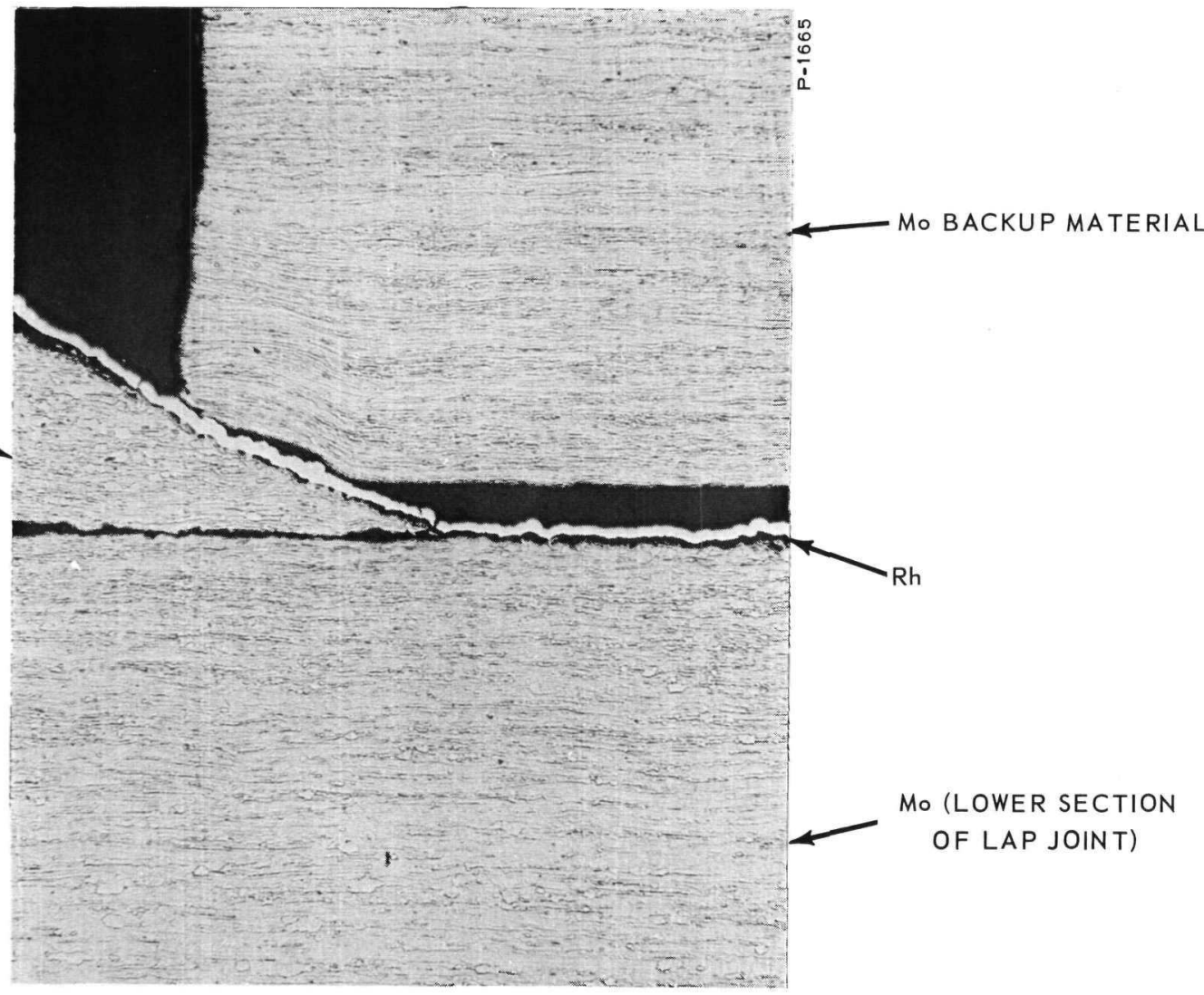

Figure 14 - Electroplated Rhodium over a Lapped Joint between Two Sheets of Molybdenum 


\subsection{Electron Beam Welding Studies}

\subsubsection{Welding to Unmetallized Alumina}

The objective of this program was the development of techniques for electron beam welding of ceramics to metals. The major amount of work was done on the welding of 96 percent aluminum oxide to molybdenum. Some attempts were made to obtain welds using sapphire, Lucalox, tantalum, tungsten and niobium as the materials to be joined.

The materials used for developmental testing were:

$\begin{array}{ll}\text { Ceramics } & \text { Metals } \\ 96 \% \mathrm{Al}_{2} \mathrm{O}_{3} & \text { Niobium } \\ \text { Sapphire } & \text { Tantalum } \\ \text { Lucalox } & \text { Tungsten } \\ 99+\% \mathrm{Be}^{*} & \text { Molybdenum } \\ 995^{*} \mathrm{Al}_{2} \mathrm{O}_{3} & \\ 614^{*} \mathrm{Al}_{2} \mathrm{O}_{3} & \text { * Suppliers' designations of commercial } \\ 652^{*} \mathrm{Al}_{2} \mathrm{O}_{3} & \text { products }\end{array}$

A trial welding program was conducted on the various material combinations to establish basic welding parameters and to determine the effects of the parameters on weld-zone characteristics. The parameters which were studied included preheating temperatures, post - weld cooling cycles, accelerating voltage, beam current, beam focus location and location of the beam with respect to the joint center line, beam oscillation, pulsed beam conditions, and welding speeds.

In order to study the reactions between alumina (the ceramic of major interest in this investigation) and the refractory metals, small crucibles of tungsten were fabricated into which were packed chips of 96 percent alumina interspersed with chips of a refractory metal. Columbium, tantalum, molybdenum and tungsten were utilized. The chip size was approximately $1 / 16^{\prime \prime} \times 1 / 8^{\prime \prime}$. These filled crucibles were then placed in the electron beam vacuum chamber and the contents of each crucible was completely fused by impingement of the electron beam. Each crucible was then embedded and sectioned. Photomicrographs showed that no usable interface had resulted in any of the crucible welds. 
It was concluded from the se studies that, although fusion does take place between the metal and ceramic when fluid, upon cooling there exists no gradation of phases from the ceramic to the metal such that the differing expansion coefficients are matched or blended. Thus, cracking results. No reaction products are formed which promote bonding.

\subsubsection{Welding to Metallized Layer on Alumina Substrate}

Lap or "seam-type" joints between alumina metallized with molybdenum-manganese and molybdenum were attempted with only partial success because of poor fit between the components. This condition was caused by the slightly curved and irregular surface of the ceramic wafers. The poor fit and inadequate control of work $=$ piece location frequently resulted either in excessive penetration, or lack of heat transfer to the metallized surface Strong joints were obtained in areas of intimate contact between the metallizing surface and the molybdenum sheet when weld penetration was limited to the molybdenum member. No fusion occurred in the ceramic and the joints were crackfree. These very narrow, 0.010 inch wide joints exhibited excellent strength in peel tests and failure occurred at the ceramic-to-metallizing interface rather than in the metal-to-metallizing bond.

\subsection{Diffusion Seal Studies}

This study was directed towards the development of a seal between alumina and molybdenum or niobium for use up to $1500^{\circ} \mathrm{C}$ Initially the basic materials to be used in this study were molybdenum and silicafree alumina, but niobium was added late in the program because of its desirable properties. While the direct output desired from this study was a seal between alumina and molybdenum (or niobium), it was expected that knowledge of the mechanisms by which formation of desired reaction zone products could be controlled would also be useful in developing joining mechanisms for material systems with capabilities for use above $1500^{\circ} \mathrm{C}$.

Two directions were taken simultaneously in this study: the investigation of seals formed directly between a metal member and a ceramic member by the interdiffusion of reaction zone products; and the investigation of seals formed between a metal member and the metallized surface of a ceramic by alloying of the two surfaces. 


\subsubsection{Diffusion Seal Studies on Unmetallized Ceramics}

Some of the systems which were considered useful in producing seals with unmetallized ceramics are shown with desired transition zone reaction products indicated by parenthesis:

$$
\begin{aligned}
& \text { 1. } \mathrm{Mo}(\mathrm{Mo} \cdot \mathrm{Cr}) \mathrm{Cr} \cdot \mathrm{MgO}\left(\mathrm{MgO} \cdot \mathrm{Al}_{2} \mathrm{O}_{3}\right) \mathrm{Al}_{2} \mathrm{O}_{3} \text {. } \\
& \text { 2. } \mathrm{Mo}(\mathrm{Mo} \cdot \mathrm{Cr}) \mathrm{Cr}_{2} \mathrm{O}_{3}\left(\mathrm{Cr}_{2} \mathrm{O}_{3} \cdot \mathrm{Al}_{2} \mathrm{O}_{3}\right) \mathrm{Al}_{2} \mathrm{O}_{3} \text {. } \\
& \text { 3. } \mathrm{Mo}(\mathrm{Mo} \cdot \mathrm{Mg}) \mathrm{MgO}\left(\mathrm{MgO} \cdot \mathrm{Al}_{2} \mathrm{O}_{3}\right) \mathrm{Al}_{2} \mathrm{O}_{3} \\
& \text { 4. } \mathrm{Mo}(\mathrm{Mo} \cdot \mathrm{Mg}) \mathrm{Mg}\left(\mathrm{MgO} \cdot \mathrm{Al}_{2} \mathrm{O}_{3}\right) \mathrm{Al}_{2} \mathrm{O}_{3} \text {. } \\
& \text { 5. } \mathrm{Mo}(\mathrm{Mo} \cdot \mathrm{Ni}) \mathrm{Ni}(\mathrm{NiO} \cdot \mathrm{MgO}) \mathrm{MgO}\left(\mathrm{MgO}^{\circ} \mathrm{Al}_{2} \mathrm{O}_{3}\right) \mathrm{Al}_{2} \mathrm{O}_{3} \text {. } \\
& \text { 6. } \mathrm{Mo}(\mathrm{Mo} \cdot \mathrm{Cr}) \mathrm{Cr}\left(\mathrm{Cr}_{2} \mathrm{O}_{3}\right) \mathrm{MgO}\left(\mathrm{MgO} \cdot \mathrm{Al}_{2} \mathrm{O}_{3}\right) \mathrm{Al}_{2} \mathrm{O}_{3} \text {. } \\
& \text { 7. Mo (Mo } \mathrm{Cr}) \mathrm{Cr}\left(\mathrm{Cr}_{2} \mathrm{O}_{3}\right) \mathrm{Cr}_{2} \mathrm{O}_{3}\left(\mathrm{Cr}_{2} \mathrm{O}_{3} \cdot \mathrm{Al}_{2} \mathrm{O}_{3}\right) \mathrm{Al}_{2} \mathrm{O}_{3} \text {. } \\
& \text { 8. } \mathrm{Mo}(\mathrm{Mo} \cdot \mathrm{Ni}) \mathrm{Ni}\left(\mathrm{NiO} \cdot \mathrm{Al}_{2} \mathrm{O}_{3}\right) \mathrm{Al}_{2} \mathrm{O}_{3} \text {. }
\end{aligned}
$$

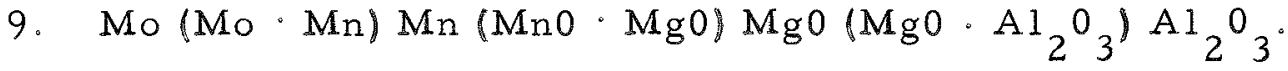

$$
\begin{aligned}
& \text { 10. Mo (Mo } \mathrm{Mn}) \mathrm{Mn}\left(\mathrm{MnO} \cdot \mathrm{Al}_{2} \mathrm{O}_{3}\right) \mathrm{Al}_{2} \mathrm{O}_{3} \text {. }
\end{aligned}
$$

Various atmospheres were suggested for promotion of the above reactions - - vacuum, hydrogen, or inert gases. Combinations of all three types were used, but vacuum treatment proved to be the best. The reactive materials were introduced by various means, such as loose powders, flame spray, and arc-plasma spray.

This series of materials yielded minor reaction zones between $\mathrm{Mo}$ and $\mathrm{Cr}, \mathrm{MgO}$ and $\mathrm{Al}_{2} \mathrm{O}_{3}$, and $\mathrm{Cr}_{2}{ }_{3}$ and $\mathrm{Al}_{2}{ }_{3}$; but there was no evidence of continuous bonding between the molybdenum and alumina. Only marginal results were obtained with flat samples that employed molybdenum sheet coated with flame sprayed (oxy-acetylene) nickel, and alumina coated with arc-plasma sprayed MgO. Definite reaction areas were developed in this test series, including a nickel molybdenum alloy on the molybdenum interlocked with a ceramic phase that was believed to be NiO.

These magnesium oxide-nickel interlayers were only moderately successful in making an aluminam molybdenum seal after development of a spinel phase. Difficulties were encountered in plasma spraying a uniform magnesium oxide layer, and only marginal adhesion conditions resulted. Extremely high spraying temperatures were needed 
for the magnesium oxide, and several water cooled nozzles were melted because of this. Small additions of other metals offered little help; the magnesium oxide did not adhere and only a small amount would remain in the matrix of lower melting materials. Alumina dipped in a slurry of finely divided magnesium oxide again offered only moderate adhesion to the molybdenum.

Because of these conditions, consideration was given to other possible interlayer materials. Niobium and niobium combinations were selected as among the most promising in the preliminary tests. It was necessary to evaluate a large number of coating combinations because of the large effect of small variations in material compositions. A complete list of the materials used in this phase of the study on the flat plates of alumina and molybdenum is shown in Table 5. Those material combinations which, in the flat plate study, showed most promise were applied to ceramic cylinders and metal cups as shown in Figures 3 and 4 for the formation of seals in this form. Table 6 is a list of the materials used on the molybdenum cups and alumina cylinders.

Better adhesion of the metallic interlayers was expected from a roughening of the surface of both the alumina and the molybdenum. Several methods were tested before the final choice was made; different grit-blasting air pressures were used on the alumina and the molybdenum, and plasma blasting was also employed with a small amount of alumina powder. The latter method provided a roughened surface but the particles deposited were only loosely attached and would not enhance mechanical adhesion. A very light grit blast - about 10 psi with -60 mesh grit - provided the best surface on the alumina pieces. Similar treatment was required to roughen the molybdenum surface sufficiently. Great care had to be taken to avoid warping the thin molybdenum sheets. This same technique was used on the alumina cylinders and molybdenum cups. The irregular shapes of the cups caused some concern that adequate uniformity of application might not be achieved, but subsequent optical examination showed little variation.

All of the ccatings used in this phase of the study were applied with a Thermal Dynamics plasma flame $F-40$ torch unless otherwise specified. Argon was found to be the best plasma gas for spraying, but several materials were sprayed in nitrogen with relative ease. The use of argon as the plasma gas reduced the possibility of contamination and byproduct formation. 
Table 5 - Interlayer Materials Used on Alumina and Molybdenum Flat Sheets

\begin{tabular}{|c|c|c|}
\hline $\begin{array}{l}\text { SAMPLE } \\
\text { NUMBER }\end{array}$ & ALUMINA COATING & MOLYBDENUM COATING \\
\hline SP- 1 & $N_{1}$ & $\mathrm{NiO}$ \\
\hline$S P-2$ & $\mathrm{Nb}$ & $\mathrm{Nb}$ \\
\hline SP-3 & $\mathrm{Ni}$ & $\mathrm{Ni}$ \\
\hline$S P-4$ & $50 \% \mathrm{Ni}+50 \% \mathrm{Al}_{2} \mathrm{O}_{3}$ & $50 \% \mathrm{Ni}+50 \% \mathrm{Mo}$ \\
\hline SP. 5 & $50 \% \mathrm{TiO}_{2}+50 \% \mathrm{MgO}$ & $\mathrm{Ni}$ \\
\hline SP- 6 & $50 \% \mathrm{Ni}+50 \% \mathrm{Al}_{2} \mathrm{O}_{3} *$ & $\mathrm{Ni}$ \\
\hline SP-7 & $\mathrm{MgO}$ & $\mathrm{Ni}$ \\
\hline $\mathrm{SP}-8$ & $50 \% \mathrm{MgO}+50 \% \mathrm{Al}_{2} \mathrm{O}_{3}$ & $\mathrm{Ni}$ \\
\hline SP-9 & $\mathrm{MgO}$ & $\mathrm{NiO}$ \\
\hline$S P-10$ & $50 \% \mathrm{MgO}+50 \% \mathrm{Al}_{2} \mathrm{O}_{3}$ & $\mathrm{NiO}$ \\
\hline SP. 11 & $\mathrm{MgO}$ & $50 \% \mathrm{Ni}+50 \% \mathrm{Mo}$ \\
\hline$S P=12$ & $50 \% \mathrm{MgO}+50 \% \mathrm{Al}_{2} \mathrm{O}_{3}$ & $50 \% \mathrm{Ni}+50 \% \mathrm{Mo}$ \\
\hline$S P-13$ & $\mathrm{Ni} *$ & $\mathrm{Ni}$ \\
\hline$S P-14$ & $\mathrm{Ni}$ & $50 \% \mathrm{Ni}+50 \% \mathrm{Mo}$ \\
\hline$S P-15$ & $\mathrm{NiO}$ & $50 \% \mathrm{Ni}+50 \% \mathrm{Mo}$ \\
\hline$S P,-16$ & $50 \% \mathrm{Ni}+50 \% \mathrm{Al}_{2} \mathrm{O}_{3}$ & $50 \% \mathrm{Ni}+50 \% \mathrm{Mo}$ \\
\hline SP-17 & $\mathrm{Ni} \& 3$ & $\mathrm{Ni}$ \\
\hline & & Polished Surfaces \\
\hline SP-18 & - & \\
\hline$S P-19$ & $\mathrm{Ni} *$ & $\mathrm{Ni}$ \\
\hline & & Polished Surfaces \\
\hline $\mathrm{SP}-20$ & -- & \\
\hline$S P-21$ & $\mathrm{Ni} *$ & $\begin{array}{l}50 \% \mathrm{Ni}+50 \% \mathrm{Mo} \\
\text { Polished Surfaces }\end{array}$ \\
\hline $\mathrm{SP}-22$ & $\mathrm{MgO}$ & $\mathrm{NiO}$ \\
\hline$S P-23$ & $50 \% \mathrm{MgO}+50 \% \mathrm{Al}_{2} \mathrm{O}_{3}$ & $\mathrm{NiO}$ \\
\hline $\mathrm{SP}-24$ & $\mathrm{Ni} *$ & $\mathrm{MgO}$ \\
\hline SP-25 & $\mathrm{Ni} *$ & $\mathrm{MgO}$ \\
\hline$S P-26$ & $\mathrm{Nb}$ & $\mathrm{Nb}$ \\
\hline SP- 27 & $\mathrm{Nb}$ & $\mathrm{Nb}$ \\
\hline SP- 28 & $80 \% \mathrm{MgO}+20 \% \mathrm{Ni}$ & $80 \% \mathrm{MgO}+20 \% \mathrm{Ni}$ \\
\hline$\cdot 5 P-29$ & $50 \% \mathrm{Nb}+25 \% \mathrm{Mo}+25 \% \mathrm{Ni}$ & Same as alumina \\
\hline$S P-30$ & $75 \% \mathrm{Nb}+15 \% \mathrm{Mo}+10 \% \mathrm{Ni}$ & Same as alumina \\
\hline$S P-31$ & $75 \% \mathrm{Nb}+15 \% \mathrm{Mo}+10 \% \mathrm{Ti}$ & Same as alumina \\
\hline$S P-32$ & $50 \% \mathrm{Nb}+25 \% \mathrm{Mo}+25 \% \mathrm{Ni}$ & Same as alumina \\
\hline SP-33 & $75 \% \mathrm{Nb}+15 \% \mathrm{Mo}+10 \% \mathrm{Ni}$ & Same as alumina \\
\hline$S P-34$ & $75 \% \mathrm{Nb}+15 \% \mathrm{Mo}+10 \% \mathrm{Ti}$ & Same as alumina \\
\hline$S P-35$ & Dipped MgO Slurry & $\mathrm{Ni}$ \\
\hline SP-36 & Dipped MgO Slurry & $50 \% \mathrm{Nb}+25 \% \mathrm{Ni}+25 \% \mathrm{Mo}$ \\
\hline SP-37 & $\mathrm{Nb}$ & $\mathrm{Nb}$ \\
\hline$S P-38$ & $\mathrm{Nb}$ & $\mathrm{Nb}$ with $\mathrm{Ni}$ interlayer \\
\hline$S P-39$ & $\mathrm{Nb}$ & Ni (flame sprayed) \\
\hline$S P-40$ & $\mathrm{MgO}$ (dipped) & Ni (flame sprayed) \\
\hline
\end{tabular}

*Nickel coating was oxidized after being sprayed on alumina plate. 
Table 6 - Coatings Applied to Alumina Cylinders and Molybdenum Cups Showing the Resulting Vacuum Capabilities

\begin{tabular}{|c|c|c|c|}
\hline $\begin{array}{l}\text { SAMPLE } \\
\text { NUMBER }\end{array}$ & ALUMINA COATING & MOLYBDENUM COATING & PRESSURE* \\
\hline CY -1 & $\mathrm{Ni}$ & $50 \% \mathrm{Ni}+50 \% \mathrm{Mo}$ & \\
\hline$C Y^{\prime}-2$ & $\mathrm{Ni}$ & $\mathrm{Ni}$ & \\
\hline$C Y-3$ & $\mathrm{Nb}$ & $\mathrm{Nb}$ & $100 \mu$ \\
\hline & & Lapped Surfaces & \\
\hline CY -4 & $\mathrm{Nb}$ & $\begin{array}{l}50 \% \mathrm{Nb}+50 \% \mathrm{Mo} \\
\text { Lapped Surfaces }\end{array}$ & \\
\hline$C Y-5$ & Ni (oxid.) & $\mathrm{Nb}$ & \\
\hline$C Y-6$ & $\mathrm{Nb}$ & $\mathrm{Nb}$ & \\
\hline CY -7 & $95 \% \mathrm{Nb}+5 \% \mathrm{Ni}$ & $95 \% \mathrm{Nb}+5 \% \mathrm{Ni}$ & \\
\hline$C Y-8$ & $95 \% \mathrm{Nb}+5 \% \mathrm{Ti}$ & $95 \% \mathrm{Nb}+5 \% \mathrm{Ti}$ & \\
\hline GY -9 & $90 \% \mathrm{Nb}+10 \% \mathrm{Ni}$ & $90 \% \mathrm{Nb}+10 \% \mathrm{Ni}$ & \\
\hline$C Y-10$ & $98 \% \mathrm{Nb}+2 \% \mathrm{Ti}$ & $98 \% \mathrm{Nb}+2 \% \mathrm{Ti}$ & \\
\hline CY -11 & $50 \% \mathrm{Nb}+25 \% \mathrm{Mo}+25 \% \mathrm{Ni}$ & Same as alumina & \\
\hline$C Y-12$ & $75 \% \mathrm{Nb}+15 \% \mathrm{Mo}+10 \% \mathrm{Ni}$ & Same as alumina & \\
\hline$C Y-13$ & $75 \% \mathrm{Nb}+15 \% \mathrm{Mo}+10 \% \mathrm{Ti}$ & Same as alumina & \\
\hline$C Y-14$ & $\mathrm{Nb}$ & $\mathrm{Nb}$ & $350 \mu$ \\
\hline$C Y-15$ & $95 \% \mathrm{Nb}+5 \% \mathrm{Ni}$ & Same as alumina & $115 \mu$ \\
\hline$C Y-16$ & $95 \% \mathrm{Nb}+5 \% \mathrm{Ti}$ & Same as alumina & $220 \mu$ \\
\hline$C Y-17$ & $75 \% \mathrm{Nb}+15 \% \mathrm{Mo}+10 \% \mathrm{Ni}$ & Same as alumina & \\
\hline$C Y-18$ & $75 \% \mathrm{Nb}+15 \% \mathrm{Mo}+10 \% \mathrm{Ti}$ & Same as alumina & \\
\hline$C Y-19$ & $\mathrm{Nb}$ & $\mathrm{Nb}$ with $\mathrm{Ni}$ interlayer & $120 \mu$ \\
\hline$C Y-20$ & $\mathrm{Nb}$ & $\mathrm{Nb}$ & \\
\hline
\end{tabular}

* Minimum achievable on a Veeco Leak Detector. Only the samples that showed any seal potential were tested on the leak tester; improper lapping and furnace malfunctions caused the others to leak.

Since the coating was applied to a roughened surface, the resulting surface was also rough. In order to promote adhesion between the two roughened surfaces some of the flat samples were wet lapped, others were dry lapped, and still others were polished. More contact area could be afforded for the mating surfaces when they were lapped together. This is not as complete as polishing the surfaces, but it was sufficient in assisting some material combinations to adhere.

Greater ease of application was experienced with the niobium separately and in combination with nickel, titanium, and molybdenum. Normally the samples were lapped or polished and placed in contact with each other under a pressure of $12-14$ pounds per square inch. While in this configuration they were subjected to $3000^{\circ} \mathrm{F}$ for five hours 
in vacuum. The lapping operation is very critical on the cylindrical samples; great care must be taken in order to form a uniform circular surface that will provide the maximum area for diffusion to occur.

This becomes a problem when more than one coating is applied to either surface because the cup becomes elevated as this thickness increases.

Several of the molybdenum cups were slightly out of round, and this could have caused some of the leakage conditions noted in testing. The pressures recorded on the Veeco Leak Detector are listed in Table 6 ; only 5 of the seals were good enough to record a pressure. One hundred microns was the best pressure recorded, but two other cylinders held pressures near this value.

The niobium (95\%) and nickel (5\%) interlayer proved to be the most reliable seal combination. Samples with the molybdenum cups had an inherent weak link in the molybdenum-niobium interface; some voids appeared in this area. The use of niobium cups eliminated this problem, and a more form fitting cup provided a greater chance for adhesion. In the final series of tests with this configuration, six cups were fabricated by heating to $1524^{\circ} \mathrm{C}\left(2775^{\circ} \mathrm{F}\right)$ for 5 hours in vacuum. All six indicated $5 \mu$ or less on the leak tester used previously, but only one cup was hermetic when a helium detector was used. Photomicrographs of the seal between the niobium cup and the alumina cylinder are shown in Figures 15 and 16.

The following conclusions can be drawn from the work completed on metal to oxide studies:

1. The magnesium oxide-nickel seal was too weak to provide a reliable leak-proof bond between the alumina and molybdenum.

2. Light grit blasting of mating surfaces provided an improved texture on both the flat and cylindrical samples.

3. The plasma sprayed materials provided the most dense and adherent coatings.

4. Extreme care must be exercised when the flat and conical surfaces are being lapped together; greater contact area promotes a better seal. 

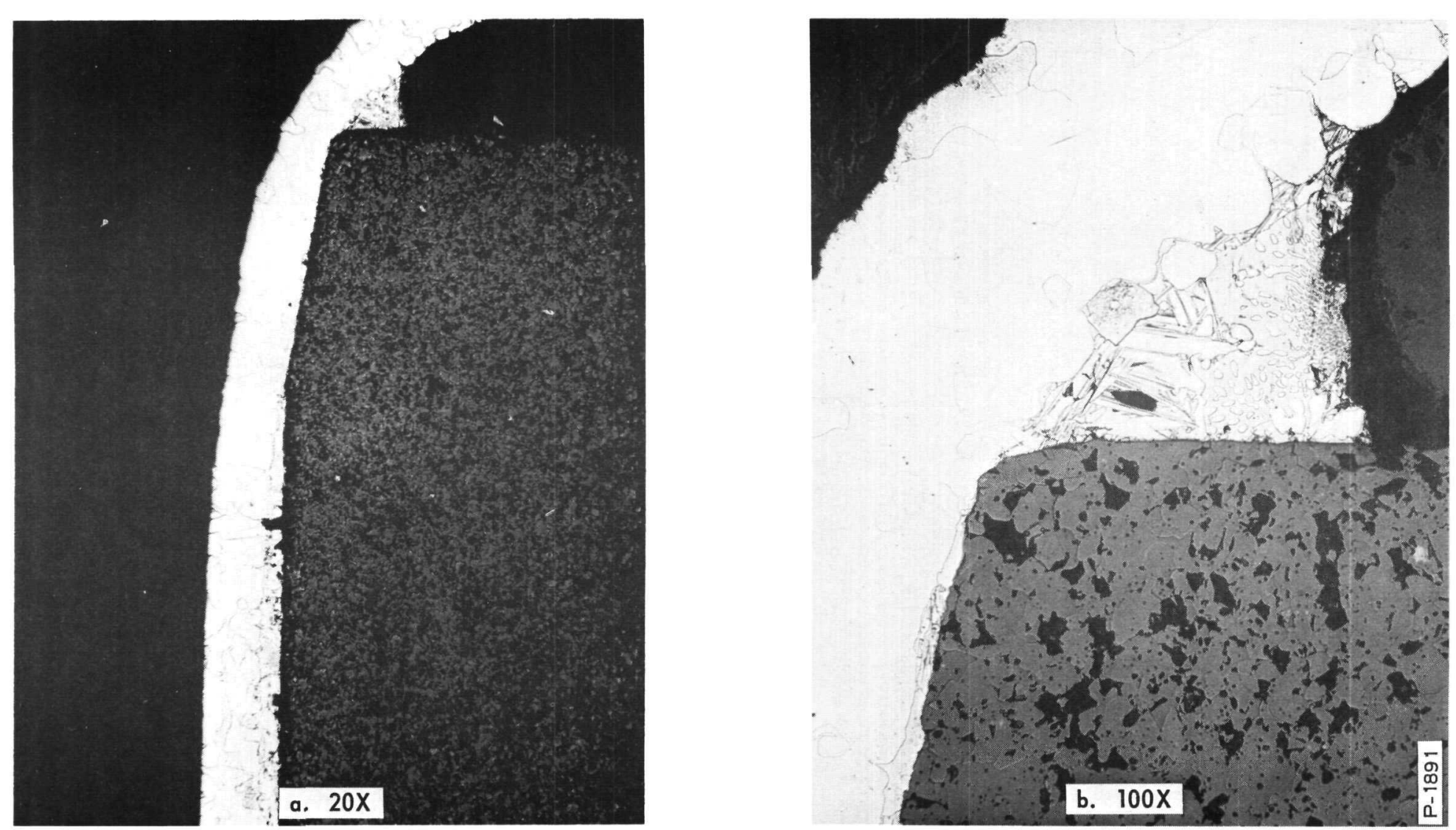

Figure 15 - Mobium-Alumina Diffusion Seal using Nickel Intermediate Material 


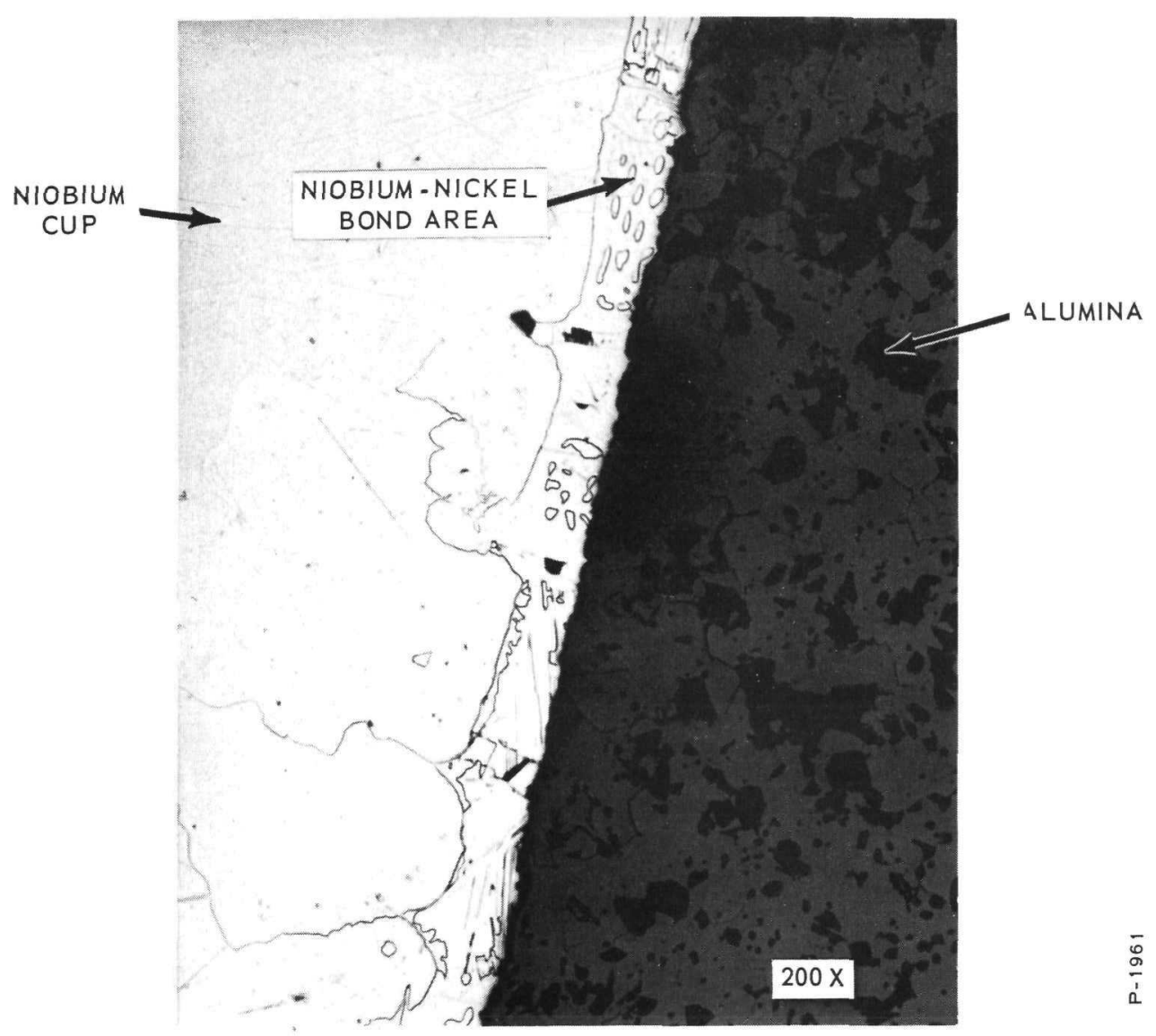

Figure 16 - Alumina Cylinder and Niobium Cup Showing the Niobium-Nickel Bond Area

The procedure listed below is recommended for the preparation of a hermetic cup that consists of a canted niobium cup and an alumina cylinder with the niobium-nickel interlayer:

1. Drylap a uniform circular area in the niobium cup with a shaped alumina cylinder.

2. Grit blast both components with 60 mesh grit at 10 psi and clean them with an organic solvent.

3. Mask all but the canted area on the alumina cylinder and plasma spray with a 95\% niobium$5 \%$ nickel mixture until a 2 - or 3-mil thickness adheres; also spray the inside of the cup with this thickness of material. 
4. Dry lap the cup and cylinder with other uncoated mating shapes.

5. Wet lap the coated pieces until a smooth uniform surface is attained.

6 Place the niobium cup firmly on the alumina cylinder.

7. Apply a load of $12-14$ psi and heat to $1524^{\circ} \mathrm{C}$ for 5 hours in a vacuum of $10^{-3} \mathrm{~mm} \mathrm{Hg}$.

\subsubsection{Diffusion Seal Studies on Metallized Ceramics}

Mechanically strong hermetic seals have been fabricated by diffusion sintering molybdenum sheet to the metallized surface of high-purity alumina. The alumina was metallized by a two layer process in which the first layer of metallizing was applied as an $85 \%$ Mo $-10 \%$ $\mathrm{Mn}-5 \% \mathrm{TiH}_{2}$ slurry fired for 15 minutes at $1600^{\circ} \mathrm{C}$. The second layer consisted of $80 \%$ Mo $-20 \% \mathrm{Cr}$. The chromium, an actively diffusing metal, was used to promote sintering between the molybdenum sheet and the metallized layer. After firing, the total thickness of the two layers was approximately 0.006 inch.

The following procedure was developed for fabricating these seals. The molybdenum sheet was lapped flat and polished. The end of an alumina cylinder was ground flat. After the end of the cylinder was metallized it was lapped flat and polished. Final thickness of the metallized layer was approximately 0.003 inch after being lapped and polished. The metal sheet was placed over the cylinder end, and a solid state diffusion bond was formed under slight 1 oad at $1800^{\circ} \mathrm{C}$ for one hour in purified argon. Mechanically strong bonds were fabricated by this process, but due to the porosity of the metallized layer on the ceramic, the bonds were not hermetic. In joints made with similarly prepared members which are brazed together using copper, the seals become hermetic because the molten copper infiltrates the voids in the porous metallized layer. However, in the solid state diffusion seal no fluid phase of any material occurs and the voids remain throughout the process. The method developed to eliminate this porosity was to infiltrate the metallized layer with a suitable ceramic eutectic. The manganese oxide-alumina eutectic was found to be suitable. When melted over the metallized layer the eutectic fills all the voids and transforms the metallized layer into a non-porous cermet. In essence, the seal is a graded seal, metal to cermet to ceramic. 
During the development of the seal, two methods of infiltration by the liquid alumina-manganese oxide phase were tried with success:

1. The eutectic mixture is applied over the metallized surface of the ceramic and fired. The liquid phase forms over the entire metallized surface. After cooling of the piece, excess hardened eutectic is lapped off to expose the metal layer. The ceramic is then diffusion bonded to the molybdenum sheet.

2. After the metal member and the metallized ceramic member have been bonded by diffusion, the eutectic mixture is applied to exposed edges of metallizing and to nearby ceramic surfaces. The eutectic mixture is then fired. While in the liquid phase, it infiltrates the porous metallizing coating. In filtrating was done at $1600^{\circ} \mathrm{C}$ in purified argon. Firing times as low as one minute were found to be sufficient.

A third method of infiltration was tried to minimize the need of handling and successive firings. In this method, alumina and manganese oxide powders were added to the metallizing mixtures. This method was not successful.

Seals in which hermeticity is achieved by infiltration with this eutectic contain manganese oxide and titanium oxide in the seal area. These oxides have been reported as being attacked by cesium vapor. Also, it can be inferred from phase diagrams of these oxides that a liquid phase would form probably below $1500^{\circ} \mathrm{C}$. While a seal formed in this manner should be an improvement over the state of the art, development of it did not represent achievement of the goal for structures of alumina. This goal was a sealing method to operate up to $1500^{\circ} \mathrm{C}$ in a cesium environment.

For these reasons, and utilizing recently disclosed information from other investigations on ceramic-metal structures, 1

\footnotetext{
$\mathrm{l}_{\mathrm{R} . W}$. Cowan and S.D. Stoddard, "Cexamic Materials for Nuclear Converters,"'University of California, Los Alamos Scientific Laboratory, Los Alamos, N.M., Paper Presented at American Ceramic Society Technical Meeting, May 1, 1963.
} 
attention was shifted to the use of yttria. Techniques for metallizing and bonding similar to those described above were used in experiments to obtain satisfactory ceramic-metal diffusion bonds.

In these experiments yttria was used instead of manganese oxide in the metallizing mixture and the yttria-alumina eutectic replaced the previous eutectics as the infiltrant. Strongly adherent hermetic seals have been made between alumina and molybdenum, niobium and tantalum. Seals between alumina and tungsten have not been successful to date. The best seal that has been developed is made by sintering a porous cermet layer of $80 \% \mathrm{Mo}-10 \% \mathrm{Y}_{2} \mathrm{O}_{3}-10 \% \mathrm{Al}_{2} \mathrm{O}_{3}$ onto the refractory metal at $1850^{\circ} \mathrm{C}$ for fifteen minutes in purified argon. The top of an alumina cylinder is painted with a slurry of pure yttria and fired in contact with the cermet coating of the refractory metal under slight load at $1800^{\circ} \mathrm{C}$ for one minute. The alumina-yttria eutectic on melting infiltrates the porous cermet and forms a mechanical as well as chemical, hermetic seal to the refractory metal. 


\subsection{ALUMINA TUNGSTEN COMPOSITE STRUCTURES}

The objective of this task was to develop the techniques for fabrication of a thermionic converter envelope employing a metalceramic composite graded from pure metal to pure ceramic. Reports of work by many agencies in the field of high-temperature thermionic converters indicate that a closed-end cylinder of approximately one inch diameter is typical of the envelope of many converters being studied. A cylindrical envelope in which a suitable refractory metal forms the closed end and in which the wall material is graded to pure ceramic at the open end was therefore to be fabricated. This type of structure would eliminate the need for a high temperature seal between the emitter and ceramic wall of the converter which simplifies design problems, and would provide improved thermal shock characteristics. A schematic representation of the desired structure is shown in Figure 17 .

A finished body of this type is shown in Figure 18. The closed end of the cylinder (not visible at the bottom) is 95 percent pure tungsten. The upper end of the cylinder is pure alumina.

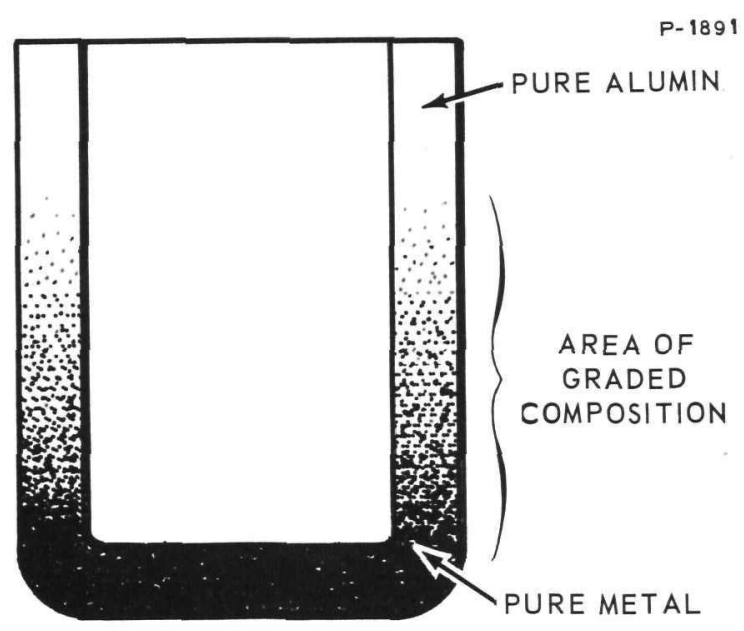

Figure 17 - Principle of CompositeCup Structure

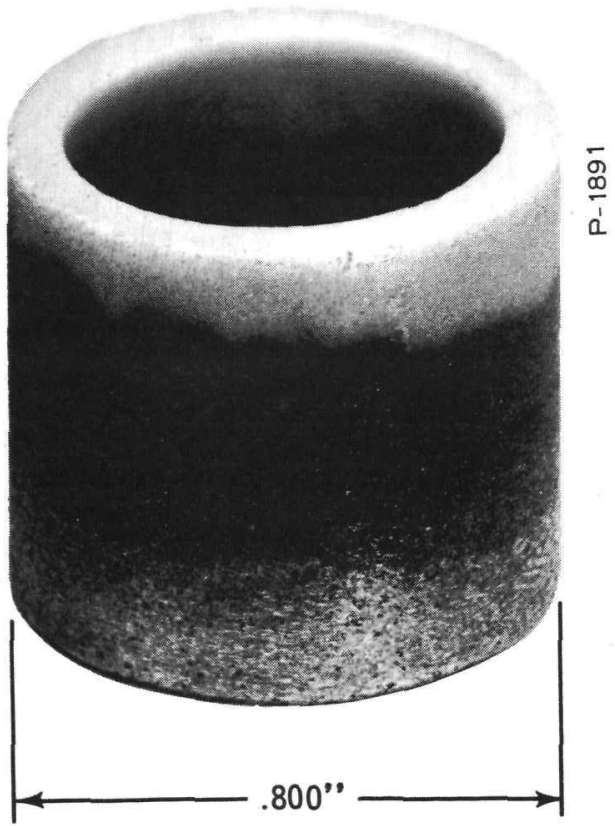

Figure 18 - Sintered Composite Cup Made from Twelve Incremental Layers 
Table 7 - Properties of Alumina Powders

\begin{tabular}{|c|c|c|c|c|}
\hline & A & B & $\mathrm{C}$ & $\mathrm{D}$ \\
\hline \multicolumn{5}{|l|}{ Physical Properties } \\
\hline Bulk Density $\left(1 \mathrm{bs} / \mathrm{ft}^{3}\right)$ Loose & 48 & 63 & 63 & 65 \\
\hline Bulk Density (1bs $\left./ \mathrm{ft}^{3}\right)$ Packed & 63 & & 83 & 80 \\
\hline Specific Gravity & 3.8 & 3.8 & 3.85 & 2.42 \\
\hline \multicolumn{5}{|l|}{$\begin{array}{r}\text { Particle Size Distribution (Sieve } \\
\text { Analysis): }\end{array}$} \\
\hline Plus 100 & 6.9 & 0 & 10.6 & \\
\hline-100 Plus 140 & 16.6 & 0 & 24.7 & \\
\hline-140 Plus 200 & 27.4 & 0 & 35.9 & \\
\hline-200 Plus 230 & 8.9 & 0.2 & 10.6 & \\
\hline-230 Plus 325 & 15.5 & 2.3 & 13.7 & \\
\hline-325 & 24.7 & 97.5 & 4.5 & \\
\hline \multicolumn{5}{|l|}{ Chemical Properties } \\
\hline $\mathrm{Al}_{2} \mathrm{O}_{3}$ & 99.0 & 99.5 & 99.6 & 64.5 \\
\hline $\mathrm{Na}_{2} \mathrm{O}$ & 0.5 & 0.10 & 0.04 & 0.25 \\
\hline $\mathrm{SiO}_{2}$ & 0.025 & 0.05 & 0.06 & 0.008 \\
\hline $\mathrm{Fe}_{2} \mathrm{O}_{3}$ & 0.04 & 0.04 & 0.04 & 0.003 \\
\hline $\mathrm{TiO}_{2}$ & 0.002 & 0.002 & 0.002 & \\
\hline Loss on Ignition & 0.30 & 0.15 & 0.15 & \\
\hline $\mathrm{H}_{2} \mathrm{O}$ (Free) & 0.10 & 0.10 & 0.10 & 0.10 \\
\hline $\mathrm{H}_{2} \mathrm{O}$ (Combined) & & & & 35.199 \\
\hline
\end{tabular}

The program consisted of investigation of the sequence of fabrication processes which could be used to produce a powdered metal or ceramic part, possible material compositions, particle size distributions, sintering aids and bonding systems. The processes considered were: blending, pressing, drying, pre-machining, sintering, post-sinter machining, and arc-plasma spraying. Several tungsten and alumina powders were selected for investigation in this study. Since the end product material must be resistant to cesium vapor, only alumina materials of extremely low silica content were considered. The alumina powders used were commercial materials, the chemical and physical properties of which are shown in Table 7. The powder characteristics 
of the tungsten used for the refractory metal component are shown in Table 8 . Phosphates have been reported in the literature to improve bonding of alumina bodies at temperatures above $600^{\circ} \mathrm{F}$. Also $\mathrm{MgO}$ and $\mathrm{Cr}_{2} \mathrm{O}_{3}$ are reported to be effective in densification of alumina above $3000^{\circ} \mathrm{F}$. The materials which were selected as possible bonding agents and sintering aids for the experimental studies are listed in Table 9.

It was thought that a bond produced during a low-temperature presinter would be helpful in providing machinability so that premachining techniques could be used to approach size and shape requirements of the final product. Phosphate bonding was considered for this purpose. Magnesium stearate was considered both as a lubricant during compacting and as a source of $\mathrm{MgO}$. Magnesium phosphate was considered as a source of $\mathrm{MgO}$ and phosphate bond.

The results of tests using various proportions of the alumina powders showed that the effect of particle size distribution can be used to control final density. The density of test bodies fell within the range of 90.5 to 93.2 percent of theoretical. All were essentially leak tight when tested on a Veeco leak detector.

Another study was performed to determine the effects of certain additives on density and shrinkage of the high purity alumina. The results indicate that magnesium stearate provides considerable densification. It was noted that this material was easily premachined after a 90 minute presinter at $2200^{\circ} \mathrm{F}$.

Additional work was performed to determine the effects of tungsten additions on density and shrinkage of alumina bodies. For this work alumina powder with 1 percent magnesium stearate was used and combined with tungsten powder. The results of these tests are shown in Table 10. The se data indicate a gradual decrease in actual density as a percent of theoretical density as the tungsten content is increased. Interestingly, the diameter shrinkage shows a marked sudden change in the range between 50 percent and 75 percent tungsten by weight. This can probably be explained by compositional changes based on volume rather than weight. The major change in shrinkage takes place between 17 and 38 percent tungsten on a volume basis.

Previous work has shown that small additions of nickel are effective in the densification of tungsten at low temperatures. A study was made to determine shrinkage and density for small additions of 
Table 8 - Properties of Tungsten Powders

\begin{tabular}{|c|c|c|c|c|}
\hline & 1 & 2 & 3 & 4 \\
\hline \multicolumn{5}{|l|}{ Physical Properties } \\
\hline Fisher Sub-Sieve Analvsis & 090 & 24 & 42 & 66 \\
\hline Bulk Density (gms//n ${ }^{3}$ ) Scott Method & 30 & 48 & 65 & 75 \\
\hline Tap Test (cc/10 grams) Packing & 24 & 18 & 16 & \\
\hline \multicolumn{5}{|l|}{ Partacle Size Distribution $(\% / w t)$} \\
\hline I Micron & 22 & 3 & 2 & \\
\hline 2 Micron & 72 & 45 & 7 & \\
\hline 3 Micron & 6 & 39 & 26 & \\
\hline 4 Micron & & 10 & 35 & \\
\hline 5 Micron & & 3 & 21 & \\
\hline 6 M3cron & & & 9 & \\
\hline \multicolumn{5}{|l|}{ Chemical Impurities } \\
\hline Non Volatile Matter & 002 & 002 & 002 & 002 \\
\hline Molybdenum & 0003 & 0003 & 0003 & 0003 \\
\hline Iron & 0003 & 0003 & 0003 & 0003 \\
\hline Oxygen & 030 & 030 & 030 & 030 \\
\hline
\end{tabular}

Table 9 - Sintering Aids and Bond Promoting Materials

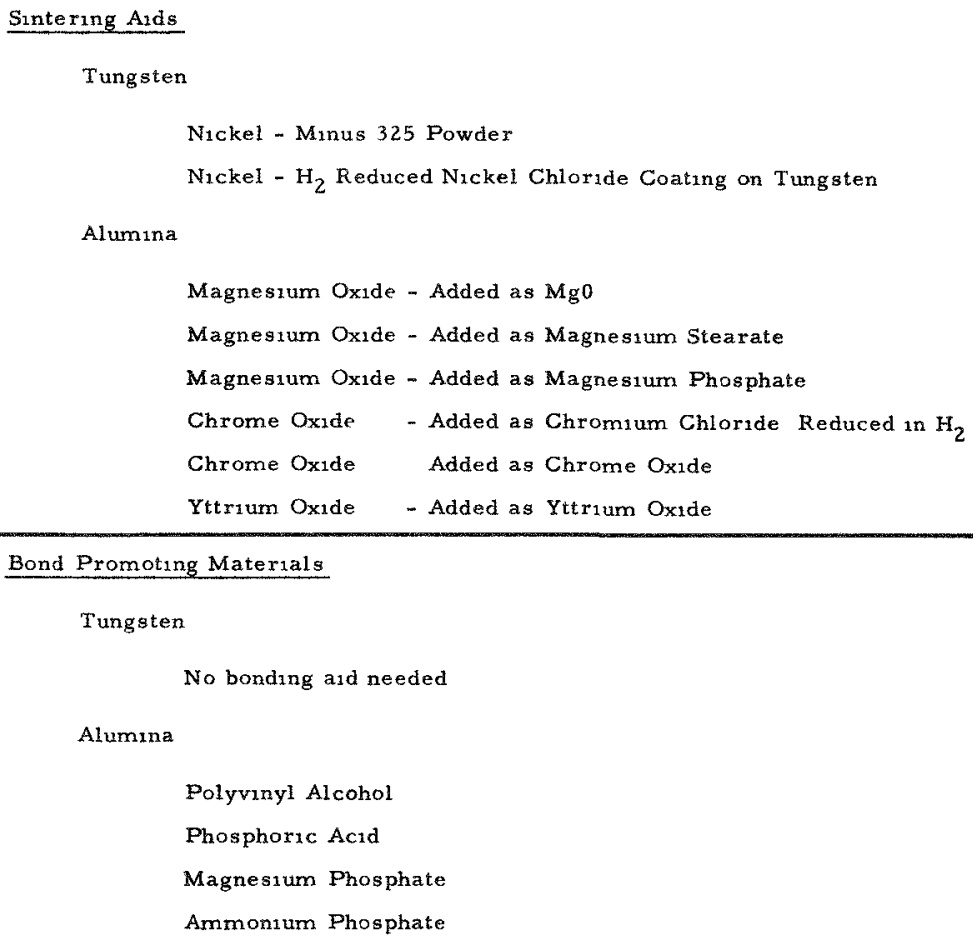


nickel at the sintering temperature of $3400^{\circ} \mathrm{F}$. In this case, the particles of tungsten were coated with $\mathrm{NiCl}_{2}$ from an alcohol solution. Results are shown in Table 11 . Previous work has indicated that 0.5 percent nickel added as a fine powder, will act similarly to the $\mathrm{NiCl}_{2}$ coated material containing 0.1 percent $\mathrm{Ni}$.

Table 10 - Effect of Tungsten Addition on Density and Shrinkage of $\mathrm{Al}_{2} \mathrm{O}_{3}$

\begin{tabular}{|c|c|c|c|c|c|}
\hline \multirow{2}{*}{$\begin{array}{c}\text { Sample } \\
\text { No. }\end{array}$} & \multicolumn{2}{|c|}{$\begin{array}{c}\text { Weight Percent } \\
\text { Al }{ }_{2} \mathrm{O}_{3}\end{array}$} & $\begin{array}{c}-325 \\
\text { Tungsten }\end{array}$ & $\begin{array}{c}\text { Actual } \\
\text { gms/cc }\end{array}$ & $\begin{array}{c}\text { Percent of } \\
\text { Theoretical } \\
\text { Shrinkage } \\
(\%)\end{array}$ \\
\hline $35-2$ & 100 & & 3.84 & 97.0 & 14.7 \\
$39-2$ & 75 & 25 & 4.80 & 97.0 & 14.0 \\
$39-3$ & 50 & 50 & 6.13 & 92.5 & 14.2 \\
$39-4$ & 25 & 75 & 8.29 & 83.6 & 10.6 \\
$39-1$ & 0 & 100 & 14.40 & 74.6 & 10.7 \\
\hline \multicolumn{5}{|c|}{ Sintering Cycle } \\
\hline \\
Heated to $2700^{\circ} \mathrm{F}$ in Hydrogen at $1000^{\circ} / \mathrm{hr}$. \\
Heated to $3400^{\circ} \mathrm{F}$ in Argon at $1000^{\circ} / \mathrm{hr}$. \\
Cooked at $3400^{\circ} \mathrm{F}$ in Argon for $3-1 / 2 \mathrm{hrs}$. \\
\hline
\end{tabular}

Table 11 - Effect of Nickel on Density and Shrinkage of Tungsten Sintered at $3400^{\circ} \mathrm{F}$

\begin{tabular}{|c|c|c|c|c|c|}
\hline \multirow{2}{*}{$\begin{array}{c}\text { Sample } \\
\text { No. }\end{array}$} & Ni & $\begin{array}{c}-325 \\
\text { Tungsten }\end{array}$ & $\begin{array}{c}\text { Actual } \\
\text { gms/cc }\end{array}$ & $\begin{array}{c}\text { Percent of } \\
\text { Theoretical }\end{array}$ & $\begin{array}{c}\text { Diameter } \\
\text { Shrinkage } \\
(\%)\end{array}$ \\
\hline $39-1$ & 0 & 100 & 14.40 & 74.6 & 10.7 \\
$39-5$ & 0.05 & 99.95 & 16.01 & 83.0 & 13.8 \\
$39-6$ & 0.10 & 99.90 & 16.56 & 84.6 & 14.5 \\
\hline
\end{tabular}

Sintering cycle - Same as that shown on Table 10 
The general steps required to make a cup-shaped envelope were determined to be:

1. Loading of die with graded material.

2. Pressing.

3. Presinter (if necessary for machining).

4. Machining。

5. Sintering.

6. Final Machining.

Prior experience has shown that hydrostatic pressing is superior to die pressing since parts with more uniform density can be obtained by this method. It had been determined by die pressing studies that the optimum pressure for pressing tungsten was in a range of from 15,000 to 20,000 psi. The optimum pressure for pressing alumina was from 40,000 to 50,000 psi. The hydrostatic press available for this type of work in the laboratory has a maximum working pressure limitation of 20,000 psi. For this reason it was decided to do the early pressing studies using the die pressing facilities.

Employing die pressing techniques, methods of grading incrementally and by infinite gradations were studied. The effect of moisture on pressing and on green strength was also studied. Addition of moisture presented a problem in some cases since damp powders could not be metered through the powder feeding equipment when infinite grading was being studied. Normally, powder and moisture were blended together prior to loading into the die; however, when the powder feeding equipment was used it was necessary to add moisture after loading. Studies of machining techniques resulting in procedures by which billets that have substantial green strength could be satisfactorily machined without a presinter.

Considerable effort was expended in attempting to obtain continuously graded cups using the Sylco precision powder feeders, shown in Figure 19 and both die pressing and hydrostatic pressing techniques. Powder flow of alumina and tungsten can be controlled accurately with the Sylco machines. The principle limitation of this equipment is that the powders must be dry to prevent blocking of the powder flow。 


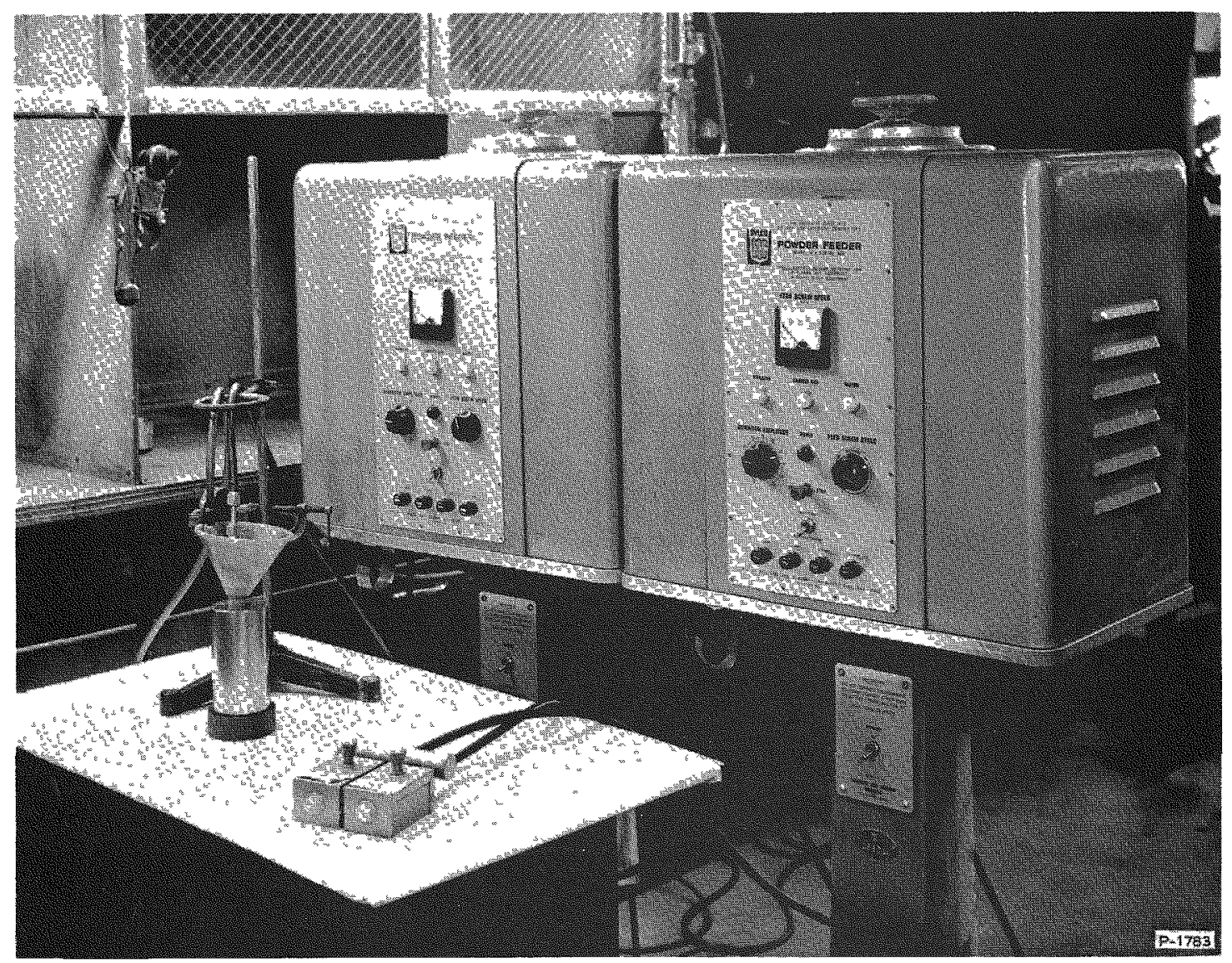

Figure 19 - Powder Loading Equipment for Continuously Graded Composite

Several attempts were made to circumvent this limitation, such as the use of activated alumina (alumina containing chemically combined water), or the use of polyvinyl alcohol as an additive. In the case where activated alumina was used, a graded billet was successfully compacted by hydrostatic pressing at 40,000 psi. How ever, the se billets could not be machined satisfactorily into a cup shape due to lack of strength in the unsintered condition. When polyvinyl alcohol was used the alumina material was first compacted using the chemical as a binder, and then was granulated to a size suitable for use in the powder feeders. This material could not be compacted at any reasonable pressure after granulation.

Another method tried was the addition of moisture in the form of 15 percent phosphoric acid solution after loading of the die. In all of these cases, which included over 30 billets, cracking occurred during drying due to nonuniform moisture distribution. 
Simultaneously with the work on continuous gradation the study of incremental gradation was continued. A number of billets graded in 5,6 , and 7 increments were die pressed. Compacting pressure was varied from $20,000 \mathrm{psi}$ to $40,000 \mathrm{psi}$, and drying temperature was varied from $140^{\circ} \mathrm{F}$ to $950^{\circ} \mathrm{F}$. The results of the se tests indicated that both pressing pressure and drying conditions are important processing variables which must be controlled within specified limits to produce satisfactory composite billets. Pressures of 30,000 psi were better than 20,000 or $40,000 \mathrm{psi}$ and drying at $200^{\circ} \mathrm{F}$ appeared to be better than higher temperature drying. The use of magnesium stearate and 0.8 percent $\mathrm{H}_{3} \mathrm{PO}_{4}$ produced a billet that could be easily machined but still had considerable dry strength.

Figure 20 shows the composite envelope at three stages in the processing. The billet shown on the left has been die pressed at 30,000 psi, and dried at $200^{\circ} \mathrm{F}$ for 24 hours. The part shown in the center is a similar structure that has been machined to form the cup-shape. On the right is a similar part after sintering at $3350^{\circ} \mathrm{F}$ for 1 hour. Details of the gradation used for the se parts are shown in Table 12 .

The most successful composite envelope was fabricated of twelve gradations of alumina and tungsten as shown in Table 13. The results of shrinkage studies on the se compositions is shown in Table 14. The fabrication process is typical for all test pieces with incremental gradations. The dry components were blended for 15 minutes in a bottle blender. The phosphoric acid solution was added and the mixture blended for another 15 minutes. A weighed amount, as shown in Table 13, was loaded into a 1 inch double punch die with wax paper between the punches and the material. The addition of pure alumina on both ends of the compact reduced lamination problems in the high tungsten area. The billets were pressed at $30,000 \mathrm{psi}$ in a hydraulic press. Upon removal from the die the billets were air dried for 24 hours and oven dried at $250^{\circ} \mathrm{F}$ for an additional 24 hours. After machining off the $\mathrm{Al}_{2} \mathrm{O}_{3}$ adjacent to the 95 percent $\mathrm{W}$, the billets were mounted in a graphite fixture with a low melting metal ( $\mathrm{mp} 165^{\circ} \mathrm{F}$ ). The machining was accomplished on a metal-working lathe with a $3 / 8$ inch carbide drill and a carbide tipped boring bar. A machined part is shown in the center of Figure 20. After premachining the part was removed from the fixture by heating in a $200^{\circ} \mathrm{F}$ oven to release the cup. Careful handling is required because of the relatively weak bond. The premachined parts were sintered in an induction furnace with a graphite susceptor. During sintering the parts were enclosed in a 
Table 12 - Composition of Gradations in Seven Layer Cup

\begin{tabular}{|c|c|c|c|}
\hline & $\begin{array}{l}\text { ALUMINA* } \\
\text { WT. PERCENT }\end{array}$ & $\begin{array}{l}\text { TUNGSTEN*** } \\
\text { WT. PERCENT }\end{array}$ & $\begin{array}{l}\text { PHOSPHORIC ACID***; } \\
\text { WT. PERCENT }\end{array}$ \\
\hline \multirow[t]{6}{*}{ Closed End } & 5 & 95 & 0.40 \\
\hline & 12 & 88 & 0.50 \\
\hline & 23 & 77 & 0.50 \\
\hline & 45 & 55 & 0.63 \\
\hline & 64 & 36 & 0.75 \\
\hline & 80 & 20 & 0.80 \\
\hline Open End & 100 & - & 0.80 \\
\hline *Alumina: & $\begin{array}{l}73.5 \% \text { A } 10 \\
24.5 \% \text { A5 } \\
2.0 \% \text { Magn }\end{array}$ & $\begin{array}{l}\text { 5) } \\
\text { 0) } \\
\text { um Stearate }\end{array}$ & \\
\hline ***Tungsten: & \multicolumn{2}{|c|}{$\begin{array}{l}99.75 \% \text { M4O } \\
0.25 \% \text { Nicke1 (-325 Mesh) }\end{array}$} & \\
\hline$* * * \mathrm{H}_{3} \mathrm{PO}_{4}:$ & \multicolumn{3}{|c|}{$\begin{array}{l}\text { Reported as weight percent added as a } 15 \% \text { Aqueous } \\
\text { solution to supply moisture for compacting }\end{array}$} \\
\hline
\end{tabular}

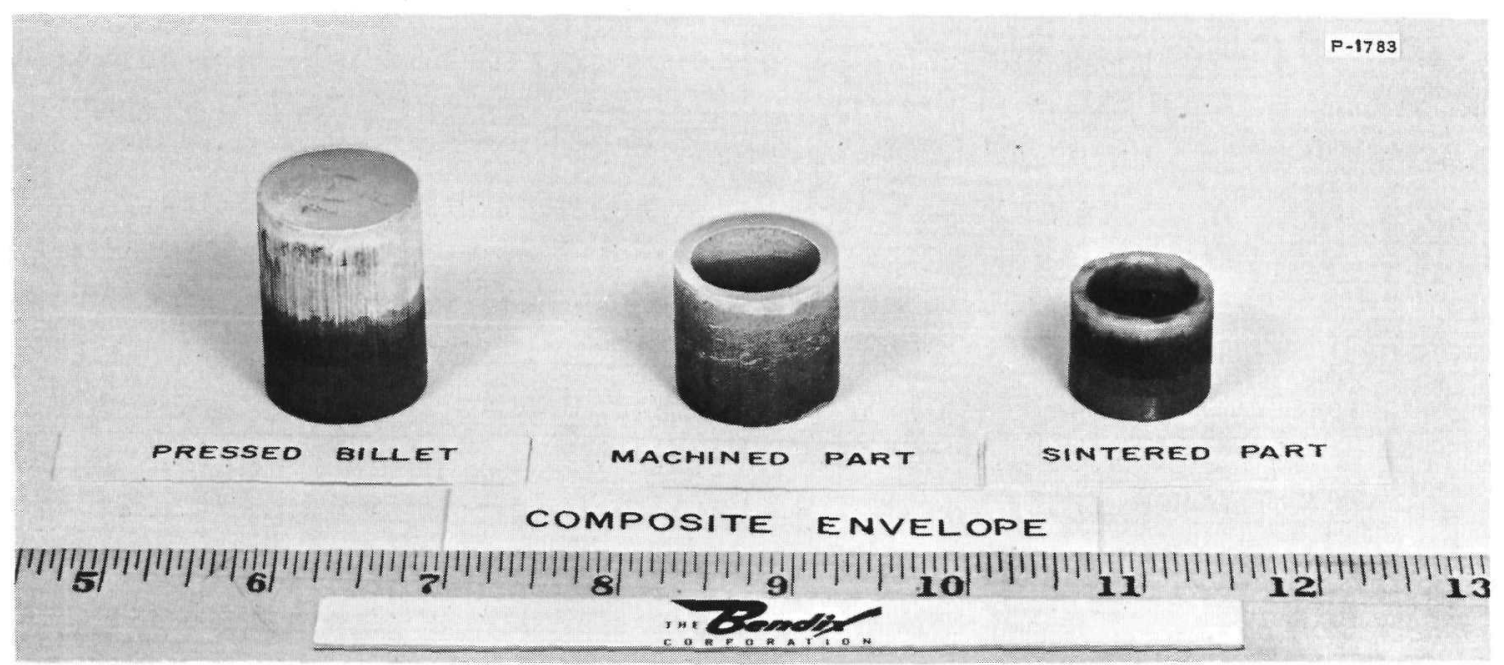

Figure 20 - Fabrication Stages of Composite Envelope 
Table 13 - Gradations of Materials Used in Twelve Layer Cup

\begin{tabular}{|c|c|c|c|c|c|c|c|}
\hline $\begin{array}{c}\text { Gradation } \\
\text { No. }\end{array}$ & $\begin{array}{l}\text { Tungsten* } \\
\text { Weight }\end{array}$ & $\begin{array}{c}\text { Alumina } * * \\
\text { Weight }\end{array}$ & $\begin{array}{l}\text { Phosphorick } \\
\text { Acid Solution } \\
\text { cc }\end{array}$ & $\begin{array}{l}\text { Percent } \\
\text { Tungsten }\end{array}$ & $\begin{array}{l}\text { y Weight } \\
\text { Alumina }\end{array}$ & $\begin{array}{l}\text { Percent } \\
\text { Tungsten }\end{array}$ & $\begin{array}{l}\text { Volume } \\
\text { Alumina }\end{array}$ \\
\hline 0 & 0 & 3.0 & 0.21 & 0 & 100 & 0 & 100 \\
\hline 1 & 13.30 & 0.70 & 0.10 & 95 & 5 & 80 & 20 \\
\hline 2 & 8.80 & 1.2 & 0.10 & 88 & 12 & 59 & 41 \\
\hline 3 & 3.08 & 0.92 & 0.10 & 77 & 23 & 40 & 60 \\
\hline 4 & 2.56 & 1.44 & 0.10 & 64 & 36 & 26 & 74 \\
\hline 5 & 1.50 & 1.50 & 0.10 & 50 & 50 & 16.5 & 83.5 \\
\hline 6 & 1.08 & 1.92 & 0.13 & 36 & 64 & 10 & 90 \\
\hline 7 & 0.93 & 2.07 & 0.14 & 31 & 69 & 8.15 & 91.85 \\
\hline 8 & 0.52 & 1.48 & 0.10 & 26 & 74 & 6.5 & 93.5 \\
\hline 9 & 0.40 & 1.60 & 0.11 & 20 & 80 & 4.7 & 95.3 \\
\hline 10 & 0.26 & 1.74 & 0.12 & 13 & 87 & 2.86 & 97.14 \\
\hline 11 & 0.12 & 1.88 & 0.13 & 6 & 94 & 1.24 & 98.76 \\
\hline 12 & & 21.0 & 1.45 & 0 & 100 & 0 & 100 \\
\hline
\end{tabular}

* Tungsten - 99.75\% \#3 Tungsten Powder (Table I) $.0 .25 \%$ - 325 Nickel Powder

* Alumina - $73.5 \%$ B (Table II)

$24.5 \%$ A (Table II)

$2.0 \%$ Magnesium Stearate

*** Phosphoric Acid Solution - 15\% Aqueous Solution of $\mathrm{H}_{3} \mathrm{PO}_{4}$

Table 14 - Shrinkage and Density Measurements

\begin{tabular}{|c|c|c|c|c|c|c|c|}
\hline $\begin{array}{c}\text { Gradation } \\
\text { No. }\end{array}$ & \multicolumn{2}{|c|}{$\begin{array}{c}\text { Percent by Weight } \\
\text { Tungsten }\end{array}$} & \multicolumn{2}{c|}{$\begin{array}{c}\text { Percent by Volume } \\
\text { Aungsten }\end{array}$} & $\begin{array}{c}\text { Shrinkage } \\
\text { Percent }\end{array}$ & $\begin{array}{c}\text { Theoretical } \\
\text { Density }\end{array}$ & $\begin{array}{c}\text { Density } \\
\text { \% of Theoretical }\end{array}$ \\
\hline 1 & 95 & 5 & 80 & 20 & 13.3 & 16.21 & 87.0 \\
2 & 88 & 12 & 59 & 41 & 14.0 & 12.96 & 92.5 \\
3 & 77 & 23 & 40 & 60 & 15.6 & 10.01 & 98.5 \\
4 & 64 & 36 & 26 & 74 & 15.7 & 7.84 & 100 \\
5 & 50 & 50 & 16.5 & 83.5 & 15.1 & 6.36 & 100 \\
6 & 36 & 64 & 10.0 & 90.0 & 15.1 & 5.35 & 100 \\
7 & 31 & 69 & 8.15 & 91.85 & 15.1 & 5.07 & 100 \\
8 & 26 & 74 & 6.5 & 93.5 & 15.6 & 4.80 & 100 \\
9 & 20 & 80 & 4.7 & 95.3 & 15.4 & 4.53 & 100 \\
10 & 13 & 87 & 2.86 & 97.14 & 15.2 & 4.24 & 100 \\
11 & 6 & 94 & 1.24 & 98.76 & 15.6 & 4.00 & 100 \\
12 & 0 & 100 & 0 & 100 & 15.7 & 3.80 & 100 \\
\hline
\end{tabular}

Measured on discs 1 " in diameter by $1 / 4$ " thick.

Sintered for 8 hours at $3350^{\circ} \mathrm{F}$ in Argon.

Hydrogen used in heat-up to $2700^{\circ} \mathrm{F}$ to reduce oxide. 
tungsten shield to reduce carbon contamination. The furnace was heated to $2700^{\circ} \mathrm{F}$ with dry hydrogen gas atmosphere and then changed to argon for the remainder of the sintering cycle The best results to date were obtained by using an 8 hour soak at $3365^{\circ} \mathrm{F}$. Sintering at somewhat higher temperatures increased the density with shorter soak periods, however, greater distortion was noted.

Several envelopes have been fabricated that were graded from 95 percent $\mathrm{W} \cdot 5$ percent $\mathrm{Al}_{2} \mathrm{O}_{3}$ at the closed end to essentially 100 percent $\mathrm{Al}_{2} \mathrm{O}_{3}$ at the open end. That shown in Figure 18 is typical. Pure tungsten has not been able to be used satisfactorily for the closed end of the cup because of laminations introduced during the pressing operation. None of these parts were leak-tight when tested on helium

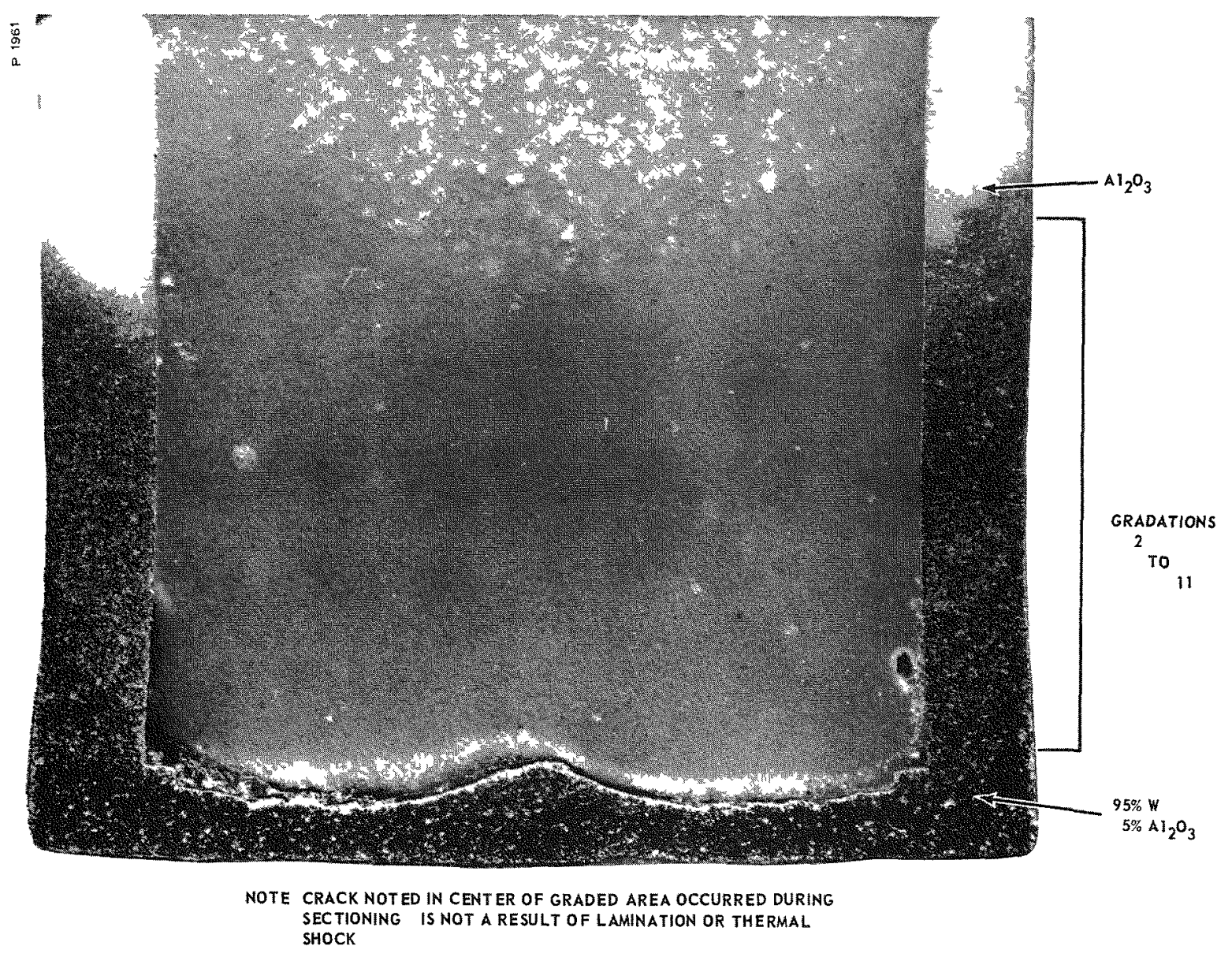

Figure 21 - Cross Section of Graded Composite Envelope 
leak detection equipment, however, the leakage rate was very low and occurred in the high tungsten area where complete densification appears to be more difficult at alumina sintering temperatures. A cross-section of a cup showing the manner in which gradation of tungsten to alumina occurs in these bodies is shown in Figure 21. 
5.0 MATERIALS AND STRUCTURES FOR USE AT TEMPERATURES ABOVE $1500^{\circ} \mathrm{C}$.

\subsection{Materials Selection}

An extensive literature study was made to determine the metal and ceramic materials which show greatest promise for use above $1500^{\circ} \mathrm{C}$, with particular attention on usefulness at $2000^{\circ} \mathrm{C}$. Table 15 lists those considered, with some pertinent characteristics and remarks.

While the refractory metals are similar as far as the effects of most characteristics are concerned, rhenium, with its high modulus, ductility, and compatability would be considered the best choice for general use, if it were not so rare and expensive.

Selection of a suitable ceramic material presents a more difficult problem. All the oxides can be expected to react to some degree with the refractory metals. Zirconia corrodes tungsten at a rapid rate at $1500^{\circ} \mathrm{C}$. The nitrides, borides, carbides and sulfides react with cathode materials at a rate beyond the oxides. One possible combination might be a carbide with a rhenium cathode since rhenium does not form a carbide. However, resistivity of these carbide materials is quite low which places them far down on the list for consideration.

Very few oxides have vapor pressures and melt points that will allow use at $2000^{\circ} \mathrm{C}$, as can be seen from Table 15. The rare earth oxides are one group that have potential. Other attractive properties of the rare earths are their low thermal expansion and good shock resistance. Erbia, however, is reactive and not very refractory. Thoria is attractive because of its inertness. The strength and the rmal shock resistance of thoria should be significantly improved by rare earth oxide additions. In order to achieve any substantially effective im provement by alloying with thoria, at least 50 mole percent rare earth oxide is believed to be needed.

Because it was found that the literature does not adequately treat the subjects of metal-ceramic compatibility, thermal expansion and property changes in alloy systems, and bonding techniques at $2000^{\circ} \mathrm{C}$, an experimental program was undertaken to provide more information in the se areas for the materials of interest.

Small plates were made from mixtures of thoria with erbia and yttria. The sinterability of the materials was found to be excellent. 
Table 15 - Materials for Thermionic Converter Structures

\begin{tabular}{|c|c|c|c|c|}
\hline Material & Melt ${ }^{\circ} \mathrm{C}$ & $\operatorname{Exp} /{ }^{\circ} \mathrm{C} \times 10^{6}$ & $\begin{array}{c}2000^{\circ} \mathrm{C} \\
\text { Vapor Press. Torr }\end{array}$ & Remarks \\
\hline Tungsten & 3410 & 4.6 & $3 \times 10^{-9}$ & Brittle \\
\hline Rhenium & 3180 & 6.7 & $4 \times 10^{-8}$ & Expensive-rare \\
\hline Molybdenum & 2625 & 4.9 & $3 \times 10^{-5}$ & Present art \\
\hline Ruthenium & 2500 & 9.0 & $10^{-4}$ & Expensive-rare \\
\hline Iridium & 2454 & 6.8 & $10^{-4}$ & Expensive-rare \\
\hline Osmium & 2700 & 6.5 & $10^{-6}$ & Expensive-rare \\
\hline Columbium & 2415 & 7.3 & $10^{-6}$ & Low Modulus and m.p. \\
\hline Tantalum & 2996 & 6.5 & $10-7$ & Reacts with certain oxides \\
\hline Alumina & 2050 & 8.5 & 3.5 & For comparison, High v.p. above $1500^{\circ} \mathrm{C}$ \\
\hline Yttria & 2450 & 9.3 & $10-4$ & Compatability good \pm \\
\hline Thoria & 3300 & 9.5 & $3 \times 10^{-3}$ & Thermal shock problem \\
\hline Holmia & 2350 & 7.9 & $10^{-3}$ & Compatability poor \pm \\
\hline Erbia & 2350 & 8.2 & $10-3$ & Compatability fair \pm \\
\hline Beryllia & 2520 & 9.2 & $1.5 \times 10^{-2}$ & Toxic, high termal cond. \\
\hline Hafnia & 2700 & 6.5 & $10-5$ & Must be stabilized, compatible \pm \\
\hline Zioconia & 2600 & 5.0 & $10^{-4}$ & Reacts with refractory metals at $1500^{\circ} \mathrm{C}$ \\
\hline Nitrides & & & & \\
\hline $\mathrm{Zr}, \mathrm{Ta}$ & 2900 & $5-7$ & $10^{-3}$ & Resistivity low, reactive \\
\hline $\mathbf{Z} \mathbf{r}, \mathrm{Hf}$ & 3000 & $5-7$ & $10^{-3}$ & Resistivity low, reactive \\
\hline Sulfides $\mathrm{Ce}$ & 2450 & $5-7$ & $2 \times 10^{-3}$ & Resistivity low, reactive \\
\hline Carbides & & & & \\
\hline $\mathrm{Ti}, \mathrm{Ta}$ & 3000 & $6-8$ & $10^{-5}$ & Resistivity low, reactive \\
\hline Zirconates & & & & \\
\hline Th, Sr, Ba & 2700 & -- & $\ldots$ & Very reactivenstructure unsound \\
\hline
\end{tabular}

\pm This work

$\mathrm{X}$-ray examination of the samples indicates complete solid solution and excellent homogeneity. The lattice parameters of the thoria mixtures were calculated from the $X$-ray patterns and are plotted in Figure 22. The continuous line represents Vegard's approximation for lattice parameters of solid solutions. Accuracy of the calculated values suffers somewhat from line broadening, but the results illustrate a true solution behavior in changing from body centered cubic rare earth to cubic thoria. The length of the cube unit cell has been taken as $1 / 2 a_{0}$ for the rare earths.

Hafnia has been stabilized with five and ten percent yttria. The stabilized hafnia appears to have excellent thermal shock resistance. For screening purposes, an oxy-acetylene burner was used to heat $3 / 8$ - inch diameter disks to $1700^{\circ} \mathrm{C}$, followed by water quenching. Thoria samples cracked immediately upon application of heat. Yttria samples disintegrated on quenching. Stabilized hafnia remained intact but exhibited some microcracks. 


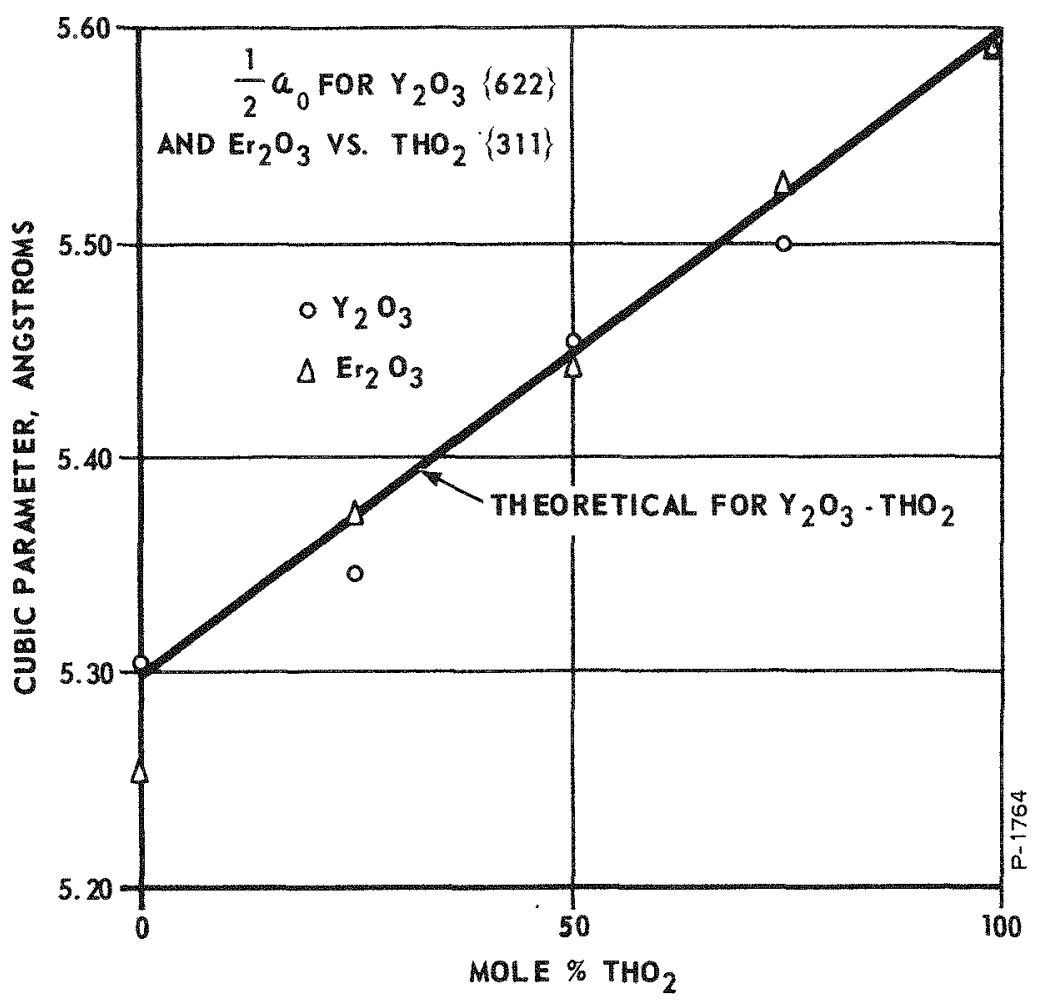

Figure 22 - Lattice Parameters for Cubic Solid Solutions of Two Rare Earth Oxides in Thoria

Holmia was dropped from consideration early because of its chemical reactivity.

\subsection{Investigations of High Temperature Stability}

High temperature tests of mixed powders wexe performed in order to evaluate stability of proposed materials for $2000^{\circ} \mathrm{C}$. Samples were held for one hour in vacuum of $10^{-5}$ Torr at the temperatures indicated in Table 16. Temperature was measured using both a total radiation and an optical pyrometer sighted through the hole in the lid on to the upper surface of the specimen lying in the bottom of the crucible. These two readings under approximate black body conditions were averaged.

The tungsten and rhenium combinations with yttria showed some vaporization at $2300^{\circ} \mathrm{C}$ and $2365^{\circ} \mathrm{C}$. Crystals on the crucible lids were examined by $\mathrm{X}$-ray and found to be $\mathrm{Y}_{2} \mathrm{O}_{3}$. The rhenium-thoria sample heated to $2445^{\circ} \mathrm{C}$ also had crystalline material present on the 
Table 16 - Typical Values of Vacuum and Temperature Metal-Ceramic Compatibility Tests

\begin{tabular}{|c|c|c|}
\hline $\begin{array}{l}\text { COMPOSITION, } \\
\text { VOL. PERCENT }\end{array}$ & TEMPERATURE & $\begin{array}{l}\text { VACUUM } \\
\text { (TORR) }\end{array}$ \\
\hline $75 \mathrm{~W} 25 \mathrm{Y}_{2} \mathrm{O}_{3}$ & $2300^{\circ} \mathrm{C}$ & $2 \times 10^{-5}$ \\
\hline $75 \mathrm{~W} 25 \mathrm{ThO}_{2}$ & $2220^{\circ} \mathrm{C}$ & $4 \times 10^{-5}$ \\
\hline $75 \mathrm{~W} 25 \mathrm{HfO}_{2}$ & $2290^{\circ} \mathrm{C}$ & $2 \times 10^{-5}$ \\
\hline $80 \mathrm{Re} 20 \mathrm{Y}_{2} \mathrm{O}_{3}$ & $2365^{\circ} \mathrm{C}$ & $2 \times 10^{-5}$ \\
\hline $80 \mathrm{Re} 20 \mathrm{ThO}_{2}$ & $2445^{\circ} \mathrm{C}$ & $1 \times 10^{-5}$ \\
\hline $80 \mathrm{Re} 20 \mathrm{HfO}_{2}$ & $2365^{\circ} \mathrm{C}$ & $3 \times 10^{-5}$ \\
\hline $80 \mathrm{Re} 20 \mathrm{Y}_{2} \mathrm{O}_{3}$ & $2045^{\circ} \mathrm{C}$ & $2 \times 10^{-5}$ \\
\hline
\end{tabular}

crucible lid. This material was found to be crystalline Th0 $0_{2}$. The yttria mixture at $2045^{\circ} \mathrm{C}$, the thoria at $2220^{\circ} \mathrm{C}$, and both hafnia samples did not exhibit detectable vaporization.

The samples were examined metallographically. The rhenium samples were found to be extensively twinned under thermal stress.

An electron microscope was used to evaluate the results at high resolution. Standard plastic negative replication was used to prepare microscope samples for examination. Oxygen solution in the rhenium and subsequent precipitation of oxide in twin lines was apparent. The effect is more severe at high temperatures as illustrated by comparison of the rhenium-yttria combination at $2045^{\circ} \mathrm{C}$, shown in Figure 23, and at $2365^{\circ} \mathrm{C}$, shown in Figure 24. Oxygen saturation of tungsten was not as apparent as can be seen in Figure 25.

Hafnia appears to be very stable in the presence of tungsten or rhenium. No interface reactions were noted with the exception that some transition zones were seen in the yttria mixtures; however, these would only be on the order of 2000 angstroms thick.

It is concluded that the principal systems $\mathrm{W}-\mathrm{Re}$, and $\mathrm{ThO}_{2}$ ? $\mathrm{Y}_{2} \mathrm{O}_{3}, \mathrm{HfO}_{2}$ should be excellent for use at $2000^{\circ} \mathrm{C}$, at least as far as chemical stability is concerned. 


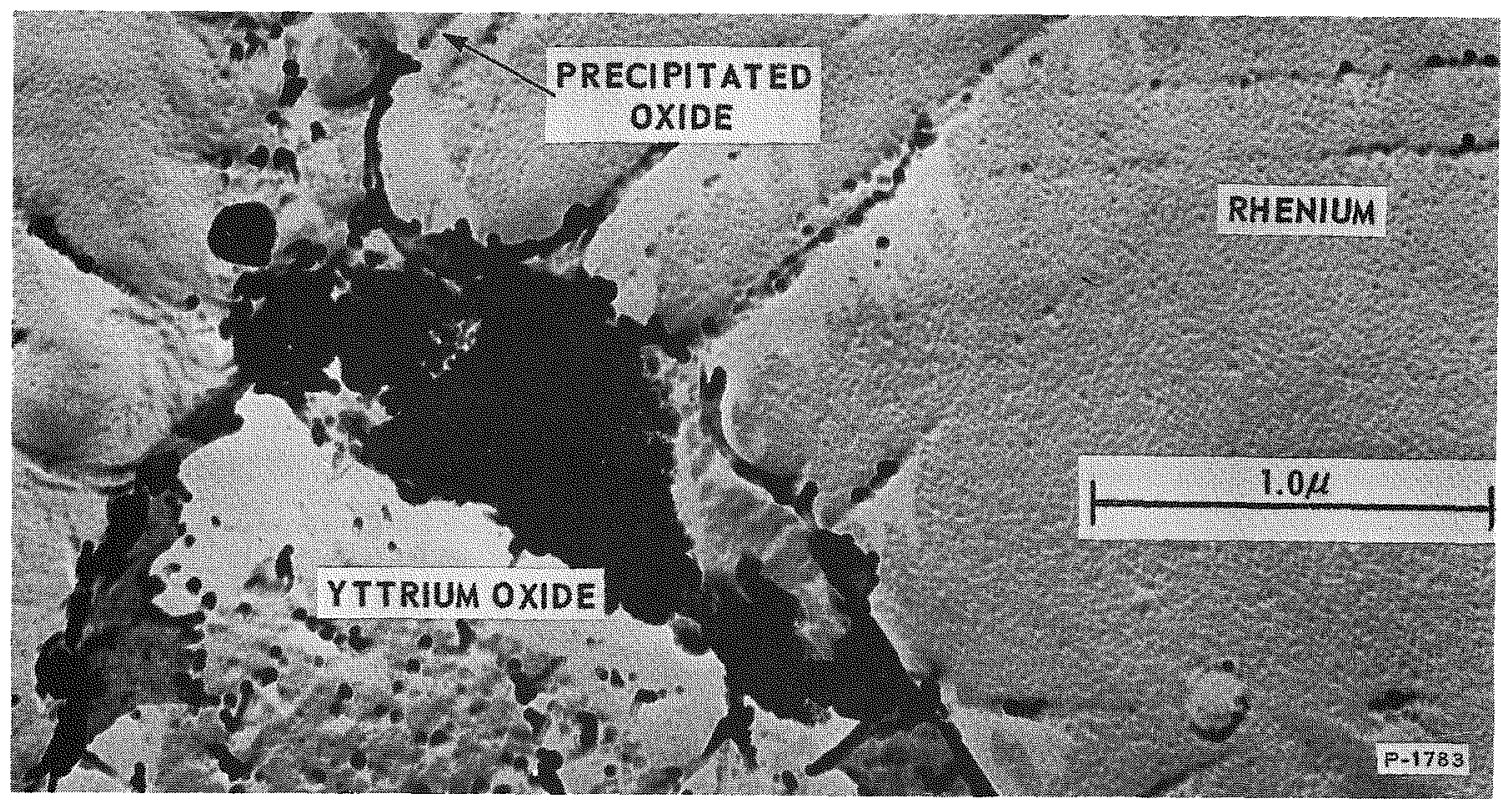

Figure 23 - 40000X Electronmicrograph of 80 Rhenium - 20 Yttria Mixture Subjected to $2045^{\circ} \mathrm{C}$

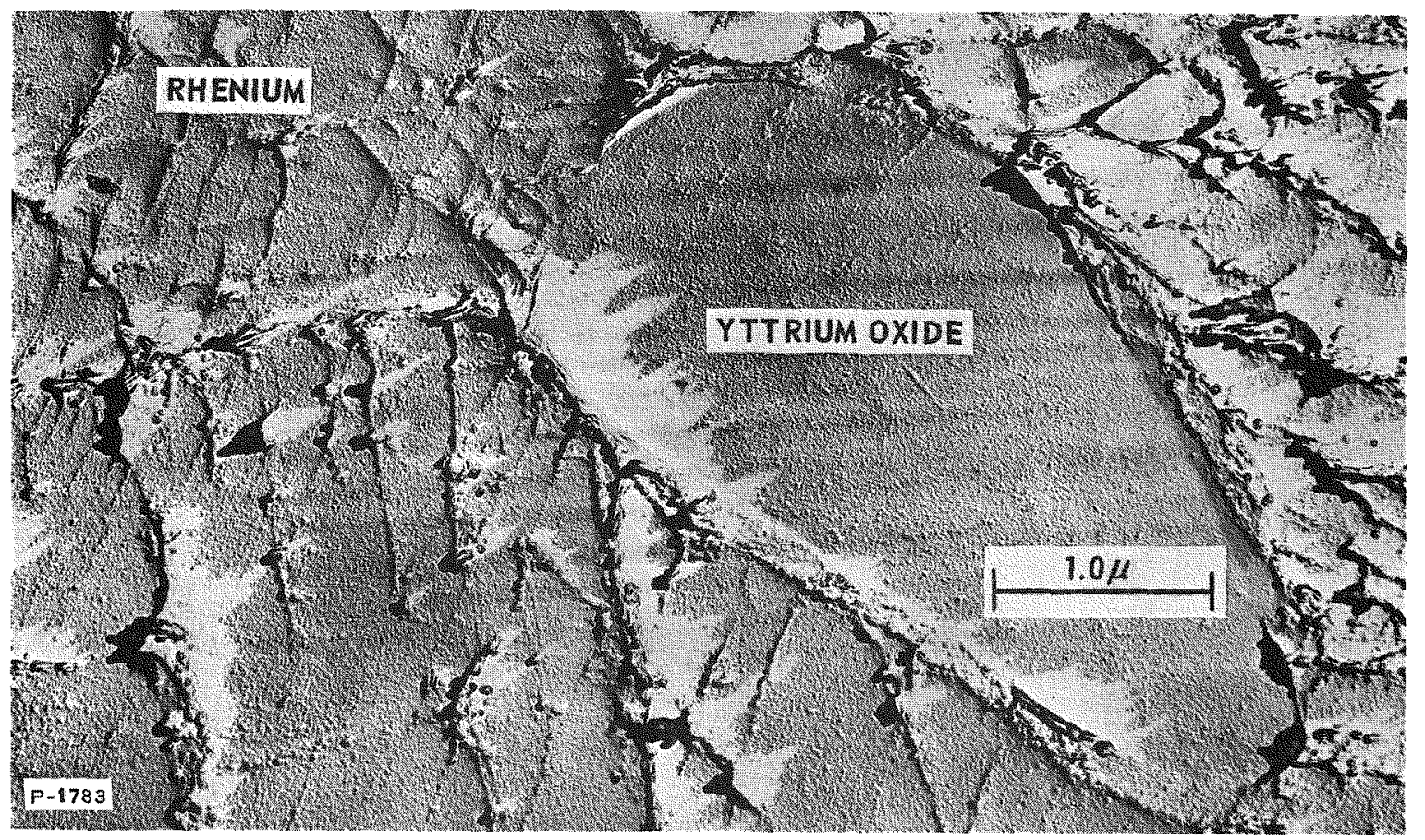

Figure 24 - 24000X Electronmicrograph of 80 Rhenium - 20 Yttria Mixture Subjected to $2365^{\circ} \mathrm{C}$ 


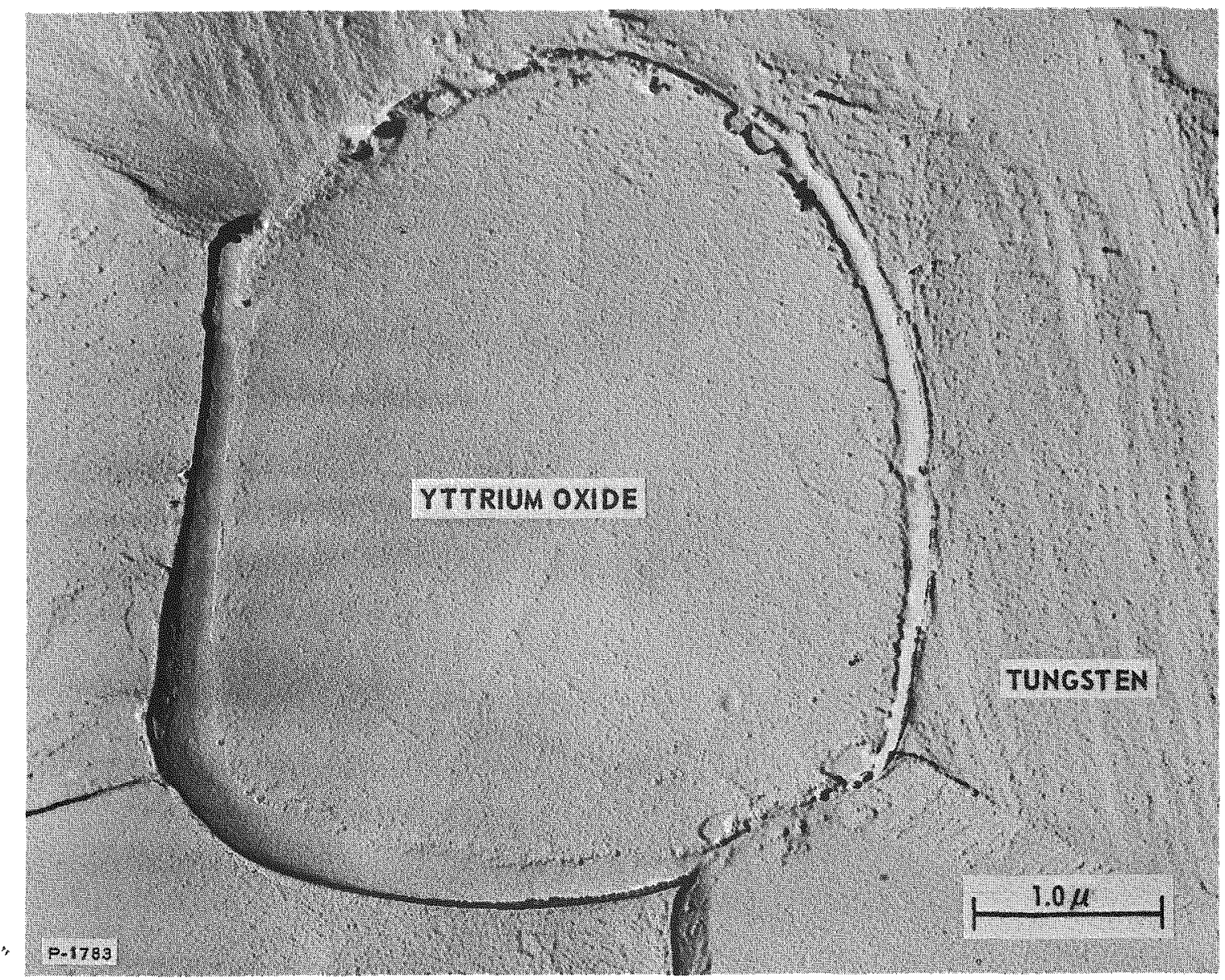

Figure 25 - 24000X Electronmicrograph of 75 Tungsten - 25 Yttria Mixture Subjected to $2300^{\circ} \mathrm{C}$

\subsection{Investigations of Expansion Characteristics}

Important parameters in the design of structures exposed to high temperatures are the coefficients of thermal expansion of the construction materials and the effects of mis-match of these coefficients on the magnitude of the consequent thermal stress. It was considered desirable to investigate the possibilities of tailoring material expansion characteristics to obtain closer matching. 
For solid solutions, an equation reported by Spurgeon ${ }^{2}$ will yield a good approximation to thermal expansion, particularly when the solution involved is very near ideal. $3^{3}$

$$
a_{a}=\frac{x_{1} a_{1} v_{1}+x_{2} a_{2} v_{2}}{x_{1} v_{1}+x_{2} v_{2}}
$$

where; $\quad a=$ respective linear coefficient,

$$
\begin{aligned}
& \mathrm{X}=\text { mole fraction, } \\
& \mathrm{V}=\text { atomic volume. }
\end{aligned}
$$

The probable metallic and insulator materials are shown in Table 17 for comparison of their expansion characteristics. The systems are either pure materials or solid solutions. The coefficients of thermal expansion for items marked (P) are those predicted from the relation cited.

\section{$5.4 \quad$ Joint Systems and Composites}

First attempts to fabricate a body of the se high temperature materials were by brazing a 75 tungsten -25 rhenium alloy to yttrium oxide and hafnium oxide disks using yttrium as an active metal bonding agent. These were unsuccessful. Clean argon proved to be too oxidizing an atmosphere to permit melting, as did a vacuum of $10^{-4}$ Torr. The yttrium oxidized and powdered prior to melting, preventing any bonding.

${ }^{2}$ W. M. Spurgeon, "Thermal Expansion Coefficient of Binary substitional Solid Solution Alloys "Thermodynamics \& Transport Properties of Gases, Liquids, \& Solids, ASME。

${ }^{3}$ For composite two-phase materials, thermal expansion can be predicted from Kerner's Equation.

$$
a=\left[\frac{4 G_{0}}{K}+3\right] \sum\left[\frac{a_{i} v_{i}}{4 G_{0} / K}+3\right]
$$

which is reported in Kirchner, et.al. "Investigation of Theoretical and Practical Aspects of the Thermal Expansion of Ceramic Materials:" Corne11 Reports,P-1-1273-M-12 NOrd-18419. 
Some very slight amount of metal apparently remained when the melting temperature was reached in the vacuum trial and oxidized after melting. This was concluded since a solidified reaction product was found on the hafnium oxide disk but had failed to wet the metal plate. This corrosion product was identified by $X$-ray examination as crystalline $\mathrm{Y}_{2}{ }_{3}$ 。

A later experiment was successful. Figure 26 shows a yttrium oxide disk which was bonded to rhenium with yttrium. The bonding mechanism which occurred is similar to brazing. The bond was formed in a gettered argon atmosphere at $1600^{\circ} \mathrm{C}$. The ceramic disk adhered tightly to the rhenium sheet. This sample was subjected to five thermal cycles between $500^{\circ} \mathrm{C}$ and $1400^{\circ} \mathrm{C}$. The high temperature in this test was limited to $1400^{\circ} \mathrm{C}$ to remain about $200^{\circ} \mathrm{C}$ below the melting point of yttrium. The bond remained strong and the pieces intact.

The same sample was then subjected to $2000^{\circ} \mathrm{C}$ to determine the effects of exposing it to temperatures above the melting point of yttrium. The bond remained intact with no cracks or defects apparent in the pieces.

Table 17 - Tentative Material Selection for Use at $2000^{\circ} \mathrm{C}$

\begin{tabular}{|c|c|c|}
\hline \multicolumn{3}{|c|}{ Metals } \\
\hline Composition & Percent & Expansion $/{ }^{\circ} \mathrm{C}$ \\
\hline 1. W & pure & $4.6 \times 10^{-6}$ \\
\hline 2. $\operatorname{Re}$ & pure & $6.7 \times 10^{-6}$ \\
\hline 3. $\mathrm{W}-\mathrm{Re}$ & $75-25$ & $5.6 \times 10^{-6}(P)$ \\
\hline 4. $\mathrm{Ru}-\mathrm{Mo} *$ & $89-11$ & $8.5 \times 10^{-6}(\mathrm{P})$ \\
\hline 5. $\operatorname{Re}-W$ & $90-10$ & $6.5 \times 10^{-6}(\mathrm{P})$ \\
\hline \multicolumn{3}{|c|}{ Insulators } \\
\hline 1. $\mathrm{ThO}_{2}$ & pure & $10.4 \times 10^{-6}$ \\
\hline 2. $\mathrm{Y}_{2} \mathrm{O}_{3}$ & pure & $9.3 \times 10^{-6}$ \\
\hline 3. $T h 0_{2}-\mathrm{Y}_{2} \mathrm{O}_{3}$ & $25-75$ & $9.5 \times 10^{-6}(\mathrm{P})$ \\
\hline 4. $\mathrm{ThO}_{2}-\mathrm{Er}_{2} \mathrm{O}_{3}$ & $50-50$ & $10.0 \times 10^{-6}(P)$ \\
\hline 5. $\mathrm{HfO}_{2}-\mathrm{Y}_{2} \mathrm{O}_{3}$ & $95-5$ & $6.5 \times 10^{-6}(P)$ \\
\hline
\end{tabular}

* Limited to $1800^{\circ} \mathrm{C}$ Use

(P) indicates value predicted from the relation of Spurgeon. 


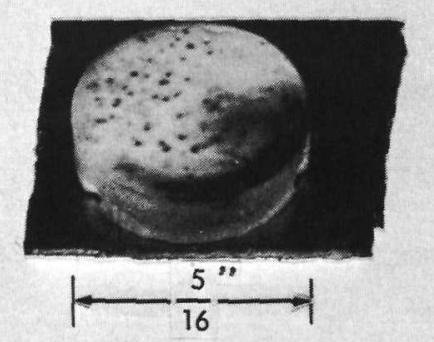

Figure 26 - Rhenium-Yttria Sample Bonded with Yttrium

The two parts of this sample were then broken apart. Visual examination of the fracture area showed that a corrosion product had formed between the two members and that the break occurred in this corrosion product. It has been concluded that this corrosion product formed because of an excess of yttrium in the bond area. From metallurgical evaluation of the pieces, it was apparent that diffusion of yttrium had occurred into both the yttria and the rhenium presumably during exposure to $2000^{\circ} \mathrm{C}$. A true metallurgical bond was formed.

It is considered that reducing the amount of yttrium in the joint will improve the bond. It may also be possible to bond the yttria to the rhenium directly by the diffusion process. Such a bond should have properties which would make it usable at $2000^{\circ} \mathrm{C}$.

Two small graded-composite structures have been processed. These consist of a structure graded from pure rhenium to stabilized hafnia in one sample, and from 95 rhenium - 5 tungsten to pure yttria in the second sample. The tungsten addition was used in the second sample to enhance sinterability since sintering was not complete in the sample made with pure rhenium and hafnia. These samples were powder pressed and sintered in argon at $1800^{\circ} \mathrm{C}$. The samples appeared to be dense and sound under visual examination.

Figure 27 shows two views of the composite cup fabricated from pure rhenium powder graded into a 5 percent yttria - - 95 percent hafnia (stabilized) ceramic. Although gradiation was crude, and some difference in the sintering shrinkage of the materials was encountered, the cup was hermetic. The thermal expansions of rhenium and hafnia are closely enough matched so that even though gradiation was crude, it was adequate to achieve a sound body. 

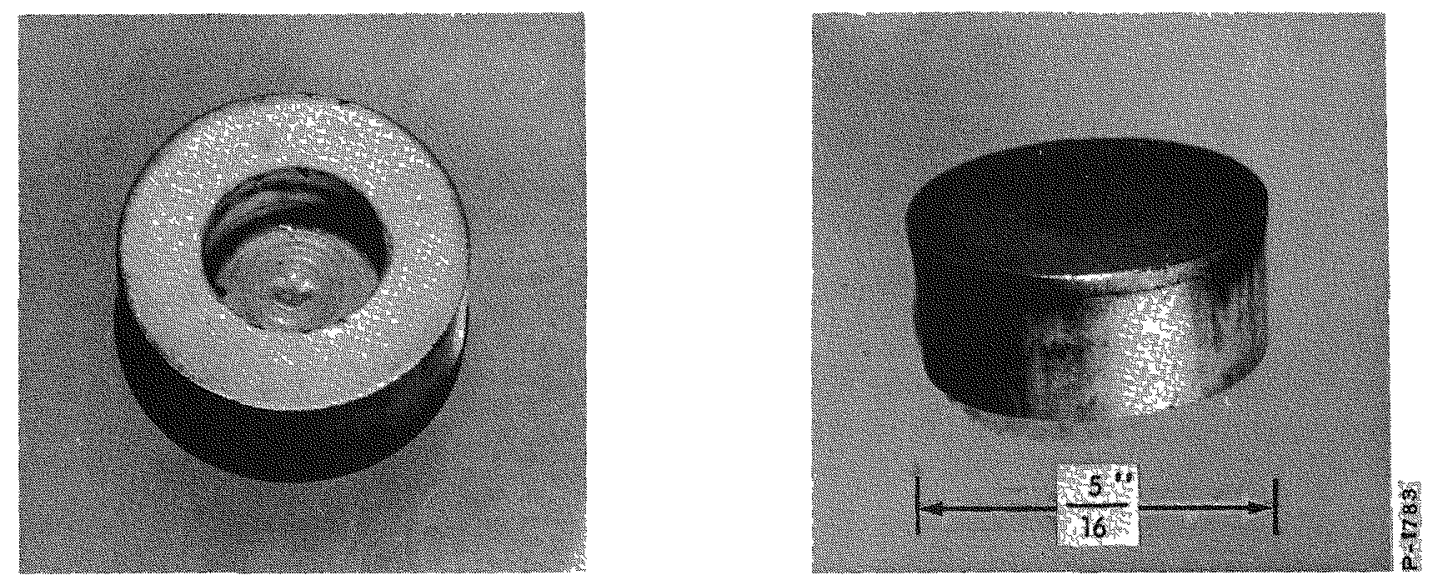

Figure 27 - Composite Cup Formed of Rhenium and Stabilized Hafnia

In addition to the diffusion joining and composite body studies, a metallizing system of $80 \mathrm{~W}-10 \mathrm{Mo}-10 \mathrm{Y}_{2} \mathrm{O}_{3}$ was successfully applied to four ceramic compositions; yttria stabilized hafnia, 50 erbia -50 thoria, yttria, and 75 yttria - 25 thoria. Firing of the slurry was performed at $1875^{\circ} \mathrm{C}$.

While significant results have been achieved in the study of materials and seals for use at $2000^{\circ} \mathrm{C}$, a considerable amount of work is required before such materials and seals can be used in the fabrication of converters with high expectation of reliable operation. 


\subsection{CONCLUSIONS AND RECOMMENDATIONS}

\subsection{CONCLUSIONS}

The following conclusions have been drawn from the results of the studies on the various sealing method and structures:

1. Present state-of-the-art ultrasonic welding methods offer little potential for the joining of metals and ceramics to be used at high temperatures. The nature of the energy input (high-frequency vibration) poses a problem in the use of the se methods with materials which have low impact resistance.

2. The use of electron-beam welding techniques for producing hermetic ceramic-metal seals is not at this time possible. Direct fusion of ceramics to refractory metals by electron-beam welding techniques is possible. However, the bonds which have been achieved to date are mechanical in nature and are not hermetic. It is possible to make strong electron-beam welds between thin refractory metal members and the metallized surface of a ceramic body. While only a small number of trials were made to fabricate this type of joint, the trials showed that the primary problem in accomplishing welded hermetic seals between a refractory metal member and a metallized surface is the control of the welding beam energy and penetration. This control requirement is a considerable problem because at least an order of magnitude improvement in penetration control is needed.

3. The formation of an electro-deposited bonding layer connecting a refractory metal member and the metallized surface of a ceramic is possible. However, the process requirements for depositing sufficient material and ensuring soundness and adequate density throughout the deposited material are lengthy and require rather precise control. This means of forming high-temperature seals is considered less practical than others which were studied. 
4. The metallizing technique which was developed using the tungsten-yttria system is a significant advancement in the metallizing art. It enables high purity aluminas to be metallized, as well as other bodies which also do not have constituents to provide glassy phase materials during metallizing. The greater adhesion strength of this material system over that of other metallizing systems provides stronger metal ceramic joints with all ceramics.

While the high temperature characteristics of this metallizing system have not been evaluated sufficiently to permit specific conclusions to be drawn, the nature of the materials used indicate that structures fabricated with this system should have capabilities of being used at temperatures up to $1500^{\circ} \mathrm{C}$.

The relative simplicity of the material systems minimizes likelihood of unwanted reaction with the use environment.

5. Seals formed by a diffusion process, in which various reaction products - usually oxides of materials inserted in the interface - provide gradual transition from metal to ceramic, can be used as joining systems for high purity alumina.

6. The seal system formed between molybdenum and highpurity alumina, using the alumina - yttria eutectic, which was described in Section 3.7.2, can be used in cesium environment at temperatures up to $1500^{\circ} \mathrm{C}$.

7. The composite structures, such as those fabricated from tungsten and alumina and from materials combinations usable at higher temperatures, offer the greatest potential for development of converter structures to withstand severe thermal shock and cycling conditions. 


\subsection{RECOMMENDATIONS}

It is recommended that additional work which may be performed on these systems be directed at the following objectives.

1. Determining the physical and electrical characteristics of the alumina - yttria eutectic seal systems described in Section 3.7.2. This determination should include evaluation at extremes of temperature and in the presence of cesium. Data should be obtained from a sufficient number of sample pieces to provide assurance or repeatability of characteristics observed.

2. Determining of the improvements obtained in converter operating characteristics by application of the seal of Section 3.7.2 to the fabrication of an essentially allceramic converter envelope wall.

3. Completing the development of the ceramic-metal composite structure using the most suitable combination of ceramic and metal. This form of structure is considered to have by far the greatest potential usefulness in thermionic converters because of its inherent resistance to thermal shock. 


\section{APPENDIX A \\ BIBLIOGR APHY ON CESIUM GORROSION}

\section{THEORY}

(1) Weeks, J.R., "Reaction Kinetics and Thermodynamics in Liquid Metal Corrosion," J. Metals, 14, 1, January 1962, p. 94.

(2) Weeks, J.R., "Corrosion and Mass Transfer in Alkali Liquid Metal Systems," Paper in "Materials Science and Technology for Advanced Applications," Prentice-Hall, 1962, p. 709.

(3) Rostoker, W., McCaughey, J.M., Markus, H.; "Embrittlement by Liquid Metals," Reinhold, 1960.

(4) Weatherfore, W.D., Ir.; Tyler, J.C.; Ku, P.M.; "Properties of Inorganic Energy-Conversion and Heat Transfer Fluids for Space Applications," WADD-TR-61-96; Contract No. AF 33(616)-7206.

\section{TESTING}

(5) Todd, H.; Barcatta, F.; Clark, D.; Worlock, R.; "Materials Requirements for Ion Propulsion," Paper in "Materials Science and Technology for Advanced Applications," Prentice-Hall, 1962, p. 94.

(6) Snoke, D. R.; Lawlor, P. J.; "Cesium Ion Propellant System," Final Report, Contract No. AF 33(616)-7219 (Thompson-RamoWoolridge).

(7) Ulrich, A. J.; "Thermionic Energy Conversion Using Film Boiling Liquid Metal Anode," Progress Report, Contract No.W-31-109eng-38 (Argonne National Laboratories).

(8) Silverberg, M.; 'Investigation of Low Temperature Plasma Diode Converters," ASD-TR-61-638; Contract No.AF 33(616)-7663 (Ford Instrument Co.), AD 273809.

(9) Arabian, R.V.; "Rubidium and Cesium Evaluation Program," Quarterly Technical Report No.3, Contract No. AT (04-3)-368 (Aerojet-General Nucleonics, AGN-8044). 
(10) Wilson, V.C.; Lawrence, J.; "Tests of a Cesium Thermionic Converter Designed to Utilize Solar Energy in Outer Space," Scientific Report No. 3, Contract No. AF 19(604) 5472 (General Electric Research Lab.) AD 260359.

(11) Dulgeroff, C.R.; Seele, G. D.; "Experimental Electrical Propulsion Study," AFOSR - TR-60-112.

(12) Petrick, E. N.; Husmann, O.K.; and Szymanowski, H.W.; "Analytical and Experimental Investigation of Compact Charge Ionization." CWR-700-10 (1960).

(13) Teitel, R.J.; "Alkali-Metal Corrosion Studies," Paper in NASA-TN-D-769, "NASA-AEC Liquid-Metals Corrosion Meeting, December, 1960," p. 49.

(14) Chandler, W. T.; "Alkali-Metal Corrosion Studies at Rocketdyne," Paper in AEC TID-7626 (Pt. 1), 'NASA-AEC Liquid-Metals Corrosion Meeting, December, 1961." p.42, (Contract No. AF 33(616)-8435).

(15) Hall, W. B.; O'Grady, J. J.; "Development of an Auxiliary Electrode Thermionic Converter," Third and Fourth Quarterly Technical Reports Contract No. AF 33(657)-8005 (RCA).

(16) Wagner, P.; Coriell, S.; "High-Temperature Compatibility of Cesium Gas with Some Dielectrics," Rev. Sci. Instr., 30, 10 (October 1960), p. 937.

(17) Slivka, M. J.; "Study of Cesium Vapor Attack on Thermionic Converter Construction Materials," Paper Given at the Symposium on Thermionic Power Conversion, Colorado Springs, May 1962.

(18) Stevens, H. L.; "Liquid-Cesium Research Program," Paper in NASA-TN-D-769," NASA-AEC Liquid Metals Corrosion Meeting, December 1960," p. 93.

(19) Parkman, M.F.; "Summary of Work at Aerojet-General Nucleonics on Liquid Metal Corrosion," Paper in AEC TID-7626 (Pt. 1), "NASA-AEC Liquid-Metals Corrosion Meeting, December 1961," p. 35, Contract No. AT(04-3)-251 and AT(04-3)-368).

(20) Crosby, J. J.; "Compatibility of Containment Metals with Cesium," ibid,; p. 109 . 


\section{APPENDIX B \\ THERMAL ANALYSIS OF IDEALIZED \\ SOLAR-POWERED THERMIONIC \\ GENERATOR IN EARTH ORBIT}

\section{MODEL}

The model established for analysis is a spherical cavity generator, 3 inches in outside diameter, made up of many converters. Taken collectively, the converter collectors constitute the outer shell, which radiates reject heat to space. The emitters constitute the inner shell, which is heated by solar energy entering through an aperture in the sphere. The solar energy is directed at the aperture by a concentrator (mirror). The effect of the aperture is considered to be small, and is neglected in the analysis. The specific heats and densities of both electrodes were taken as typical values for refractory metals. These values were arrived at by averaging these properties for molybdenum, tungsten, tantalum, and titanium. A representative value for work function was also determine.

The orbital period assumed is 90 minutes, the satellite being in the earth's shadow for 32 minutes (35.55 percent) of this time. The attenuation of solar energy by the atmospheric layer around the earth has been ignored because it was reasoned that its effect on the curves would be small. Traveling at $18,000 \mathrm{mph}$, the time during which the input solar energy is appreciably attenuated by the atmosphere is only a small fraction of a minute.

The following cases were chosen to be evaluated. The steady-state conditions were given as:

$$
\begin{aligned}
\text { Case I - } & 2000^{\circ} \mathrm{C} \text { cathode, } 900^{\circ} \mathrm{C} \text { anode, } \\
& 10 \text { percent efficiency, } \\
\text { Case II - } & 1500^{\circ} \mathrm{C} \text { cathode, } 900^{\circ} \mathrm{C} \text { anode, approxi- } \\
& \text { mately } 1 \text { percent efficiency. }
\end{aligned}
$$

During the analysis, it was found that the initial conditions for Case II defined a completely different system than Case Is thereby making comparison of the two cases impossible. It was felt that these two cases should be run for the same diode, on the basis of physical 
configuration and heat transfer characteristics. Later it will be shown that this basis yields the following steady-state conditions, the $1500^{\circ}$ cathode temperature being retained:

$$
\begin{aligned}
\text { Case II }- & 1500^{\circ} \mathrm{C} \text { cathode, } 582^{\circ} \mathrm{C} \text { anode, } \\
& 0.0631 \text { percent efficiency. }
\end{aligned}
$$

\section{DERIVATION OF EQUATIONS}

\section{Equation for Cathode Temperature}

Taking a heat balance between $A$ and $B$ shown in the schematic of Figure $\mathrm{B}-1$.

$$
\begin{aligned}
& \text { heat in }=\begin{array}{c}
\text { heat giving change } \\
\text { in cathode temp. }
\end{array}+\begin{array}{l}
\text { radiative heat } \\
\text { transfer, } \rightarrow 2
\end{array}+\begin{array}{l}
\text { heat loss due to } \\
\text { electron boil-off }
\end{array} \\
& q(\tau)=\rho_{1} c_{1} v_{1} \frac{D T_{1}}{d \tau}+K_{1 \rightarrow 2}\left[T_{1}^{4}(\tau)-T_{2}^{4}(\tau)\right]+\begin{array}{l}
\text { heat loss due to } \\
\text { electron boil-off }
\end{array}
\end{aligned}
$$

The average total energy loss from the cathode per electron boiled off is equal to the energy required to raise the electron over the work function potential and space-charge repulsion $\left(\mathrm{q}_{\mathrm{e}} \mathrm{V}_{1}\right)$ plus the average kinetic energy of the electrons in the plasma. If the gas in the diode is effective in reducing the space charge, $v_{1} \approx \phi_{1}$.

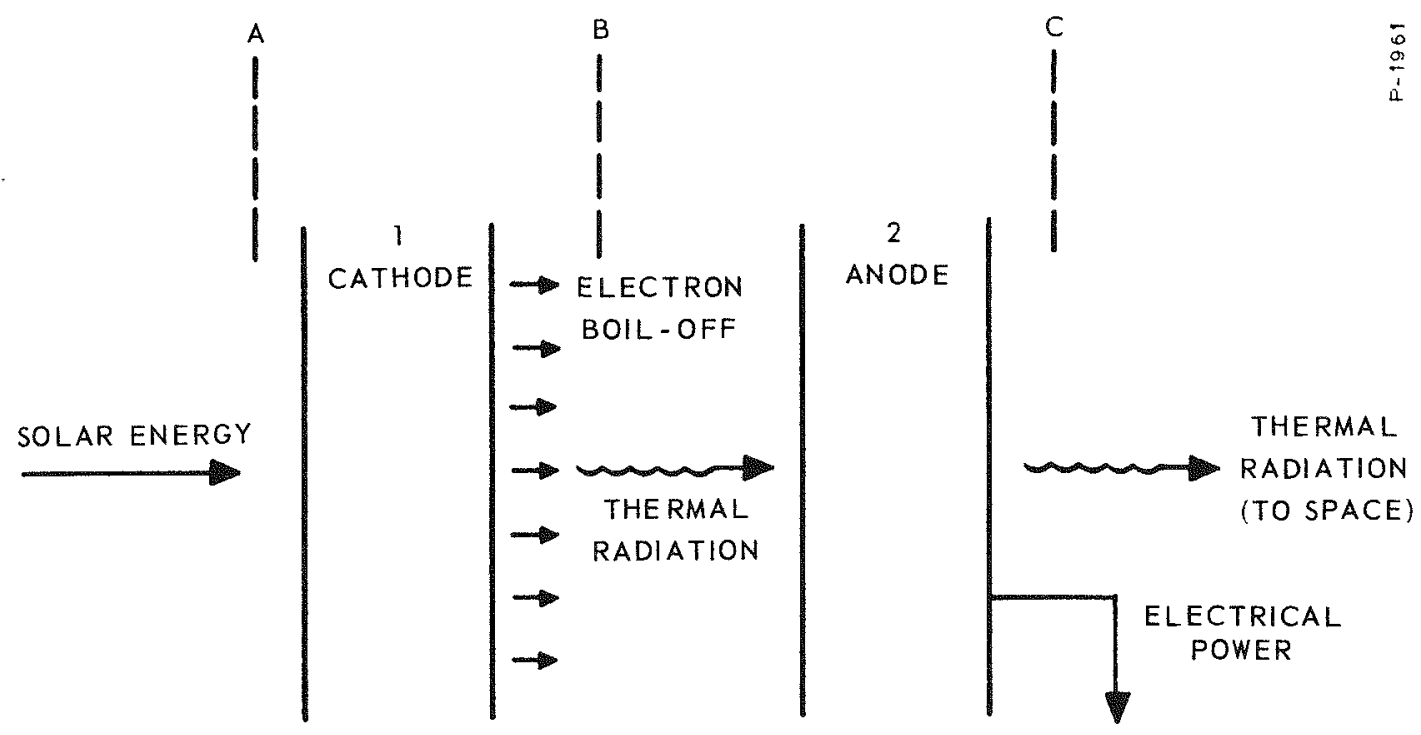

Figure B-1 - Heat - Balance Schematic 
The average energy of the electrons in the plasma was determined as follows:

The energy of an emitted electron in a direction perpendicular to the surface of the cathode must be greater than $\phi_{1}$. The average energy above the work function is about $\mathrm{kT}$; in the other two axes of motion, the electron has its average energy $1 / 2 \mathrm{kT}$ for a total of $2 \mathrm{kT}$.

The total energy removed by the boiled-off electrons may now be expressed as

$$
I\left(\phi_{1}+\frac{2 k T_{1}}{q_{e}}\right)
$$

The current, $I$, created is a definite function of the cathode temperature, the effect of the anode characteristics being small. Richardson's equation states

$$
J_{1}=C \frac{T_{1}^{2}}{\exp \cdot\left(\frac{q_{e} V_{1}}{k T_{1}}\right)} \operatorname{amps} / \mathrm{cm}^{2}
$$

where $C$ is a constant $\approx 120 \mathrm{amps} / \mathrm{cm}^{2}{ }^{\circ} \mathrm{K}^{2}$. The electrical power is then the voltage $\mathrm{V}$ times the above current. A voltage of 1.5 volts has been experimentally found to yield the best efficiency.

The heat input $q(\tau)$ may be expressed in terms of rated power $P(\tau)$ and efficiency $\eta$ by

$$
q(\tau)=\frac{P(\tau)}{\eta}
$$

At steady-state $d T_{1} / d \tau=0$ and $K_{1 \rightarrow 2}$ turns out to be

$$
K_{I \rightarrow 2}=\frac{\frac{P(0)}{\eta}-\left[\phi_{1}+\frac{2 k}{q_{e}} T_{1}(0)\right] I(0)}{T_{1}^{4}(0)-T_{2}^{4}(0)}
$$


Writing the original differential equation in difference form to facilitate solution by an iterative procedure on the digital computer yields the following result:

$$
\begin{aligned}
T_{1}^{\prime}(n) & =T_{1}^{\prime}(n-1)+0.876 \frac{\Delta T}{\rho_{1} c_{1}^{v} v_{1}}\left\{\frac{P(T)}{\eta}-\left[\frac{P(0)}{\eta}-\phi_{1}+\frac{2 k}{q_{e}} T_{1}(0)\right) I(0)\right] \\
& \left.\times \frac{T_{1}^{4}(n-1)-T_{2}^{4}(n-1)}{T_{1}^{4}(0)-T_{2}^{4}(0)}-\left(\phi_{1}+\frac{2 k}{q_{e}} T_{1}(n-1)\right) I(n-1)\right\},
\end{aligned}
$$

where $\mathrm{n}$ is the number of iterations, equal to $T / \Delta \tau$.

The primed temperatures indicate ${ }^{\circ} \mathrm{C}$ rathe $\mathrm{r}$ than ${ }^{\circ} \mathrm{K}$, and 0.876 is a units conversion factor.

\section{Equation for Anode Temperature}

Taking a heat balance between $\mathrm{A}$ and $\mathrm{C}$,

heat in $=\begin{aligned} & \text { heat giving change } \\ & \text { in cathode temp. }\end{aligned}+\begin{aligned} & \text { heat giving change } \\ & \text { in anode temp. }\end{aligned}+\begin{aligned} & \text { electrical } \\ & \text { power output }\end{aligned}+\begin{aligned} & \text { radiation to } \\ & \text { space, } 2 \rightarrow s\end{aligned}$

$q(\tau)=\rho_{1} c_{1} v_{1} \frac{d T_{1}}{d \tau}+\rho_{2} c_{2} v_{2} \frac{d T_{2}}{d \tau}+P\left(T_{1}\right)+K_{2 \rightarrow s}\left[T_{2}^{4}(\tau)-T_{s}^{4}\right]$

From steady-state conditions,

$$
K_{2 \rightarrow s}=\frac{\frac{P(0)}{\eta}-P(0)}{T_{2}^{4}(0)-T_{s}^{4}}
$$

Writing in difference form and solving for ' $T_{2}$ '

$$
\begin{aligned}
T_{2}^{\prime}(n) & =T_{2}^{\prime}(n-1)-\frac{\rho_{1} c_{1} v_{1}}{\rho_{2} c_{2} v_{2}}\left[T_{1}^{\prime}(n)-T_{1}^{\prime}(n+1)\right]+0.876 \frac{\Delta T}{\rho_{2} c_{2} v_{2}} \\
& \times\left\{\frac{P(T)}{\eta}-P\left(T_{1}\right)-\left[P(0)\left(\frac{1}{\eta}-1\right) \frac{T_{2}^{4}(n-1)-T_{s}^{4}}{T_{2}^{4}(0)-T_{s}^{4}}\right]\right\} .
\end{aligned}
$$




\section{CASES CONSIDERED}

Note that the constants $K_{1 \rightarrow 2}$ and $K_{2} \rightarrow s$ are completely spelled out by the steady-state conditions. For Case $\mathrm{I}_{\text {, }}$ the values used appear realistic when compared with literature. However for Case II, no such comparison was made because cases using such low cathode temperatures have not been found described in literature. It soon became evident that the results for Case II could not be compared meaningfully to Case I. This was because the new set of steady-state conditions defined a. new diode having different values of $\mathrm{K}_{1 \rightarrow 2}$ and $\mathrm{K}_{2} \rightarrow \mathrm{s}$. In terms of heat transfer theory, these constants are comprised of view factors and emissivity. If we assume that the emissivities do not vary with temperature, a diode in the same orbit and having identical geometry should have the same $K_{1 \rightarrow 2}$ and $K_{2 \rightarrow s}$ values. Making these values the same for both cases and fixing the new cathode temperature at $1500^{\circ} \mathrm{C}$, a new anode temperature and thermionic efficiency were calculated.

Comparing Case II to Case I then, what we have now is the same diode in the same orbit, but with a smaller mirror, thereby heating the cathode to a lower temperature and causing considerably less current to flow, which in turn reduces the efficiency.

The steady-state power for Case I is 142.6 watts; for Case II it is 0.239 watts.

\section{RESULTS}

The results of the digital computation are shown in Figures B-2 and $B-3$. The sudden leveling off of the cathode temperature soon after light time begins is due in a large part to the emission of electrons, which is a very strong function of temperature and becomes very importantat high temperatures.

\section{FUTURE POSSIBILITIES}

It might be interesting to see how varying different parameters affects these curves. Since the programming is already done, the substitution of different values would be very inexpensive. 


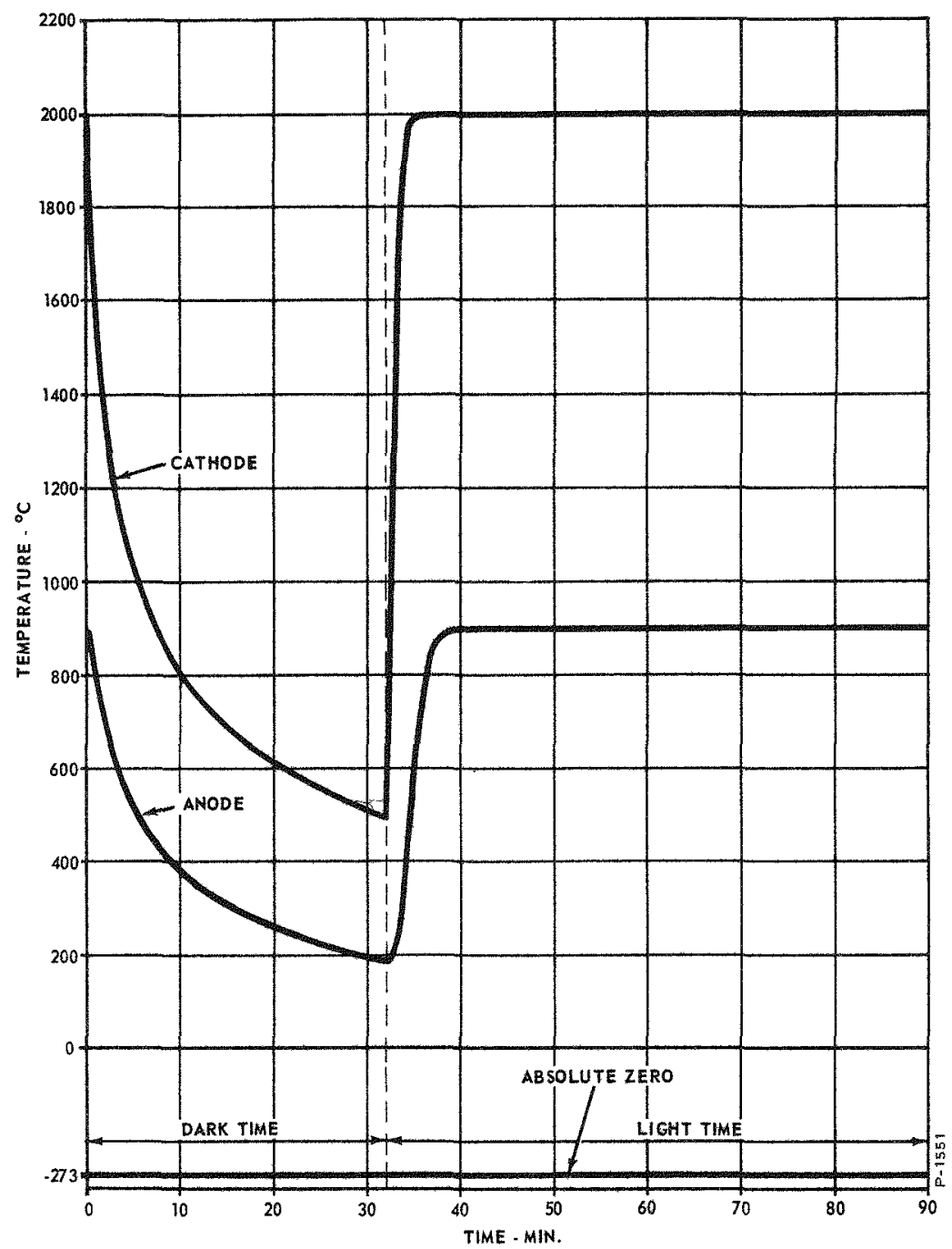

Figure B-2 - Thermionic Electrode Temperature Profiles - Case I: $\mathrm{T}_{1}(0)=2000^{\circ} \mathrm{C}$

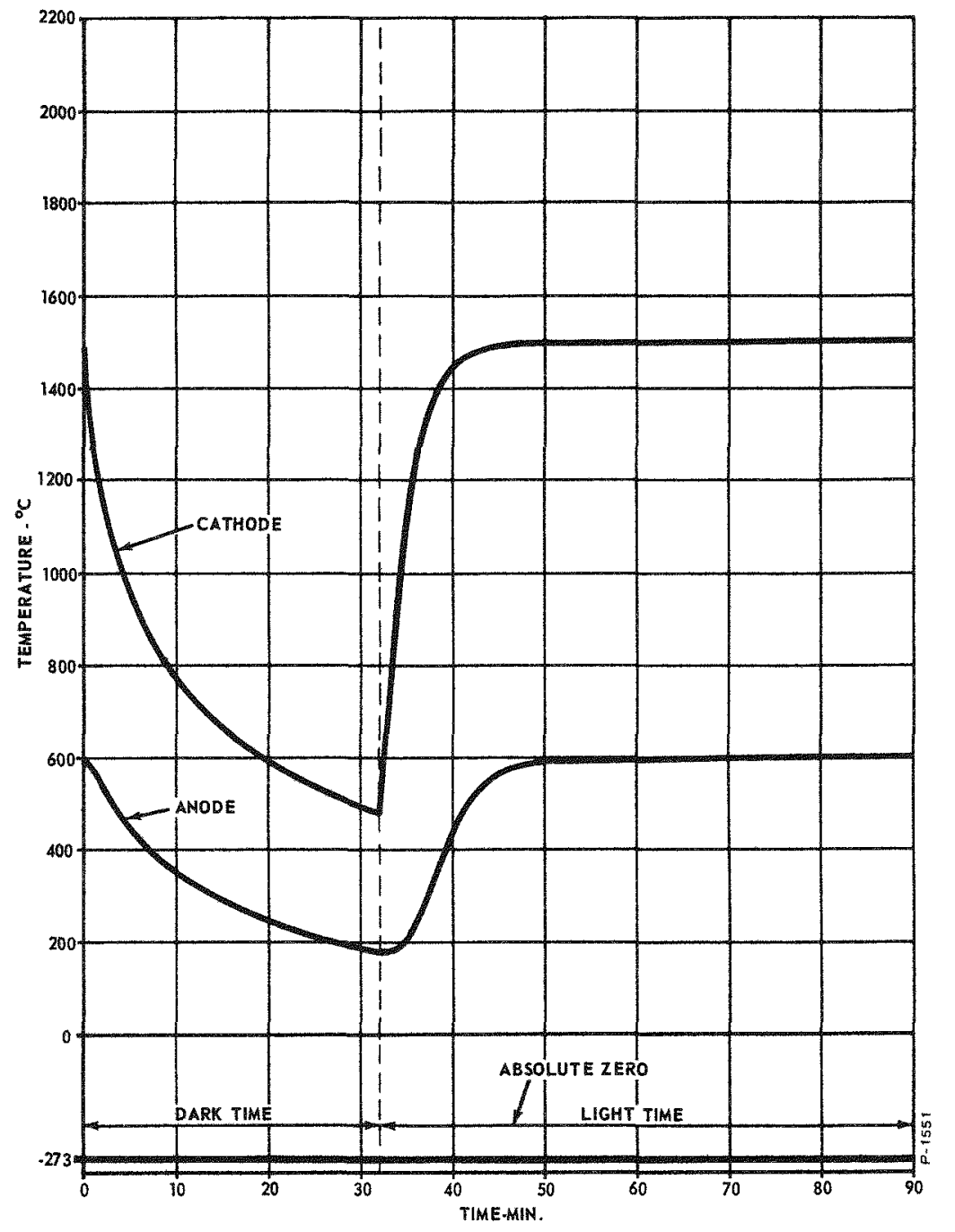

Figure B-3 - Thermionic Electrode Temperature Profiles - Case II: $\mathrm{T}_{1}(0)=1500^{\circ} \mathrm{C}$ 
SUMMARY OF EQUATIONS

$$
\begin{aligned}
& T_{1}^{\prime}(n)=T_{1}^{\prime}(n-1)+0.876 \frac{\Delta \tau}{\rho_{1} c_{1} v_{1}}\left\{\frac{P(\tau)}{\eta}-\left[\frac{V I(0)}{\eta}-\left(\phi_{1}+\frac{2 k}{q_{e}} T_{1}(0)\right) I(0)\right]\right. \\
& \left.x \frac{T_{1}^{4}(n-1)-T_{2}^{4}(n-1)}{T_{1}^{4}(0)-T_{2}^{4}(0)}-\left(\phi_{1}+\frac{2 k}{q_{e}} T_{1}(n-1)\right) I(n-1)\right) \\
& T_{2}^{\prime}(n)=T_{2}^{\prime}(n-1)-\frac{\rho_{1} c_{1} v_{1}}{\rho_{2} c_{2} v_{2}}\left[T_{1}^{\prime}(n)-T_{1}^{\prime}(n-1)\right]+0.876 \frac{\Delta T}{\rho_{2} c_{2} v_{2}} \\
& x\left\{\frac{P(T)}{\eta}-V I(n-1)-\left[V I(0)\left(\frac{1}{\eta}-1\right) \frac{T_{2}^{4}(n-1)-T_{S}^{4}}{T_{2}^{4}(0)-T_{S}^{4}}\right]\right\} \\
& I(n-1)=775 A_{1} \frac{T_{1}^{2}(n-1)}{\exp \cdot\left(\frac{q_{e} \phi_{1}}{k T_{1}(n-1)}\right)}
\end{aligned}
$$

SYMBOLS, VALUES, AND UNITS

Temperature: Case I

$\begin{array}{clcc}\mathrm{T}_{1}^{\prime}(0) & \text { initial cathode temperature } & 2000 & { }^{\circ} \mathrm{C} \\ \mathrm{T}_{1}(0) & \text { initial cathode temperature } & 2273 & { }^{\circ} \mathrm{K} \\ \mathrm{T}_{2}^{\prime}(0) & \text { initial anode temperature } & 900 & { }^{\circ} \mathrm{C} \\ \mathrm{T}_{2}(0) & \text { initial anode temperature } & 1173 & { }^{\circ} \mathrm{K}\end{array}$

Temperature: Case II

$\begin{array}{cccc}\mathrm{T}_{1}^{8}(0) & \text { initial cathode temperature } & 1500 & { }^{\circ} \mathrm{C} \\ \mathrm{T}_{1}(0) & \text { initial cathode temperature } & 1773 & { }^{\circ} \mathrm{K} \\ \mathrm{T}_{2}^{\prime}(0) & \text { initial anode temperature } & 592 & { }^{\circ} \mathrm{C}\end{array}$




$\begin{array}{clrr}\mathrm{T}_{2}(0) & \text { initial anode temperature } & 865 & { }^{\circ} \mathrm{K} \\ \mathrm{T}_{\mathrm{S}} & \text { space temperature } & 4 & { }^{\circ} \mathrm{K}\end{array}$

$\underline{\text { Rated Power }}$

$$
\begin{aligned}
& P(\tau) \quad \text { rated power }=0 \text { for } 0<\tau<32 \\
& =\mathrm{VI} 0) \text { for } 32<\tau<90 \text { watts } \\
& \text { steady-state }\} \text { Case I: } 142.6 \text { watts } \\
& \text { power output }\}\{\text { Case II: } 0.239 \text { watts }
\end{aligned}
$$

Time

$\begin{array}{cll}\tau & \text { time } & \text { minutes } \\ \Delta T \quad \text { time interval (use own discretion) } 0.02 & \text { minutes }\end{array}$

Thermionic Efficiency: Case I

$\eta \quad$ thermionic efficiency $\quad 0.1$

Thermionic Efficiency: Case II

$\eta \quad$ thermionic efficiency $\quad 0.000631$

Electrical Output

$$
\begin{array}{ccc}
\text { I generated electrical current } I(n-1)=21900 & \frac{T_{1}^{2}(n-1)}{\exp \cdot\left(\frac{4.75 \times 10^{4}}{T_{1}(n-1)}\right)^{a m p}} \\
J_{1} & \text { current density from cathode } & \text { amps } / \mathrm{cm}^{2} \\
V & \text { load voltage } & 1.5 \text { volts }
\end{array}
$$

Physics Parameters

$\begin{array}{clcl}\phi_{1} & \text { cathode work function } & 4.1 & \text { volts } \\ \mathrm{V}_{1} & \begin{array}{l}\text { cathode work function and } \\ \text { space charge potential }\end{array} & & \text { volts } \\ \mathrm{q}_{\mathrm{e}} & \text { electron charge } & 1.6 \times 10^{-19} & \text { coulombs } \\ \mathrm{k} & \text { Boltzmann constant } & 1.38 \times 10^{-23} & \text { joules } /{ }^{\circ} \mathrm{K} \\ \frac{2 \mathrm{k}}{\mathrm{q}_{\mathrm{e}}} & & 1.723 \times 10^{-4} & \text { volts } /{ }^{\circ} \mathrm{K}\end{array}$


Electrode Properties

$\begin{array}{ll}\rho_{1} & \text { cathode density } \\ \rho_{2} & \text { anode density } \\ c_{1} & \text { cathode specific heat } \\ c_{2} & \text { anode specific heat }\end{array}$

$12.7 \mathrm{~g} / \mathrm{cc}$

$12.7 \mathrm{~g} / \mathrm{cc}$

$0.077 \mathrm{cal} / \mathrm{gm}^{\circ} \mathrm{C}$ or B TU $/ \mathrm{lb}^{\circ} \mathrm{F}$

$0.077 \mathrm{cal} / \mathrm{gm}^{\circ} \mathrm{C}$ or BTU $/ 1 b^{\circ} \mathrm{F}$

Geometry

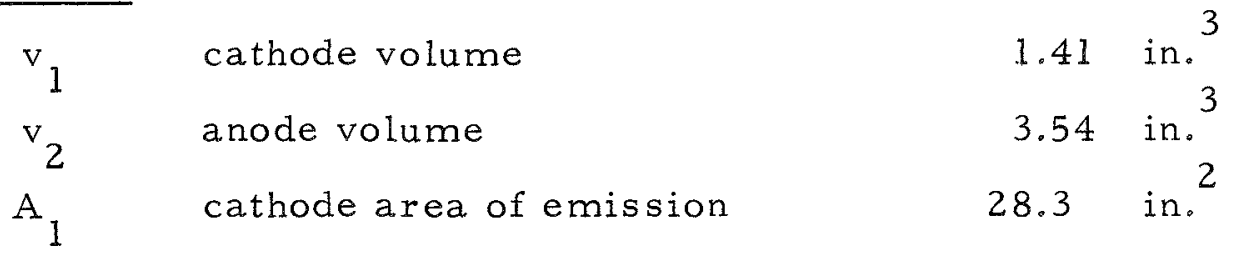

Others

$\begin{array}{lll}\mathrm{q}(\tau) & \begin{array}{l}\text { heat input (step function of time) } \\ \mathrm{K}_{1 \rightarrow 2}\end{array} & \begin{array}{l}\text { constant of thermal radiation from } \\ \text { cathode to anode }\end{array} \\ \mathrm{K}_{2 \rightarrow \mathrm{s}} & \begin{array}{l}\text { constant of thermal radiation from } \\ \text { anode to space }\end{array} & \text { watts } /{ }^{\circ} \mathrm{K} \\ \mathrm{n} & \text { number of iterations } & \text { watts } /{ }^{\circ} \mathrm{K}\end{array}$




\section{APPENDIX C \\ PLATING PROCEDURE FOR HEAVY \\ RHODIUM PLATE ON MOLYBDENUM}

The following procedure was found to give the best results in plating of rhodium on a molybdenum base metal.

1. Sandblast

$\begin{array}{lll}\text { Air Pressure } & - & 60-80 \mathrm{psi} \\ \text { Grit Size } & - & 80 \mathrm{Mesh}\end{array}$

2. Hot Alkaline Electroclean Cathodically

$\begin{array}{lll}\text { Temperature } & - & 150^{\circ} \mathrm{F} \\ \text { Voltage } & - & 6 \text { volts } \\ \text { Solution } & - & 6 \mathrm{oz} / \mathrm{gal} . \text { Wyandot \#38 }\end{array}$

3. Water Rinse

4. Woods Nickel Strike

$\begin{array}{lll}\text { Time } & - & 1 \text { Minute } \\ \text { Current Density } & - & 150 \text { amps/ft }{ }^{2} \\ \text { Temperature } & - & \text { Room } \\ \text { Nickel Chloride } & - & 2 \# / g a l . \\ \text { HCl } & - & 16 \text { fluid ounces/gal. }\end{array}$

5. Water Rinse

6. Rhodium Plate

$\begin{array}{lll}\text { Time } & - & 1-1 / 2 \mathrm{hrs} \text {. to plate } 0.001^{\prime \prime} \\ \text { Current Density } & - & 15 \mathrm{amps} / \mathrm{ft}^{2} \\ \text { Temperature } & - & 110-130^{\circ} \mathrm{F} \\ \text { Solution } & - & 15 \mathrm{grams} / \text { liter }\end{array}$


7. Vacuum Anneal

$\begin{array}{lll}\text { Time } & - & 30 \text { minutes } \\ \text { Temperature } & - & 1800^{\circ} \mathrm{F} \\ \text { Vacuum } & - & 1 \times 10^{-4} \mathrm{~mm} / \mathrm{Hg}\end{array}$

8. Electroclean

Temperature

Voltage

$-\quad 150^{\circ} \mathrm{F}$

Solution

- 6 volts

- $6 \mathrm{oz} / \mathrm{gal}$. Wyandot \#38

9. Surface Activation

Time - $\quad 1-2$ minutes

Voltage

- $\quad 6-8$ volts

Temperature

Room

Solution

- Cobalt Cyanide

Potassium Cyanide (80 grams/liter)

Cobalt Sulfate $(2-4$ grams/liter $)$

10. Water Rinse

11. Platinic Chloride Strike

Time

$-$

2 minutes,

Temperature

- Room

Current Density

$10 \mathrm{amps} / \mathrm{ft}^{2}$

Solution

$-$

$3 \%$ chloroplatinic Acid

12. Water Rinse

13. Rhodium Plate

Same as Step 6 
14. If heavier plating is desired, repeat Steps 6 through 12 .

The highly stressed condition of the plated coating caused considerable surface cracking to occur. The use of the vacuum anneal after each plating operation is required to relieve the coating stresses. Attempts to over-plate previously plated specimens directly after the vacuum annealing operation were unsuccessful. The use of the cobalt cyanide strike reactivated the surface so that plating could proceed. 


\section{DISTRIBUTION LIST}

$\begin{array}{cl}\text { CYS } & \text { ACTIVITIES AT WPAFB } \\ 1 & \text { ASNXRR (Library) } \\ 1 & \text { ASNXRT } \\ 1 & \text { AVTP } \\ 13 & \text { APIP - } \\ 1 & \text { MAA } \\ 1 & \text { MAM } \\ 1 & \text { MAM } \\ \text { DEPARTMENT OF DEFENSE } \\ \text { ACTIVITIES }\end{array}$

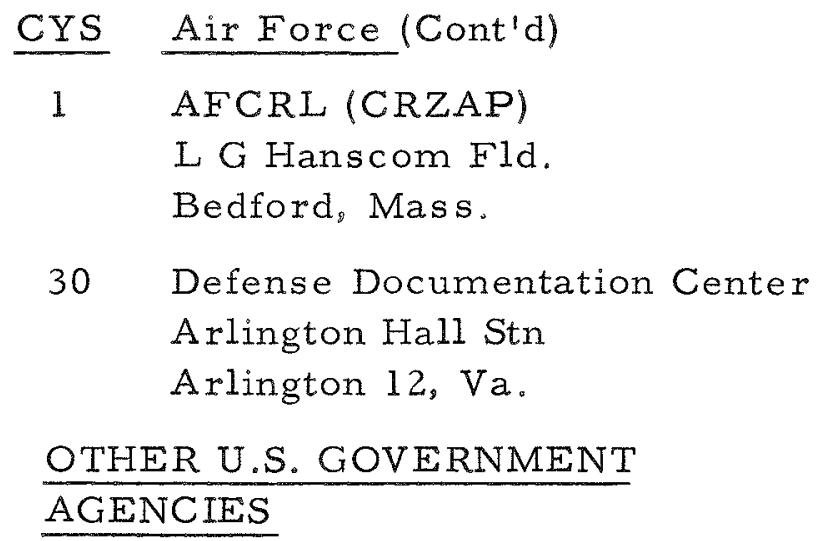

1 Institute for Defense Analysis Attn: Dr. R. Hamilton 1825 Connecticut NW Washington 25, D.C.

1 Director ARPA

Army

1 U.S. Army Signal R\&D Lab. Attn: SIGRA/SL-PS(Dr. Kittl) 2 Fort Monmouth, New Jersey

2 NASA Lewis Research Center Attn: Library Navy

1 Office of Naval Research Power Branch, Code 429 21000 Brookpark Road Cleveland 25, Ohio Attn: CDR J.J. Connelly Washington 25, D.C.

1 U.S. Naval Research Lab. Technical Information Div. Washington $25, \mathrm{D} . \mathrm{C}$.

1 Chief, Bureau of Ships The Pentagon Attn: Dr.J.Huth Department of the Navy Attn: Code 342B, Mr. Rosenbaum Washington 25, D.C.

$1 \quad$ NASA Manned Spacecraft Center SEDD (Attn: J.D. Murrell) Houston, Texas

1 Jet Propulsion Laboratory Spacecraft Secondary Power Sec. Attn: Mr. Paul Goldsmith 4800 Oak Park Drive Pasadena, California Scientific \& Technical Information Facility Attn: NASA Representative Air Force

1 SSD (SSTRE, Maj. Iller) AF Unit Post Office (SAK/DL - 1444) P.O. Box 5700 Bethesda, Maryland Los Angeles 45, California 
OTHER U.S.GOVERNMENT

AGENCIES (Cont'd)

CYS

1 Los Alamos Scientific Lab. P.O.Box 1663

Los Alamos, New Mexico

Attn: Dr. G. M. Grover

1 U.S. Atomic Energy Commission Division of Reactor Developmt. Attn: Lt. Cmdr. J. Prosser Washington $25, \mathrm{D} . \mathrm{C}$.

1 U.S.Atomic Energy Commission San Francisco Operations Office Attn: Reactor Division

2111 Bancroft Way

Berkeley 4, California

1 U.S.Atomic Energy Commission Office of Technical Information Extension

P.O. Box 62

Oak Ridge, Tennessee

1 National Aeronautical and Space Administration

Attn: Dr.Walter Scott

$1520 \mathrm{H}$ Street N.W.

Washington $25, \mathrm{D}, \mathrm{C}$.

100 OTS STOCK

1200 South Eads Street

Arlington, Va.

OTHERS

1 Aerospace Corporation

Attn: Library Technical

Document Group

P.O. Box 95085

Los Angeles 45, California
CYS OTHERS (Cont'd)

1 Aerojet General Nucleonics Attn: K, E. Buck

Box 77

San Ramon, California

1 Atomics International

Attn: Dr. R. C. Allen

P.O. Box 309

Canoga Park, California

1 Ford Instrument Company

A.ttn: T.Jarvis

3110 Thomson Avenue

Long Island City, New York

1 General Atomic

Attn: Dr.W. Pidd

P.O. Box 608

San Diego 12, California

1 The Martin Corporation

Attn: Dr。M. Talaat

Baltimore 3, Maryland

1 General Electric Company

Research Laboratory

Attn: W. Grattidge

P.O. Box 1088

Schenectady, New York

1 General Electric Company

Attn: Mr。D. L. Shaefer

1 River Road

Schenectady 5, New York

1 General Electric Company

Valley Forge Space Techno-

logy Center

Attn: Dr. J.C. Danko

P.O. Box 8555

Philadelphia 1, Pa. 


\begin{tabular}{|c|c|c|c|}
\hline EYS & OTHERS (Cont'd) & CYS & OTHERS (Cont'd) \\
\hline \multirow[t]{4}{*}{1} & $\begin{array}{l}\text { International Telephone \& } \\
\text { Telegraph }\end{array}$ & 1 & $\begin{array}{l}\text { Battelle Memorial Institute } \\
\text { Attn: R. F. Dickerson }\end{array}$ \\
\hline & ITT Industrial Laboratories & & 505 King Avenue \\
\hline & Attn: Dr.D.K. Coles & & Columbus 1 , Ohio \\
\hline & $\begin{array}{l}3700 \text { East Pontiac Street } \\
\text { Fort Wayne, Indiana }\end{array}$ & 1 & $\begin{array}{l}\text { Radio Corporation of America } \\
\text { Electron Tube Division }\end{array}$ \\
\hline \multirow[t]{2}{*}{1} & $\begin{array}{l}\text { Thermol Electron Engineering } \\
\text { Corporation }\end{array}$ & & $\begin{array}{l}\text { Attn: F. G. Bloch } \\
\text { Lancaster, Pa. }\end{array}$ \\
\hline & $\begin{array}{l}\text { Attn: Dr. G. Hatsopoulos } \\
85 \text { First Avenue } \\
\text { Waltham } 54 \text {, Mass. }\end{array}$ & 1 & $\begin{array}{l}\text { Marquardt Corporation } \\
\text { Attn: C. Kaplan } \\
\text { Van Nuys, California }\end{array}$ \\
\hline 1 & $\begin{array}{l}\text { Thompson Ramo Wooldridge Inc. } \\
\text { New Products Research } \\
\text { Attn: W. J. Leovic } \\
23555 \text { Euclid Avenue } \\
\text { Cleveland 17, Ohio }\end{array}$ & $\therefore 1$ & $\begin{array}{l}\text { The Boeing Company } \\
\text { Aerospace Power } \\
\text { Attn: P.H. Entz/Mail Stop } 15-50 \\
\text { Seattle, Washington }\end{array}$ \\
\hline 1 & $\begin{array}{l}\text { General Motors Corporation } \\
\text { Allison Division } \\
\text { Attn: Mr. D. L. Dresser } \\
\text { Indianapolis } 6 \text {, Indiana }\end{array}$ & 1 & $\begin{array}{l}\text { Westinghouse Electric Corp. } \\
\text { Research Laboratories } \\
\text { Beulah Road, Churchill Bord } \\
\text { Pittsburgh } 35 . \text { Pa. } \\
\text { Attn: Dr.R.J.Zollweg }\end{array}$ \\
\hline 1 & $\begin{array}{l}\text { The Bendix Corporation } \\
\text { Research Laboratory } \\
\text { Attn: George Burton } \\
\text { Southfield, Michigan }\end{array}$ & 1 & $\begin{array}{l}\text { Electro Optical Systems, Inc. } \\
\text { Attn: Dr.A.D. Jensen } \\
125 \text { N. Vinedo Avenue } \\
\text { Pasadena, California }\end{array}$ \\
\hline 1 & $\begin{array}{l}\text { Union Carbide Corporation } \\
\text { Parma Research Laboratory } \\
12900 \text { Snow Road } \\
\text { Parma, Ohio }\end{array}$ & 1 & $\begin{array}{l}\text { Hughes Aircraft Company } \\
\text { Attn. Dr.R. C. Knechtli } \\
3011 \text { Malibu Canyon Road } \\
\text { Malibu. California }\end{array}$ \\
\hline 1 & $\begin{array}{l}\text { Pratt and Whitney Aircraft } \\
\text { United Aircraft Corporation } \\
400 \text { Main Street } \\
\text { East Hartford, Connecticut } \\
\text { Attn: W. H. Podolny }\end{array}$ & 1 & $\begin{array}{l}\text { General Electric Company } \\
\text { Special Purpose Nuclear } \\
\text { System Operation } \\
\text { Attn: C. H. Seaton } \\
\text { Pleasanton, California }\end{array}$ \\
\hline
\end{tabular}




$\begin{array}{ll}\text { CYS } & \text { OTHERS (Cont'd) } \\ & \text { Defense Metals Information Center } \\ & \text { Battelle Memorial Institute } \\ & 505 \text { King Avenue } \\ & \text { Columbus 1, Ohio } \\ 2 \quad \text { General Electric Company } \\ \text { Central Technical Information Center } \\ \text { 3081 East Lake Road } \\ \text { Erie 1, Pa. } \\ \text { Cummins Engine Company, Inc. } \\ \text { Attn: N. A. Weil } \\ \text { Columbus, Indiana } \\ \text { Materials Research Corporation } \\ \text { Attn: Mr. V. E. Adler } \\ \text { Orangeburg, New York } \\ \text { Eitel-McCullough, Inc. } \\ \text { 30l Industrial Way } \\ \text { San Carlos, California } \\ \text { Power Information Center } \\ \text { University of Pennsylvania } \\ \text { Moore School Building } \\ \text { 200 South 33rd Street } \\ \text { Philadelphia 4, Pa. }\end{array}$

